UNiVERSidAde de São PaUlo

FACUldade de Filosofia, Letras E CiÊnCIAS Humanas

DEPARTAMENTO DE LINGUÍSTICA

Programa de Pós-Graduação em Semiótica e Linguística Geral

\title{
Adaptação de empréstimos em esperanto
}

Karina Gonçalves de SOUZA de Oliveira 
UNIVERSIDADE DE SÃo PAUlo

Faculdade de Filosofia, Letras e CiênCias Humanas

DEPARTAMENTO DE LINGUÍSTICA

Programa de Pós-Graduação em Semiótica e Linguística Geral

\section{Adaptação de empréstimos em esperanto}

Karina GONÇALVES DE SOUZA dE OliveirA

DisSERTAÇÃo APRESENTADA AO PROGRAMA De PÓs-GraduaÇÃo EM SEMiótica E LiNGUÍSTICA GERAL DO DEPARTAMENTO DE LINGUística dA FACUldade DE FILOSOFIA, LETRAS E CIÊNCIAS HuMANAS DA UNIVERSIDAdE DE SÃo PAUlo, PARA A OBTENÇÃO DO TÍTULO DE MESTRE EM LETRAs.

Orientador: Prof. Dr. Paulo Chagas de Souza

São Paulo

2016 
BANCA EXAMINADORA

Prof. Dr.

Julgamento:

Prof. Dr.

Julgamento:

Prof. Dr.

Julgamento:

Prof. Dr.

Julgamento:
Instituição:

Assinatura:

Instituição:

Assinatura:

Instituição:

Assinatura:

Instituição:

Assinatura: 
Aos falantes de esperanto, e a todos aqueles que acreditam na convivência humana pacífica. 


\section{Agradecimentos}

À Faculdade de Filosofia, Letras e Ciências Humanas - FFLCH/USP -, pela desconstrução constante de paradigmas, e por me forçar a me reinventar continuamente.

Ao Conselho Nacional de Pesquisas - $\mathrm{CNPq}$-, pela bolsa de estudos concedida (processo 160611/2014-8), que me possibilitou dedicação integral à pesquisa.

Aos professores da banca de qualificação, a Profa. Dra. Rosane de Sá Amado, que foi minha orientadora nas duas iniciações científicas que fiz durante a graduação, sempre amável e paciente para corrigir os erros comuns de quem está iniciando a vida acadêmica, além de ter sido a primeira professora que abriu as portas para que eu pesquisasse a língua que queria, e o Prof. Dr. Nicolau Dols Salas, que conheci em Poznań (Polônia) e que sempre me respondeu prontamente sobre os questionamentos sobre a fonologia e fonética do esperanto. Suas contribuições tiveram um grande peso no encaminhamento da pesquisa.

Ao Prof. Dr. Paulo Chagas de Souza, pela orientação acadêmica, por ter me passado um pouco de sua paixão por aprender línguas "exóticas", e por ter aceitado orientar uma dissertação de mestrado um tanto quanto incomum, sobre uma língua planejada.

Ao Prof. Dr. Maurício Cardoso, que leu e comentou a parte desta dissertação que versa sobre a cultura do esperanto e a questão do nacionalismo, e me forneceu indicações valiosas de leitura.

À Prof. Dra. Olga Ferreira Coelho, pelo aprendizado proporcionado durante o estágio PAE (Programa de Aperfeiçoamento do Ensino), na disciplina Elementos de Linguística II, no segundo semestre de 2015. Voltar a uma sala do ciclo básico do curso de Letras e poder esclarecer dúvidas daqueles que estavam iniciando seus cursos, assim como o fiz em 2009, foi uma experiência muito gratificante. Agradeço à professora Olga pela confiança e pelas conversas após o término das aulas, que me ensinaram muito (as conversas e as aulas).

Aos colegas do grupo de estudos FONEMOS. A pesquisa acadêmica em nossa área por vezes é muito solitária, e o contato com vocês foi importante para que eu percebesse que estávamos solitários juntos, cada um com seu tema de pesquisa. Aprendi muito no grupo, e agradeço todas as contribuições que foram feitas durante as apresentações parciais sobre esta pesquisa. 
À Aline Benevides e ao Daniel Moser, pela ajuda com programas computacionais para formação do corpus. Vida longa e próspera ao Python! Também a Túlio Flores, por ter me concedido a lista de palavras referentes à edição de 1975 do dicionário PIV.

Aos ministrantes do curso "LaTeX para linguistas", que cursei em 2013. Graças ao aprendizado desse curso pude escrever esta dissertação em um editor de textos que me proporcionou recursos tipográficos e de diagramação valiosos.

À Manuele Bandeira de Menezes, por ter me concedido o arquivo LaTeX do corpus de sua pesquisa de mestrado para usar como modelo nesta dissertação.

Aos amigos da USP, que, de forma mais ou menos intensa, fizeram parte da minha trajetória acadêmica: Paulo Borges, André Guedes, Aline Oliveira, Gustavo Scanavachi, Raul Cabral, Luiz Henrique Silva, Talita Yosioka Colaccio. Obrigada pelos muitos encontros (espontâneos ou agendados), que sempre renovavam minhas energias para os estudos e para a vida em si.

A todos os alunos e professores do curso de Interlinguística em Poznań. Sem dúvida, todos contribuíram para que eu entendesse um pouco melhor a complexidade de ser parte de uma comunidade de fala de uma língua planejada, que tem falantes espalhados pelo mundo. Além disso, as discussões feitas em aula (e também nos corredores, durante os intervalos) me ajudaram a expandir meu conhecimento teórico sobre o esperanto, e desfizeram certezas que eu tinha, o que é sempre bom para uma cientista.

Aos pesquisadores, falantes de esperanto, que dialogaram comigo sobre a pesquisa, principalmente ao Prof. Dr. Marc Van Oostendorp, ao Dr. Marc Bavant e ao Dr. Cirilo Broch, pela atenção dispensada às minhas dúvidas.

Aos amigos que a língua esperanto trouxe para minha vida: José Roberto Tenório, que foi meu professor de esperanto em 2008, e continuou me ensinando muitas coisas sobre a língua mesmo depois de o curso ter acabado; Eder Benedetti, Priscila Benedetti e Lais Benedetti, que sempre estiveram presentes na minha vida desde o momento que os conheci; Fernando Maia Jr, que me mostrou que seria possível, com o apoio de outros falantes de esperanto, participar do curso de pós-graduação sobre Interlinguística em Poznań, e me deu toda a ajuda necessária para que eu realizasse as viagens para participar das aulas; Regis de Castro, que é o amigo que mais me diverte na vida; Vinícius HPR e Rodolfo Boffo, que em tão pouco tempo se tornaram "amigos de infância" e pessoas de minha plena confiança.

A todos os que foram meus alunos de esperanto durante o tempo da graduação 
e começo do mestrado. Obrigada por terem me permitido vivenciar a experiência de ser professora da língua que estudo como objeto acadêmico, e por tudo que me ensinaram. A graça da profissão docente está no constante aprendizado durante a prática de repassar conhecimento aos outros. Cada aula é única, e cada aluno deixa suas marcas na gente. Obrigada por terem confiado em mim como agente de transformação parcial do conhecimento de vocês. Agradeço especialmente a Vivian Cintra, que de aluna passou a ser uma importante amiga para mim, além de ter revisado esta dissertação de forma tão competente.

Às amigas que me sustentaram sentimentalmente durante o tempo em que vivi em São Paulo. Martha Costa, Rosana de Oliveira e Viviane Longo, obrigada por terem sido (e continuarem sendo) as irmãs que a vida colocou em meu caminho. Pensei em muitas coisas para escrever como agradecimento a vocês, mas nem sempre as palavas expressam bem o que queremos, como vocês bem sabem. Deixo para nossa convivência presencial o eterno agradecimento por estarem presentes na minha vida.

Às amigas que me alegram com nossos encontros esporádicos, porém sempre divertidos e amorosos. Ayla, Jenifer, Natália e Tamires, obrigada pela amizade de longa data.

A minha família, por me lembrar o que é socialmente "normal" e sempre ter me deixado livre para decidir quais caminhos seguir, além de apoiar minhas decisões. Agradeço especialmente a minha mãe, Ana Maria Gonçalves de Souza, por ter sempre me incentivado aos estudos, e por ser uma de minhas melhores amigas.

Ao André, pela companhia constante, por ser meu companheiro de vida.

Hoje, em 2016, ao terminar o mestrado, não posso deixar de mencionar que tudo o que aconteceu ao longo desses 07 anos em que estou na USP me moldaram para que eu fosse a pessoa que sou hoje. Agradeço a cada professor, a cada aluno, a cada funcionário da faculdade que fez parte dessa trajetória. 


\section{Resumo}

Esta dissertação buscou avaliar por quais caminhos fonológicos novas raízes são incorporadas ao esperanto. As palavras foram selecionadas a partir das revistas Kontakto, revista oficial da Tutmonda Esperantista Junulara Organizo (TEJO - Organização Mundial da Juventude Esperantista), lançada em 1963, enviada a assinantes em mais de 90 países, e Esperanto, revista oficial da Universala Esperanto-Asocio (UEA - Associação Universal de Esperanto), que teve sua primeira publicação em 1905, e é enviada a leitores em 115 países, além de uma lista terminológica sobre tecnologia (Nevelsteen, 2012), e, ainda, palavras listadas como não dicionarizadas no blog <http:/ / vortaro-blogo.blogspot.com.br/2009/09/nepivaj-vortoj-i.html>. Foram coletadas palavras de 13 línguas diferentes: árabe, chinês, coreano, espanhol, francês, inglês, japonês, komi, português, russo, turco, sânscrito e suaíli. A base teórica que orientou a análise foi a Fonologia de Empréstimo (Loanword Phonology), principalmente os escritos de Calabrese \& Wetzels (2009), Vendelin \& Peperkamp (2006), Paradis (1988), Kang (2011), Friesner (2009), Menezes (2013), Chang (2008) e Kenstowicz \& Suchato (2006), Roth (1980). Fizemos, também, um levantamento bibliográfico de trabalhos já realizados sobre a fonética e a fonologia do esperanto, e comentamos questões gerais sobre as línguas planejadas e a comunidade de fala que o esperanto possui. A análise do corpus evidenciou que as palavras podem ser adaptadas tanto por meio da forma fonética ou da forma ortográfica da raiz na língua de origem. Além disso, verificou-se que ataques complexos que não violam restrições fonológicas do esperanto foram mantidos; a rima sofre, necessariamente, influência da morfologia quando adaptada; vogais longas foram adaptadas, em sua maioria, como vogais simples; e que algumas palavras possuem duas formas em variação sincrônica na língua.

Palavras-chave: Esperanto; Fonologia; Empréstimos; Línguas Planejadas. 


\section{Abstract}

This master's dissertation tried to investigate by which phonological directions new roots are incorporated into Esperanto. Words were selected from the following magazines: Kontakto, official magazine of Tutmonda Esperantista Junulara Organizo (TEJO - World Esperanto Youth Organization), which was first published in 1963 and is sent to subscribers in over 90 countries, and Esperanto, official magazine from Universala Esperanto-Asocio (UEA - Esperanto Universal Association), which had its first release in 1905 and is sent to readers in 115 countries, in addition to a terminology list about technology (Nevelsteen, 2012) and to words not quoted on dictionaries but published on a list in the blog <http://vortaroblogo.blogspot.com.br/2009/09/nepivajvortoj-i.html>. Words were collected from 13 different languages: arabic, chinese, corean, spanish, french, english, japanese, komi, portuguese, russian, turkish, sanskrit and swahili. The theory basis that guided this analysis was Loanword Phonology, mostly the works of Calabrese \& Wetzels (2009), Vendelin \& Peperkamp (2006), Paradis (1988), Kang (2011), Friesner (2009), Menezes (2013), Chang (2008) and Kenstowicz \& Suchato (2006), Roth (1980). We also made a bibliographic search on previous works about Esperanto's phonetics and phonology, and we discussed general matters about planned languages and Esperanto's community of speakers. The corpus's analysis showed that words can be adapted by its phonetic form as well as by its root's orthographic form on the original language. Furthermore, we observed that complex onsets which do not violate phonological restrictions of Esperanto were sustained; rime, when is adapted, is necessarily influenced by morphology; long vowels were, for the most part, adapted as simple vowels; and some words present two forms in language's synchronic variation.

Keywords: Esperanto, Phonology; Loanwords; Planned languages. 


\section{Resumo}

Ĉi tiu disertacio provis analizi per kiuj fonologiaj vojoj novaj radikoj eniras en Esperanton. La vortoj estis selektitaj el la revuoj Kontakto, oficiala revuo de Tutmonda Esperantista Junulara Organizo (TEJO), ekeldonita en 1963, sendita al abonantoj en pli ol 90 landoj, kaj Esperanto, oficiala revuo de Universala Esperanto-Asocio (UEA), kiu havis sian publikigon en 1905 kaj estas sendita al legantoj en pli ol 115 landoj, krom terminologia listo pri teknologio (Nevelsteen, 2012) kaj ankoraŭ vortoj listigitaj kiel ne vortarigitaj en la blogo <http:/ / vortaroblogo.blogspot.com.br/2009/09/nepivaj-vortoj-i.html>. Estis kolektitaj vortoj el 13 lingvoj: araba, ĉina, korea, hispana, franca, angla, japana, komia, portugala, rusa, turka, sanskrita kaj svahila. La teoria bazo, kiu gvidis la analizon, estis la Pruntvorta Fonologio (Loanword Phonology), precipe la verkoj de Calabrese \& Wetzels (2009), Vendelin \& Peperkamp (2006), Paradis (1988), Kang (2011), Friesner (2009), Menezes (2013), Chang (2008) kaj Kenstowicz \& Suchato (2006), Roth (1980). $\mathrm{Ni}$ ankaŭ faris bibliografian esploron pri jam faritaj laborajoj pri la fonetiko kaj fonologio de Esperanto, kaj ni komentis generalajn punktojn pri la planitaj lingvoj kaj la parola komunumo, kiun Esperanto havas. La analizo de la korpuso montris, ke la vortoj povas esti adaptitaj kaj per la fonetika elparolo kaj per la ortografia formo de la radiko en la origina lingvo. Krome, ni rimarkis, ke kompleksaj atakoj, kiuj ne malrespektas fonologiajn malpermesojn de Esperanto estis konservitaj; la rimo suferas, necese, influon de la morfologio kiam ĝi estas adaptita; longaj vokaloj estis adaptitaj, plej multe, kiel simplaj vokaloj; kaj ke kelkaj vortoj havas du sinkronajn variajn formojn en la lingvo.

Ŝlosilvortoj: Esperanto; Fonologio; Pruntvortoj; Planitaj Lingvoj. 


\section{Sumário}

Agradecimentos $\quad$ v

Resumo viii

$\begin{array}{ll}\text { Abstract } & \text { ix }\end{array}$

Resumo $x$

Lista de Tabelas $\quad$ xiv

$\begin{array}{ll}\text { Lista de Figuras } & \text { xv }\end{array}$

1 Introdução 1

1.1 Línguas planejadas . . . . . . . . . . . . . . . 2

1.2 O esperanto e sua comunidade linguística . . . . . . . . . . . 8

1.2.1 Onde se fala esperanto . . . . . . . . . . . . . . 9

1.2.2 Falantes nativos . . . . . . . . . . . . . . . . 12

1.3 A cultura de uma língua planejada . . . . . . . . . . . . . . . . . 14

1.3.1 Nacional versus Internacional . . . . . . . . . . . . . . . 18

1.3.2 O esperanto e a possibilidade de se pensar de forma transnacional ...................... 21

2 Esperanto: estudos prévios $\quad 24$

2.1 A fonologia do esperanto . . . . . . . . . . . . . . . . . 24

2.2 Estudos anteriores . . . . . . . . . . . . . . . . . 25

2.2.1 Manuais, gramáticas, livros e dissertações . . . . . . . . . . . 28

2.2.2 Artigos em livros, revistas, jornais e blogs . . . . . . . . . . . 29

2.3 Sistema consonantal . . . . . . . . . . . . . . . . . 32

2.4 Sistema vocálico . . . . . . . . . . . . . . . . . . . . . . . . 34

2.5 A estrutura silábica . . . . . . . . . . . . . . . . . 36

2.5 .1 O que é sílaba? . . . . . . . . . . . . . . 37

2.5 .2 A sílaba em esperanto . . . . . . . . . . . . . 40

2.5.3 Resumo sobre a sílaba ............... 51 
3 A fonologia de empréstimo (Loanword phonology) 53

3.1 Diferentes linhas de estudo e análise . . . . . . . . . . . . . . 54

3.2 Fonética ou Fonologia . . . . . . . . . . . . . . . . 59

3.3 Influência da ortografia . . . . . . . . . . . . . . 62

4 Dados e análise $\quad 65$

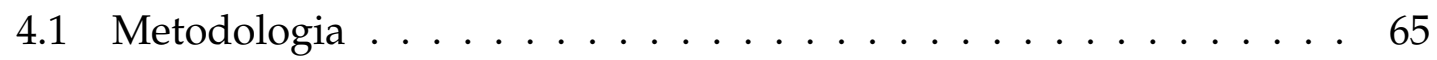

4.2 Fontes ........................... 70

4.3 Análise dos dados . . . . . . . . . . . . . . . . . . . . . . . . . . . 73

4.3 .1 Consoantes . . . . . . . . . . . . . . . 74

4.3 .2 Vogais . . . . . . . . . . . . . . 77

4.3 .3 Estrutura silábica . . . . . . . . . . . . . 80

4.3.4 Adaptação por meio da fonética . . . . . . . . . . . . . . . . . . . . . . . . . . 90

4.3.5 Adaptação por meio da ortografia . . . . . . . . . . . . . . 92

4.3.6 Palavras em variação sincrônica e propostas intencionais de

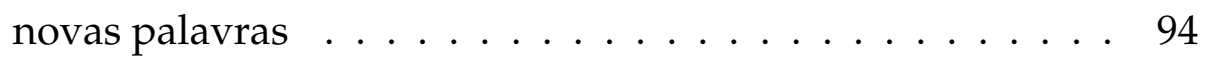

4.3 .7 Topônimos.......................... 95

5 Considerações finais $\quad 97$

$\begin{array}{ll}\text { Referências bibliográficas } & 100\end{array}$

$\begin{array}{ll}\text { Corpus } & 108\end{array}$ 


\section{Lista de Tabelas}

2.1 Segmentos consonantais do esperanto (os símbolos à direita representam consoantes sonoras) (Colling, 2012) . . . . . . . . . . . . . 33

2.2 Fonemas do esperanto cujas representações ortográficas não correspondem ao símbolo fonético (Colling, 2012). . . . . . . . . . . . . 33

2.3 Segmentos vocálicos do esperanto (os símbolos à direita representam consoantes sonoras) (Colling, 2012) . . . . . . . . . . . . . . 35

2.4 Tipos estruturais possíveis de formação silábica (Zec, 2007, 165). . . 39

2.5 Ataques complexos existentes em esperanto segundo Oostendorp (1999, 57-58) (tabela adaptada).

2.6 Ataques complexos com os segmentos [s] e [f] Oostendorp (1999, 63) (tabela adaptada) . . . . . . . . . . . . . . . . . . . 43

2.7 Rimas possíveis em esperanto, segundo Oostendorp (1999). . . . . 44

2.8 Estruturas silábicas possíveis encontradas por Bavant (2006b). . . . 50

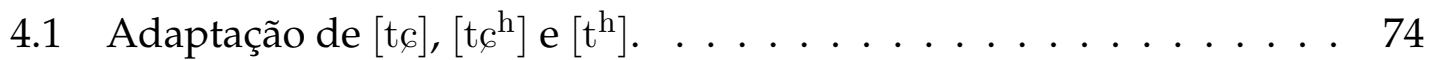

4.2 Adaptação de $[6]$ e $[\mathrm{s}]$ para $\left[\int\right] \ldots \ldots \ldots \ldots$. . . . . . . . . . 75

4.3 Adaptação de $[\mathrm{w}]$ para $[\mathrm{v}] \ldots \ldots \ldots$. . . . . . . . . . . . 76

4.4 Manutenção de [w] para [w] - ortograficamente representado como

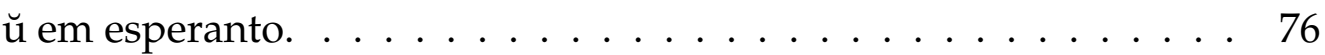

4.5 Adaptação de vogais longas. . . . . . . . . . . . . . . . . . . . 77

4.6 Adaptação do segmento [æ] do inglês para [a] no esperanto. . . . . 79

4.7 Palavras adaptadas com ataque complexo sem modificação. . . . . 81

4.8 Acréscimo da vogal /o/ ao fim de palavras que terminam em consoante. . . . . . . . . . . . . . 82

4.9 Elisão do segmento consonantal final. . . . . . . . . . . . . . . . . 85

4.10 Mudança da vogal final para /o/. . . . . . . . . . . . . . 86

4.11 Manutenção da vogal final e acréscimo de /o/ . . . . . . . . . . . . 88

4.12 Palavras que tem, na língua de origem, uma vogal final marcada ortograficamente, mas que não são pronunciadas. . . . . . . . . . . 89

4.13 Palavras que se parecem mais com a forma fonética do que com a forma ortográfica da L2 . . . . . . . . . . . . . . . . . . . . . 90 
4.14 Palavras que se parecem mais com a forma ortográfica do que com a forma fonética da L2 . . . . . . . . . . . . . . . . . . . . . 93

4.15 Topônimos que apresentam duas formas em esperanto. . . . . . . . 96 


\section{Lista de Figuras}

2.1 Comparação entre a realização fonética das vogais $[o]$ e $[u]$, pronunciadas por cinco falantes diferentes (cada sigla representa um falante). . . . . . . . . . . . . . . . 36

2.2 Constituição silábica possível segundo Blevins $(1995,216)$. . . . . 38

3.1 Manutenção de distinções fonêmicas na adaptação de palavras do inglês no birmanês (Chang, 2008, 48). . . . . . . . . . . . . 60

3.2 Dados de adaptação dos fonemas /p/e /f/ do inglês para os fonemas $/ \mathrm{p} / \mathrm{e} / \mathrm{p}^{\mathrm{h}} /$ do birmanês (Chang, 2008, 46). . . . . . . . . 61 


\section{Introdução}

O esperanto é uma língua planejada, mas não é artificial. Evoluiu naturalmente para uma língua corrente, que, assim como qualquer língua, está sujeita à variação e à mudança. Por ter sua comunidade linguística espalhada por vários países, fatores linguísticos e de identificação da cultura esperantista são difíceis de serem estudados.

Há mais de um século ele vem sendo usado como meio de comunicação, e pouco se sabe, cientificamente, como isso acontece. Oostendorp (2000) nos chama a atenção para o fato de que alguns linguistas consideram o estudo científico do esperanto como não importante, uma vez que ele não é uma língua que surgiu natural e espontaneamente no seio de uma sociedade. Veremos, entretanto, nesta dissertação, que o assunto é complexo e há muito ainda a se estudar sobre línguas planejadas, e, em especial, sobre o esperanto.

No Brasil, teses e dissertações foram elaboradas tratando de temas referentes à língua (Dias (2009), Laroca (2009)), mas ainda em quantidade baixa, e nenhuma na área de fonética e fonologia. Na Polônia, na cidade de Poznań (Uniwersytet im. Adama Mickiewicza) há um curso de pós-graduação inteiramente ministrado em esperanto, que trata não só da língua em si, mas também da problematização geral das línguas planejadas, e tem como estudo maior a área denominada interlinguística. ${ }^{1}$ Ou seja, é uma língua viva, corrente, mas que é pouco conhecida.

A pesquisa se justifica, portanto, frente à necessidade de se estudar uma língua que vem sendo usada para comunicação internacional, mas cuja comunicação em todos os campos dos estudos linguísticos (fonética, fonologia, morfologia, sintaxe etc.) não se sabe bem como realmente ocorre.

\footnotetext{
${ }^{1}<$ http://www.staff.amu.edu.pl/ interl/interlingvistiko/index.html>.
} 
Esta dissertação é uma pequena contribuição para a reflexão das questões apontadas, e está estruturada da seguinte forma.

O capítulo 1 traz informações sobre línguas planejadas. Nele, problematizamse as questões culturais sobre o esperanto, quem são seus falantes, que relações culturais mantêm e como podem se identificar como parte de uma mesma comunidade linguística estando tão dispersos geograficamente. Além disso, há uma pequena explanação sobre outras línguas planejadas.

A seguir, no capítulo 2, apresentamos estudos sobre a fonologia do esperanto, uma revisão bibliográfica dos trabalhos acadêmicos sobre o tema, os sistemas consonantal e vocálico da língua, assim como especificações sobre a estrutura silábica.

No capítulo 3, a teoria usada para a análise dos dados é explicitada. São expostos conceitos importantes para a reflexão sobre o empréstimo de palavras, assim como exemplos de como a adaptação é feita em outras línguas.

Na sequência, o capítulo 4 se configura pela exposição da metodologia para seleção das palavras do corpus e a análise dos empréstimos.

Por fim, o capítulo 5 retoma as principais questões do texto, e expõe considerações finais sobre a pesquisa. A seguir, estão as referências bibliográficas utilizadas e o corpus da pesquisa.

\subsection{Línguas planejadas}

O esperanto é a língua planejada mais conhecida, e que criou a maior comunidade de falantes, mas muitas outras línguas surgiram pelo mesmo processo ao longo da história da humanidade.

Planejar uma língua significa pensar em todos os níveis linguísticos (fonológico, morfológico, sintático, semântico, etc.) antes que ela seja usada por qualquer falante. Deste ponto de vista, tais línguas diferem daquelas que conhecemos (o 
português, por exemplo), pois antes de ser falada a língua é escrita (e o processo normal de uma língua é ser oral primeiramente, e só depois receber um sistema escrito de representação dela).

É difícil, entretanto, definir o que é uma língua planejada, visto que são muitas categorias existentes.

Stria (2016) afirma que sob o nome de "artificial" são enquadrados, frequentemente, os seguintes tipos de língua:

- linguagens de programação e de máquina (COBOL, Assembler, C\#)

- línguas formais (cálculos proposicionais)

- línguas experimentais

- filosófica (toki pona)

- lógica (lojban)

- pasigrafias $^{2}$ (pictopen $^{3}$ ) e pasilalias ${ }^{4}$

- línguas auxiliares internacionais ou línguas planejadas (esperanto, novial)

- línguas artísticas (klingon, kenya)

- línguas normativas

- superdialetos (romanche, árabe standard)

- línguas literárias standard (Ausbausprachen)

- revividas (córnico)

- línguas clássicas (sânscrito, latim)

- línguas controladas (Caterpillar Fundamental English)

- reconstruções (proto-indoeuropeu)

- pidgins e creolos

- línguas oníricas e glossolalias (Stria, 2016:29)

A autora cita a classificação feita por Blanke (1997), que é mais compacta, com menos categorias, e mostra que tais categorias não são estanques, visto que o assunto é complexo e pouco estudado até agora (Stria, 2016:30). Nem todas

\footnotetext{
${ }^{2}$ Uso de símbolos escritos, como ideogramas, para representar conceitos. Só há a forma escrita da língua.

${ }^{3}<$ http://www.pictopen.com/>.

${ }^{4}$ Termo proveniente da língua grega, que quer dizer "língua universal". Só há a forma falada da língua.
} 
as línguas sob o rótulo de "artificiais" têm o propósito de servir de meio para comunicação humana. Linguagens computacionais, por exemplo, como Python, IDL, Fortran, entre outras, foram criadas para a área específica de programação, para formular comandos sintáticos dentro de programas computacionais.

Línguas artísticas, apesar de poderem ser aprendidas e usadas por seres humanos, também não são criadas objetivando a comunicação entre pessoas, mas sim com fins específicos, seja para histórias literárias, séries televisivas, produções cinematográficas, etc., como o klingon (Star Trek - filmes e seriado televisivo), o dothraki (Game of Thrones - livros e seriado televisivo) e as línguas élficas (O Senhor dos Anéis - trilogia de livros), entre outras.

Oostendorp (2016), ao explicar ${ }^{5}$ a tipologia de línguas construídas, diz que é fácil falar sobre a questão, do ponto de vista histórico: basta pensar no motivo que leva as pessoas a construir línguas. Ele afirma que, no mundo ocidental, houve três razões principais para o planejamento de línguas, que se relacionam, sempre, com o que as pessoas pensam sobre a linguagem em geral, para que precisamos de línguas.

The first group is mostly placed in the 17th-18th Century; and the first reason was to make languages which would make us to think better. The idea is that the language is the instrument of thought, but there are many problems, and we can think things which can be wrong, we can make mistakes, we can lie, so we can say things which are wrong, and if you have a sentence, you cannot see from the form of a sentence on its own whether it's false or true. (Oostendorp, 2016)

Leibniz, filósofo, matemático e diplomata alemão, tentou construir uma língua com esse objetivo (fazer as pessoas pensarem melhor), na qual não fosse possível mentir, e, se alguma mentira fosse dita, seria possível reconhecê-la por meio da formação da sentença. Esse tipo de língua é conhecido como a priori, pois é construída completamente, e não se baseia em outras línguas já existentes.

\footnotetext{
${ }^{5}$ Em entrevista ao site Serious Science - http://serious-science.org/. Disponível em: http://serious-science.org/constructed-languages-6242. Acesso em: 12 set. 2016.
} 
The second idea, this was mostly in the 19th century, was the idea that language is a means of communication. It's a way to express the ideas in one's head and to bring them to another's head. And the problem is that in the 19th century people start discovering that there are people across other sides of the language border. It becomes easier to travel because of trains, it becomes even easier to communicate because of telegraphy, telephone, and radio. But people all speak different languages. Let us solve that by making a language that is easy to learn for all! (Oostendorp, 2016)

A intenção, portanto, era fazer as pessoas se comunicarem de forma mais prática, e não mais fazer as pessoas pensarem melhor, como era a motivação vista anteriormente. O esperanto se enquadra nesta classificação, e outras línguas construídas com o mesmo proprósito são comentadas adiante no texto. Este tipo de língua é chamada de a posteriori, pois se baseia em línguas já existentes.

The third is the more modern project, one of which we see many examples now; that is you make the language for fun, for beauty. Typically people invent a world for a movie or a book, and then inhabitants of that world need to have a language. Why won't you be happy with actors saying random stuff? No, it has to be a real language! Why do people do that? Just because it's fun, that's the art. Tolkien was probably one of the first of those. However, even in the Medieval times people were sometimes making small languages for fun as well, so the boundaries don't make complete sense, but this is what seems to be the right classification. (Oostendorp, 2016)

Uma terceira motivação, mais recente, como afirma Oostendorp (2016), seria planejar línguas por diversão, ou para fins artísticos específicos.

Alguns autores consideram a língua ignota, que data do século XII, como "a primeira língua criada conscientemente e sistematicamente" (Stria, 2016:37). Foi criada por Hildegarda de Bingen, monja beneditina alemã. A segunda língua criada seria blaibalan, por volta do século XV e XVI. Estas duas são as únicas das quais se tem notícia anteriores ao século XVII, quando o florescimento do planejamento de línguas teve um impulso maior (Stria, 2016:37).

The seventeenth century brought the advent of universal schemes. These were not only spoken languages but also pasygraphies, gestural as well as musical languages. The need arose for various reasons, some very old ones and some newly discovered. (Stria, 2016:38) 
No fim do século XIX (em 1879) surgiu o projeto da língua volapük, de autoria do padre católico Johann Martin Schleyer. Esta língua conquistou muitos adeptos e teve congressos presenciais para que os falantes a praticassem. Todavia, ela era de difícil aprendizagem e aparentemente não era um bom instrumento para comunicação internacional. Duliĉenko (2006 : 87) afirma que no começo do século XX um dicionário russo definia a palavra Volapük como "projeto de língua universal, criado por J. M. Schleyer", mas também, de forma pejorativa, como "coisa não compreensível, língua mal feita" ${ }^{6}$

Em 1887 foi publicado o primeiro livro referente ao esperanto. Zamenhof, seu idealizador, aprendeu volapük e observou fatores importantes em relação ao sucesso e ao declínio da língua para selecionar certos parâmetros em relação ao seu próprio projeto. Schleyer, por exemplo, adaptou radicais para o volapük transformando-os em monossilábicos, o que nem sempre permitia ao aprendiz reconhecer tal radical de sua língua proveniente ${ }^{7}$. Assim, Zamenhof evitou transformações muito profundas para que os radicais fossem de fácil reconhecimento. Ele observou também que a gramática deveria ser simples, diferentemente da complicada gramática do volapük (Duliĉenko, 2006 : 97).

Um ponto importante foi a relação do autor com o seu projeto. Enquanto Schleyer quis ter controle total sobre as possíveis mudanças da língua e como seu desenvolvimento se daria, Zamenhof dizia, desde o lançamento do primeiro livro do esperanto, que ele não mais tinha domínio sobre o que aconteceria com a língua, deixando sua futura comunidade de falantes livre para tomar decisões em conjunto quando fosse necessário.

No fim do século XIX e começo do XX, entretanto, não só o volapük e o

\footnotetext{
6"Jam en la komenco de la 20a jarcento en populariga klariga vortaro de la rusa lingvo la vorto Volapük estis difinita ne nur rektasence kiel 'tutmonda lingvo' aŭ 'projekto de tutmonda lingvo, kreita por J. M. Schleyer', sed ankaŭ figure, pejorative kiel 'nekompreneblajo' , 'fuŝa lingvajo'"' (Dulicenko, 2006: 87).

${ }^{7}$ Pode-se reconhecer, com certa facilidade, que vol (mundo) provém de world (mundo, em inglês), ou que pük (língua) se originou do radical speak, mas não é muito óbvio que plim (elogio) é proveniente de compliment (Korjenkov, 2011:84).
} 
esperanto vieram à luz.

Outros projetos posteriores ao esperanto, embora com maior ênfase nas raízes latinas, não obtiveram qualquer grau notável de sucesso, tendo ficado restritos ao uso por elites não numerosas, dentre eles, o "latino sine flexione" (de Giuseppe Peano, em 1903 - não chegou a se tornar língua), a "interglossa" (de Lancelot Hogben, em 1943), a "interlíngua" (de Alexander Gode, em 1951) e o "ido" - que significa "filho, descendente" -, idealizado por divergentes do esperanto, que introduziu reformas nessa língua, sem ter conseguido obter muitos seguidores, mas que sobrevive até hoje. (Dias, 2009:20)

Além das línguas citadas por Dias (2009), podemos ainda mencionar o occidental (1922), de Edgar de Wahl e o novial (1928), de Otto Jespersen. Estas duas línguas foram planejadas a partir do esperanto, pois os autores não concordavam com certas características e achavam que reformas no projeto inicial eram necessárias.

A interlíngua (1951), citada por Dias (2009) como de autoria de Alexander Gode foi, na verdade, uma criação em conjunto. A IALA (International Auxiliary Language Association) foi um grupo de trabalho que reuniu vários linguistas, entre eles o conhecido André Martinet (entre 1946 e 1948), para construir uma língua para comunicação internacional.

Além desses projetos que se basearam em radicais latinos, há, também, projetos de línguas planejadas com base em radicais eslavos. Tiĥmirov (2013: 200) afirma que há muitas similaridades entre as línguas eslavas ${ }^{8}$. Assim como as línguas planejadas com radicais latinos são de fácil aprendizado para falantes de línguas neolatinas, como o espanhol, o italiano e o francês, a similaridade entre as línguas eslavas permitiu que radicais eslavos fossem usados para o planejamento de línguas auxiliares que fossem de fácil aprendizado para falantes de línguas desse tronco linguístico.

\footnotetext{
${ }^{8}$ Orientais: russo, bielorrusso, ucraniano; ocidentais: polonês, cachubo, alto sorábio, baixo sorábio, tcheco, eslovaco; do sul: esloveno, croata, bósnio, sérvio, montenegrino, búlgaro e macedônio (Tihomirov, $2013: 212$ ).
} 
Slovio (1999), de Mark Hučko e o slovianski (2006), de Jan van Steenbergen, Gabriel Svoboda e Ondrej Rečnik são exemplos recentes de projetos com línguas eslavas (Zouzalík, 2013:229). Há vários outros projetos ${ }^{9}$, que têm traços em comum, como ausência de artigo gramatical, declinações expressas por sufixos, casos (de 6 a 8), terminações verbais claras, o que dispensa o uso de pronomes pessoais com verbos conjugados, etc. (Barandovská-Frank, 2015).

Em 2007 foi criada, nos Estados Unidos, a Language Creation Society ${ }^{10}$, cujo objetivo é divulgar informações sobre a criação de línguas e unir pessoas interessadas pelo assunto. A associação tem 142 membros, de 23 países diferentes. O site possui informações sobre quais são os passos importantes para a criação de uma língua, informações históricas sobre o assunto, e até mesmo informações sobre oportunidades de emprego relacionadas à criação de línguas (normalmente para fins artísticos).

O assunto tratado nesta seção é amplo, e não é nossa intenção analisar o tema de modo mais profundo. Nosso intuito era apenas o de colocar em evidência um ramo que é pouco tratado na linguística, mas que pode ser de interesse para outros acadêmicos, e que mostra que o esperanto, apesar de se diferenciar de outras línguas planejadas por ser mais conhecido e ter mais falantes, não é algo isolado nesse universo de planejamento e criação linguística.

\subsection{O esperanto e sua comunidade linguística}

O esperanto teve seu projeto publicado em 1887 (Zamenhof, 1887). Seu organizador, Lázaro Luis Zamenhof, idealizava um meio de comunicação que pudesse superar as barreiras geográficas, religiosas, étnicas, etc., a fim de trazer paz aos

\footnotetext{
${ }^{9}$ Glagolica (2002), proslava (2002), mezxduslavske (2003), panslavien (2005), sojaz (2005), panslavensk (2005), noven slovio - slavenen (2006), rozumio (2008), slavski jezik (2009), pidžinosloviansk (2009), vseslavjanski (2010), simple slavic auxlang (2010), rusich (2010), novosloviensky (2011) (BarandovskáFrank, 2015).

${ }^{10}<$ http://conlang.org/>.
} 
povos que se utilizassem dessa língua. Apesar de suas expectativas não terem sido plenamente alcançadas, a língua se popularizou e formou uma comunidade linguística geograficamente dispersa e policultural. Falantes de esperanto são encontrados em todas as partes do mundo, o que torna difícil entender e teorizar quais efeitos ou possibilidades de cultura tais falantes são capazes de formar.

\subsubsection{Onde se fala esperanto}

A língua aqui estudada não é oficial em nenhum país, mas pelo mundo todo há falantes, que a usam nas organizações esperantistas, nos encontros promovidos, ou simplesmente pela internet ou presencialmente.

A UEA - Universala Esperanto-Asocio (Associação Mundial de Esperanto) - promove anualmente o UK - Universala Kongreso (Congresso Universal). O número de participantes costuma variar entre mil e três mil pessoas.

Além disso, organizações nacionais também promovem encontros frequentemente. No Brasil, o congresso anual acontece no período entre maio e junho (com exceção dos que foram realizados entre 2012 e 2016, em janeiro), e sempre em uma região diferente do país. Há também encontros regionais, ou seja, ao longo do ano há muitas opções de encontros para que o falante pratique a língua.

Pela internet, há conferências realizadas pelo Skype e outras ferramentas, grupos em redes sociais e outras possibilidades.

Apesar de os lugares onde se pode falar a língua serem, em sua maioria, esses encontros esporádicos, ou o ambiente on-line, há tambem lugares físicos onde o esperanto é usado como língua corrente, todos os dias, a todo momento.

A fazenda-escola Bona Espero ${ }^{11}$ (Boa Esperança), localizada no município de Alto Paraíso de Goiás, no Brasil, foi fundada em 1957, e ao longo de sua existência utilizou o esperanto como língua corrente. Falantes de esperanto de vários paí-

\footnotetext{
${ }^{11}<$ fazendaescolabonaespero.org $>$
} 
ses trabalharam, voluntariamente, no local, que funcionou, ao longo das últimas décadas, como abrigo de crianças carentes da região, local de produção agrícola ecologicamente sustentável, e escola regular para o Ensino Fundamental (ciclos I e II). A partir de 1974, a instituição passou a ser dirigida por Ursula Grattapaglia (alemã) e Giuseppe Grattapaglia (italiano), falantes de esperanto que vieram ao Brasil especificamente para administrar Bona Espero. Desde 2014 a fazenda não funciona mais como abrigo para crianças em situação de risco, e a escola que lá funcionava cessou suas funções em 2012. Entretanto, novos projetos são desenvolvidos, e o esperanto continua sendo usado e divulgado na fazenda. Em seu livro Bona Espero: idealo kaj realo (Bona Espero: ideal e realidade), o jornalista Roman Dobrzyński conta qual foi a trajetória (o livro foi escrito em formato de entrevista) do casal que administra a fazenda há mais de 40 anos, e, consequentemente, a história da fazenda em si (Dobrzyński, 2008). Há relatos, por exemplo, de como foi gratificante para o casal (cada um em seu país de origem) aprender esperanto após o término da Segunda Guerra Mundial, pois a perspectiva de ter uma língua internacional, que permitisse a comunicação pacífica entre pessoas de países diferentes, parecia-lhes bastante útil e necessária depois de tudo o que havia acontecido durante a guerra.

A Kulturdomo de Esperanto - Kastelo Greziljono (Casa de cultura do esperanto Castelo Grésillon), localizada na França (a $250 \mathrm{~km}$ de Paris), é outro local onde o esperanto é falado de forma contínua. A organização promove cursos da língua durante o verão (do hemisfério norte do planeta) e durante os outros períodos das férias escolares francesas, desde 1951, ano de sua fundação. O Castelo e o terreno em volta dele foram comprados por um grupo de esperantistas justamente para esse propósito.

Na Alemanha, há uma cidade que recebe o título de "cidade do esperanto". Trata-se de Herzberg, que, desde 2006, passou a receber a designação de Herzberg 
am Harz - die Esperanto-Stadt. A decisão da nova denominação da cidade foi tomada por meio de votação pelos parlamentares locais. Lá se encontra o Interkultura Centro Herzberg (Centro intercultural Herzberg), que é o centro cultural da UEA e promove atividades relacionadas ao esperanto. A ideia geral é que a cidade tenha o esperanto como língua corrente (além do alemão, é claro) e que os falantes possam se comunicar em restaurantes e hotéis, ver informações geográficas na língua, etc.

O lugar talvez mais óbvio e frequente em que a língua é usada de forma sistemática é no escritório oficial da UEA, em Roterdã, na Holanda. Lá trabalham diariamente funcionários (contratados pela UEA e pela TEJO - Tutmonda Esperantista Junulara Organizo - Organização Mundial da Juventude Esperantista) da associação e voluntários, que organizam o movimento esperantista mundial e promovem ações para a divulgação da língua nos mais variados meios.

A rádio internacional da China tem transmissão de seu conteúdo midiático em várias línguas, inclusive esperanto ${ }^{12}$. Há, portanto, funcionários da rádio que trabalham, profissionalmente, com a língua. No mesmo país, o grupo China International Publishing Group mantém a publicação periódica El Popola Ĉinio ${ }^{13}$, que tem como objetivo divulgar a cultura chinesa pelo mundo (e notícias gerais da China).

A organização $E @ I$, fundada em 2005, também usa o esperanto como língua de trabalho diário. $\mathrm{O}<$ eo.lernu.net> foi criado por essa organização, e, durante anos, foi o lugar on-line mais popular para se aprender esperanto ${ }^{14}$. Sua sede é na Eslováquia, e o objetivo da organização é promover seminários que envolvam esperanto e educação, além de ter vários projetos sobre o assunto.

\footnotetext{
${ }^{12}$ Português: <portuguese.cri.cn>; tcheco: <czech.cri.cn>; hindi: <hindi.cri.cn>; ucraniano: $<$ ukrainian.cri.cn>; esperanto: <esperanto.cri.cn>, entre muitas outras línguas disponíveis.

${ }^{13}$ Disponível em: <www.espero.com.cn>.

${ }^{14}$ Com o aparecimento do curso de esperanto no aplicativo de aprendizado de línguas Duolingo, talvez o <lernu.net $>$ tenha deixado de ser o lugar central para o aprendizado da língua, apesar de as estruturas e propósitos dos sites serem bastante diferentes.
} 
Enfim, fala-se esperanto onde há falantes da língua. Definir onde os falantes estão, como já mencionado, é tarefa difícil. Nossa intenção, com esse pequeno resumo de lugares nos quais pode-se usar o esperanto de forma mais "oficial", foi apenas informar, de forma breve, os possíveis interessados pelo assunto.

\subsubsection{Falantes nativos}

Há casais que se conhecem em encontros de esperanto, e essa língua é o único meio de comunicação em comum que eles possuem. Nesse tipo de contexto, se o casal tem filhos, a criança aprende o esperanto como língua nativa, pois é a língua do ambiente familiar. Entretanto, tais crianças sempre são falantes de mais de uma língua, pois além do esperanto aprendem as línguas dos pais (é comum, portanto, que saibam três línguas: o esperanto, a língua da mãe e a língua do pai).

Em outros casos, pais que têm uma outra língua em comum, fora o esperanto, decidem ensiná-la aos filhos, pois querem que eles sejam falantes nativos desta língua.

Lindstedt (2010:02) calcula que há por volta de mil falantes nativos no mundo. Além disso, o autor afirma que já há falantes nativos de segunda e terceira geração, apesar de não haver nenhuma comunidade que use a língua de forma uniforme (portanto, outras línguas sempre estão presentes em ambientes familiares com tais falantes nativos).

Os falantes nativos são uma evidência de que o esperanto é tão natural quanto qualquer outra língua.

O termo denaskulo ${ }^{15}$ é usado para designar os falantes nativos. Dias (2009:26) traz informações sobre os primeiros denaskuloj:

O primeiro caso foi o de Emilia Gastón, da Espanha, conforme o livro do ano da UEA de 1966. Nascida em 2 de junho de 1904, filha de Emilio Gastón, foi

\footnotetext{
${ }^{15} \mathrm{de}$ - proveniência, nask- - nascer, $u l$ - indivíduo caracterizado pelo radical da palavra que este sufixo acompanha, $o$ - terminação de substantivos.
} 
considerada a primeira falante nativa fluente da língua. No entanto, segundo a versão em esperanto da Wikipedia, os primeiros falantes nativos que se tornaram importantes para o movimento esperantista foram Inés Gaston (nascida em 12/09/1906) e Ino Kolbe (nascida em 28/02/1914).

Lindstedt (2010:03) afirma que os primeiros falantes nativos nasceram no início do século XX. Saber quantos são exatamente e quem são esses falantes, entretanto, não é tarefa simples. Muitos falantes nativos preferem não se envolver com a comunidade esperantista, ou simplesmente não querem ser mencionados em estudos acadêmicos por terem uma língua planejada como língua materna.

Mazur (2015), cartunista, escreveu, em forma de história em quadrinhos, fatores interessantes sobre os falantes nativos. Ele usou a história de cinco denaskuloj para retratar aspectos de como é ser falante nativo de uma língua planejada. $\mathrm{Na}$ fala dos personagens da história são contados fatos sobre como foi o processo de aquisição, as perguntas que as pessoas normalmente fazem quando descobrem sobre essa particularidade (como questionar sobre onde se fala esperanto, já que normalmente pensamos em línguas relacionadas a nacionalidades) e o entusiasmo de alguns pais, que aprenderam esperanto durante a Segunda Guerra Mundial, ou logo após o término dela ${ }^{16}$.

É importante lembrar que nem todo falante nativo de esperanto faz parte do movimento social que promove a língua (Lindstedt, $2010: 06)$.

No que se refere ao estudo linguístico da aquisição do esperanto como língua materna, há poucas referências. Versteegh (1993:540) enfatiza que essa área é de interesse específico para a linguística, mas que o estudo sistemático de crianças se torna difícil, pois elas estão espalhadas geograficamente e pouco convivem entre si. O autor também afirma que o processo de aquisição do esperanto pode ser comparado ao processo de aquisição de pidgins, que se concretizarão como línguas crioulas, uma vez que o input recebido pelas crianças é de adultos que não

\footnotetext{
${ }^{16}$ A história em quadrinhos traz a informação de que Hitler, em seu livro "Mein Kampf", chamou o esperanto de "língua da conspiração judaica" e que Stalin proibiu o uso da língua na Rússia do fim dos anos 1930 até 1956.
} 
são nativos da língua, e, portanto, não têm um conhecimento tão completo quanto um falante nativo teria (Versteegh, 1993:546). No caso da língua aqui estudada (e do hebraico moderno, com o qual o autor compara o processo de aquisição por ser também uma língua planejada e introduzida em uma comunidade linguística de forma sistemática), não se esperam mudanças de categorias gramaticais quando os falantes nativos adquirem a língua, uma vez que as categorias já estão bem definidas (diferentemente do que acontece com pidgins e crioulos).

Como os falantes são sempre bilíngues, presume-se que há influência do sistema linguístico do meio em que a criança vive nas categorias gramaticais do esperanto. Isso depende muito da convivência que as crianças possam ter com outras crianças que falam outras línguas, e da própria periodicidade com que as crianças usam o esperanto com os pais. Há um congresso anual, chamado Infana kongreseto (Congressinho infantil), que ocorre paralelamente ao UK, que nos parece ser o momento em que mais crianças de países diversos convivem entre si.

Abrahamsen (2015) estudou produções de palavras compostas de uma criança falante de esperanto e norueguês como línguas nativas, e encontrou influências dos padrões de acentuação do norueguês na acentuação de palavras compostas em esperanto que eram formadas espontaneamente. Por outro lado, em palavras compostas já lexicalizadas o padrão do esperanto era o que predominava. Esse estudo foi um dos poucos que encontramos na área de aquisição de linguagem referente ao esperanto.

\subsection{A cultura de uma língua planejada}

Cultura é um conceito complexo de se definir, e muitas são as discussões em torno deste vocábulo. Eagleton (2005) discute a etimologia da palavra e as possíveis acepções que ela adquiriu ao longo do tempo (p. 10 e ss.). Trazendo à discussão a história da concepção do tema, ele afirma: 
A cultura como civilização tinha tomado emprestadas suas distinções entre elevado e baixo dos primórdios da antropologia, para quem algumas culturas eram claramente superiores a outras; mas à medida que os debates foram desenvolvendo-se, o sentido antropológico da palavra tornou-se mais descritivo do que avaliativo. Ser simplesmente uma cultura de algum tipo já é um valor em si; mas não faria mais sentido elevar uma cultura acima da outra do que afirmar que a gramática do catalão era superior à do árabe. (Eagleton, $2005: 27)$.

A ideia, portanto, de que existem culturas mais evoluídas ou mais importantes que as outras foi bastante usada, e é ainda o que impera, muitas vezes, nas críticas feitas à cultura esperantista. Nesse caso, culturas de línguas nacionais seriam mais concretizadas e com mais valores do que a cultura de uma língua não étnica, que não tem uma comunidade local.

Se, contudo, tudo que o homem produz constitui sua cultura, em contraposição ao que é natural, e formou-se sem sua interferência, as criações literárias, musicais, teatrais, as fraseologias da língua, tudo que os falantes de esperanto produzem, também é cultura.

Nas primeiras décadas de existência da língua a ideia de uma "cultura de paz" foi importantíssima para que a língua continuasse viva e ganhasse novos adeptos. Com o tempo, a questão de justiça linguística e possível solução para o "problema da língua internacional" (Eco, 1996) ganhou força e importância para que ela continuasse despertando interesse em pessoas de diferentes localidades. Hodiernamente, com a possibilidade de se usar a internet e ter contato instantâneo com pessoas de qualquer lugar do mundo, o esperanto ganha nova força e significação. Seu aprendizado, por exemplo, se torna mais fácil, uma vez que os cursos, anteriormente, eram comumente feitos por carta (além dos cursos presenciais, é claro, mas que não estão presentes em todas as cidades). Foi lançado, recentemente, um curso on-line de esperanto no site Duolingo ${ }^{17}$, específico para o aprendizado de línguas, que teve grande alcance em pouco tempo, e já conta com mais de

\footnotetext{
${ }^{17}<$ https://www.duolingo.com/>.
} 
438.000 usuários aprendendo a língua ${ }^{18}$. Anualmente acontece o ARKONES ${ }^{19}$ (Artaj Konfrontoj en Esperanto - Confrontos artísticos em esperanto), em Poznań, na Polônia. O festival tem como objetivo reunir apresentações musicais, teatrais, palestras, cursos, entre outros, em esperanto.

Laroca (2009: 83), sobre traduções literárias, comenta que

[...] Há mais de 50000 títulos de caráter literário, científico e religioso escritos em Esperanto. Pode-se ler sobre qualquer assunto: literatura, psicanálise, política, filosofia, sociologia, linguística, história, humor, comportamento, moda, turismo, astrologia, esoterismo, educação, engenharia, televisão, cinema, artes, etc.

No âmbito da literatura religiosa, destacamos, por exemplo, a Bíblia, o Corão, o Bhagavad-Gita, o Livro dos Espíritos. Apontamos também obras de autores consagrados da literatura universal como a Divina Comédia, Hamlet, Dom Quixote, e muitos outros. Podemos também ler em Esperanto obras de Maupassant, Baudelaire, Sartre, Goethe, Marx e Engels, Nietzche, Garcia Lorca, Chekov, Kipling, Lewis Carroll, Andersen, etc. Entre as traduções literárias editadas nos últimos tempos em Esperanto estão $O$ Velho e o Mar de Hemingway, $O$ Senhor dos Anéis de Tolkien, Cem Anos de Solidão de García Márquez. Quanto aos autores de língua portuguesa traduzidos, citamos, por exemplo, José Saramago, Machado de Assis, Carlos Drummond de Andrade, Jorge Amado, Ziraldo, Paulo Coelho e muitos outros entre poloneses, alemães, franceses, italianos, ingleses, russos, chineses, coreanos, vietnamitas, japoneses. (Laroca, 2009: 83)

Há também grande número de obras escritas originalmente em esperanto. Sutton (2008), no seu livro Concise Encyclopedia of the Original Literature of Esperanto, 1887-2007 traz informações detalhadas sobre o tema. Tonkin (in Sutton (2008:01) afirma que tudo que é possível em relação a outras literaturas é possível em relação ao esperanto também (estilos literários, recursos métricos, divisão em escolas literárias, etc.).

A grande questão, todavia, é qual o vínculo que une os esperantistas, fora a língua que falam. Uma vez que não formam uma nação, a vinculação cultural

\footnotetext{
${ }^{18}$ Dados do dia 30 de junho de 2016. Mais informações podem ser vistas em: <https://www.duolingo.com/course/eo/en/Aprenda-Esperanto-Online>.

${ }^{19} \mathrm{Em} 2015$ o evento se realizou entre os dias 25 e 27 de setembro: <http://www.arkones.org/eo $>$. Fotos do evento podem ser vistas em: <http://www.arkones.org/eo/galerio >.
} 
que possam ter se torna, talvez, mais fraca, visto que o sentimento nacional por trás das expressões culturais costuma ser bastante forte. Assis (1959 [1873]) fala do instinto ${ }^{20}$ de nacionalidade presente na literatura brasileira do século XIX, que tinha o objetivo de criar independência literária de Portugal. Fala também da língua empregada nos escritos, e na opinião do escritor o poeta não deve dar vazão à toda influência "popular" que a obra recebe, principalmente se houver desvios gramaticais nas novas formas idioléticas (p. 7-8). Essa tentativa - por mais que não leve em conta todas as expressões locais brasileiras - de se criar uma comunidade literária que se desvinculasse do colonizador nos mostra como a questão geográfica é importante quando falamos de representação cultural de um "povo".

Anderson (2008), entretanto, nos leva a pensar na questão de união comunitária de forma mais abstrata. O autor propõe o termo "comunidade imaginada", para mostrar que o senso de participação de uma determinada nação é, muitas vezes, apenas uma criação mental. Ele compara a ideia de nação com a estrutura imaginada de um romance. Dois personagens podem ser importantes para a trama sem se cruzarem em nenhum momento. Eles estão relacionados a outras personagens, que, por sua vez, se relacionam entre si, e todos fazem parte de um mesmo todo, que é a trama do livro, por mais que os personagens das "pontas" da trama não se relacionem. Assim seria também em relação à nação. Todos se sentem parte de um mesmo todo, por mais que não se conheçam pessoalmente (Anderson, 2008:56).

Uma simpatia natural acontece entre os falantes de esperanto, onde quer que se encontrem. A "comunidade imaginada" da qual fazem parte cria um vínculo que os une, um laço que faz com que se considerem parte de uma mesma trama, por mais que nunca tenham se visto antes na vida. Isso acontece com um brasileiro, por exemplo, que esteja em outro país e encontre outro brasileiro. Eles

\footnotetext{
${ }^{20}$ Termo usado pelo autor.
} 
podem não terem se conhecido antes, mas há algo que os une, um sentimento de pertencimento a um mesmo grupo.

\subsubsection{Nacional versus Internacional}

Ianni (1994) chama atenção para o fato de a globalização estar produzindo categorias até então desconhecidas de fenômenos culturais. Para ele, é um desafio para as ciências sociais pensar que

[...] a sociedade global [...] não é a mera extensão quantitativa e qualitativa da sociedade nacional. Ainda que esta continue a ser básica, evidente e indispensável, manifestando-se inclusive em âmbito internacional, é inegável que a sociedade global se constitui como uma realidade original, desconhecida, carente de interpretações. (Ianni, 1994:s / pg.)

Dentro dessa perspectiva, podemos discutir se a "cultura" é sempre relacionada a uma determinada nação. Há populações que se identificam e representam sua cultura mas que não constituem um Estado político nacional único reconhecido. Os curdos, por exemplo, estão presentes em mais de um país, e a diáspora desse povo foi grande ao longo do século XX. Seria necessário definir como a identificação cultural se dá, se por meio de etnias, religiões, fronteiras políticas, ideologias, etc. Os judeus também têm uma história de dispersamento de sua população que, por mais que esteja em lugares diferentes, se identifica como judaica, sem necessariamente compartilhar o mesmo território geográfico.

A sociedade ocidental está acostumada a pensar no nacional como fator de identificação. No campo esportivo, vibramos pelas vitórias dos times de nossos países quando há competições internacionais; no campo da política, nos indignamos quando nossos representantes federais são espionados por governantes de outros países; em relação à religiosidade, estranhamos tudo que esteja fora dos campos de normalidade definidos pelas religiões conhecidas (e reconhecidas) em nosso país; linguisticamente falando, toma-se como anormais fenômenos 
gramaticais de línguas de países de outros continentes que pertençam a troncos linguísticos diferentes de nossas línguas maternas, etc.

A ideia de nação ou comunidade nacional também é complexa, e sua definição não é trabalho trivial. Albrow (1999) discute a possível origem de tal conceito e como ele se consolidou na era moderna:

A questão das raízes é o que Anthony Smith trata justa e adequadamente em sua explicação sobre a origem étnica das nações, em que a distinção conceitual que ele traça entre ethnie e nação nos dá os marcos da sequência da narrativa histórica subjacente que culmina em um mundo de Estadosnação. Para ele, a nação emergiu nos tempos modernos, mas tem raízes na ethnie, ou comunidade étnica, pré-moderna. As ethnies têm mitos de ancestral comum, compartilham memórias históricas, cultura comum diferenciada, solidariedade e terra natal. Contudo, se comparadas às nações, elas estão frequentemente sem território, não necessitam de código legal comum, nem direitos ou obrigações. As nações são construídas sobre comunidades étnicas, mas adquirem outras características, no período moderno. (Albrow, 1999: 2425).

Albrow (1999) reforça ainda a ideia de que Smith pensa nas ethnies como um processo histórico, e não como definições de grupos por cor de pele ou religião, por exemplo.

Retomando o conceito de comunidades imaginadas de Anderson (2008), pensemos na força de identificação que línguas nacionais proporcionam aos seus falantes. O autor afirma que "O advento da impressão trouxe consigo a possibilidade de imaginação das comunidades, que seriam aquelas sob o escopo de tal ou qual língua escrita" (Anderson, 2008:79). Quando não havia quantidade significativa de material impresso circulando, portanto, talvez a capacidade de abstração e identificação de comunidade linguística fosse menor. Até onde vão as fronteiras do meu país e da minha comunidade? Até onde seja inteligível para as pessoas o que está escrito em tal ou qual livro, jornal, etc., que utiliza a língua que me é familiar como meio de comunicação.

Com o tempo, os descobrimentos e as conquistas também provocaram uma revolução nas ideias europeias sobre as línguas. Desde o começo, marinheiros, 
missionários, comerciantes e soldados portugueses, holandeses e espanhóis, por razões práticas - navegação, catequização, comércio e guerra -, tinham montado listas de palavras em línguas não europeias para formar dicionários elementares. Mas foi apenas no final do século XVIII que o estudo científico comparado das línguas realmente deslanchou. (Anderson, 2008:110)

A conscientização de que as línguas eram várias pelo mundo todo talvez também tenha impulsionado a necessidade de se definir quem fazia parte de qual comunidade.

[...] No caso da Noruega, que por muito tempo compartilhou a mesma língua escrita com os dinamarqueses, apesar da pronúncia totalmente diferente, $\mathrm{o}$ nacionalismo surgiu com a nova gramática (1848) e o novo dicionário (1850) de norueguês, da lavra de Ivar Aasen, obras que incentivavam e respondiam às demandas de uma língua impressa especificamente norueguesa. (Anderson, $2008: 117)$

\section{$[\ldots]$}

Para enaltecer a consciência nacional da Turquia túrquica, em detrimento de qualquer identificação islâmica mais profunda, Atatürk impôs uma romanização obrigatória (Hans Kohn, The age of nationalism, p. 108). As autoridades soviéticas seguiram a mesma trilha, primeiro com a romanização compulsória anti-islâmica e antipersa depois, nos anos 30, com Stálin e sua civilização russificante obrigatória. (Seton-Watson, Nations and states, p. 317). (Anderson, 2008)

A questão de identidade linguística, portanto, está intrinsecamente ligada à noção de comunidade nacional, a fatores de identificação. Anderson (2008:101) afirma ainda que "O surgimento da consciência nacional americana se deu no final do século XVIII". Antes da ideia de estados-nação, então, como se dava a identificação de comunidade? Não pretendemos responder essa questão, mas sim apenas levantar a problemática de que nem sempre as definições de barreira geopolíticas foram sinônimo único de identificação (e não o são atualmente, é claro, mas têm um grande poder sobre isso). O caso da Noruega e da Turquia ilustram, por exemplo, que esse tipo de preocupação é antiga. 
Atualmente a mobilidade geográfica é mais fácil do que nos séculos anteriores. Sendo assim, é vantajoso que se conheça mais línguas do que apenas a(s) sua(s) língua(s) materna(s). Muitas vezes, aprender uma outra língua se torna necessário, como para as pessoas que se deslocam de seus países por causa de guerras, e se refugiam em outros lugares temporariamente (como os sírios no Brasil, por exemplo).

\subsubsection{O esperanto e a possibilidade de se pensar de forma trans- nacional}

A língua que falamos influencia fortemente a visão de mundo que temos e como nos relacionamos com os outros. Falantes do esperanto tendem a se considerar como "cidadãos do mundo", por poderem falar com pessoas de várias localidades do globo utilizando a língua esperanto como ferramenta para tanto. Por isso, a língua cria uma ideia de igualdade entre os povos, uma vez que todos tiveram que aprender a língua para poderem se comunicar de forma internacional (apesar de haver falantes nativos de esperanto).

Esperantistas costumam criticar o uso do inglês como língua internacional pela falta de neutralidade, gerada pelo fato de que falantes nativos de inglês sempre estão em posição de vantagem em relação àqueles que devem aprender a língua para se comunicar internacionalmente. Discutir este tópico não constitui nosso objetivo, mas enfatizamos que a chamada "globalização" trouxe novas perspectivas para se pensar a cultura e como as realizações culturais humanas podem se manifestar. Uma língua que seja usada para a comunicação entre pessoas de nacionalidades diferentes é algo necessário e digno de atenção de estudos. Houve um tempo em que a comunicação internacional era feita por meio do latim; posteriormente, o francês teve importante papel sobre esse assunto, mas após a Segunda Guerra Mundial o inglês assumiu essa posição sem concorrentes. 
O crescimento geral da alfabetização, do comércio, da indústria, das comunicações e dos aparelhos de Estado, que marcou o século XIX, gerou um vigoroso impulso em busca de uma unificação linguística vernácula dentro de cada reino dinástico. O latim se manteve como língua oficial do Império Austro-húngaro até o começo dos anos 1840, mas a seguir desapareceu quase instantaneamente. Ele podia ser língua oficial, mas não era, em pleno século XIX, a língua dos negócios, das ciências, da imprensa ou da literatura, principalmente num mundo em que tais línguas se interpenetravam sem cessar. (Anderson, 2008:120)

Entretanto, devemos também ficar atentos à possibilidade de uma única língua para comunicação internacional empobrecer o cenário cultural possível. Afinal de contas, é claro o domínio que a indústria cultural estadunidense exerce sobre vários países com menor representação cultural projetada internacionalmente. Esse é o caso do Brasil, por exemplo. Aqui, assiste-se a filmes produzidos em Hollywood, come-se no McDonald's e no Burger King, ouvem-se músicas cantadas em inglês por cantores majoritariamente provenientes dos Estados Unidos, compram-se roupas em sales com preço off, etc. Hannerz (1996) reflete sobre a possibilidade, como afirmam alguns pesquisadores, de que a globalização torne a(s) cultura(s) no mundo menos diversificada(s). Ele afirma que o termo globalização significa

[...] uma homogeneização global na qual práticas e ideias particulares se espalham pelo mundo, principalmente partindo dos centros do Ocidente, excluindo outras alternativas. Na visão de alguns, isso é um marco triunfante da modernidade. Outros lamentam isso como uma tomada por parte dos grandes comerciantes de mercadorias culturais, que se certificam que a Coca Cola seja bebida, que Dallas seja assistido, e que bonecas Barbie sejam usadas como brinquedo em todos os lugares, tanto no ex segundo mundo como no terceiro mundo, assim como são usadas no primeiro mundo, onde se originaram. (Hannerz, 1996:24) (tradução nossa).

Possivelmente, poderíamos também falar de um mundo plurilíngue, no qual ao invés de se escolher uma língua apenas para a comunicação internacional se escolhessem várias, e fosse algo corriqueiro aos cidadãos serem multilíngues, como de fato o é na Europa e África ${ }^{21}$. Talvez esse fosse um panorama mais motivador em relação ao respeito à diversidade (linguística e cultural).

\footnotetext{
${ }^{21}$ Sobre bilinguismo e multilinguismo verificar Bhatia \& Ritchie (2013).
} 
Segundo Smith (1999), após 1945, e o fim da Segunda Guerra Mundial, a noção de Estado estava falida e a ideia de "ideologias 'supranacionais"' começava a ganhar força.

[...] No mundo do pós-guerra, o estado nacional era nitidamente ultrapassado, junto com o nacionalismo e todos os seus rituais. Em seu lugar surgiram os novos imperialismos culturais, do comunismo soviético, do capitalismo americano, e lutando para encontrar o seu lugar entre os dois, um novo europeísmo. Nisto reside a esperança da corrosão do estado e de superar a nação. (Smith, 1999: 185)

Ao longo do século XX, então, essa desconstrução nacional e ideias transnacionais foram se firmando. O surgimento da internet e sua popularização a partir dos anos 1990 talvez tenha acelerado o processo. Nesse mundo interconectado, o esperanto é visto, por muitos, como ferramenta útil e prática para a comunicação internacional, visto que seu aprendizado é mais fácil do que o da língua inglesa, pela regularidade da gramática.

Featherstone (1999) afirma ser impossível existir uma cultura global, visto que a cultura está sempre ligada ao conceito de estado nacional, e é impossível o processo de formação de um estado universal. Contudo, se nos atentarmos aos processos de integração e de desintegração cultural, podemos falar sobre uma globalização da cultura, que ocorre a nível transnacional (Featherstone, 1999:07).

A questão aqui tratada envolve muitos conceitos pluriformes, como "cultura", "nação", "identificação cultural”, "povo", "etnia", etc. Até mesmo a língua aqui tratada, o esperanto, é fenômeno ainda não bem entendido e complexo. Nosso intuito é levantar questões a serem pensadas e relacionadas, no que diz respeito à possibilidade de um mundo globalizado, de uma cultura que rompa as barreiras nacionais e de uma língua planejada, que rompe, também, os parâmetros e paradigmas de análise do campo linguístico. 


\section{Esperanto: estudos prévios}

Discorremos, neste capítulo, sobre a fonologia da língua de forma geral e resumimos a produção bibliográfica que encontramos sobre o tema.

\subsection{A fonologia do esperanto}

Como língua planejada, o esperanto segue um processo inverso em relação à maioria das línguas, que se desenvolvem oralmente e posteriormente passam a ser escritas (Dols Salas, 2012:38). O que veio primeiro foi a ortografia, a forma escrita, e só depois disso a língua passou a ser falada.

Até hoje não há um consenso sobre a pronúncia "correta" dos sons, uma vez que a influência dos sons da língua materna é sempre forte. Apesar de todo e qualquer sotaque que o falante possa ter, Wells (1989) diz que o importante é que haja a comunicação entre os falantes da língua. Se há entendimento entre eles, então a pronúncia deve estar mais ou menos boa.

A gramática da língua foi planejada para ser regular e de fácil aprendizagem. Os substantivos têm todos a mesma terminação, o que vale para adjetivos, advérbios, verbos no infinitivo, tempos verbais conjugados, e assim por diante.

Os estudos científicos sobre o esperanto não são muito numerosos aqui no Brasil. Os dados que tínhamos até o início deste levantamento bibliográfico se referem a trabalhos (não só daqui do Brasil) na área de fonética e fonologia (Wells, 1989; Oostendorp, 1998, 1999), alguns na área de morfologia/sintaxe (Laroca, 2009; Herring, 2005), além de trabalhos sobre aquisição do esperanto como língua materna (Bergen, 2001; Corsetti, 1994, 1996b,a; Corsetti et al., 2004; Lindstedt, 1997, 2006, 2010), entre outros (Sherwood, 1982; Bíró, 2004; Gobbo, 2009; Blanke, 2009; 
Dias, 2009).

Visto ser o primeiro trabalho na área escrito no Brasil, achamos necessário um levantamento bibliográfico mais detalhado sobre o assunto geral (a fonologia do esperanto), para nossa própria pesquisa e também para pesquisadores que se interessem pelo tema no futuro.

Entender que tipos de pesquisas tinham sido feitas antes da nossa foi válido para perceber que os estudos, infelizmente, são dispersos e há, ainda, muitas lacunas em relação à própria descrição estrutural da língua falada.

\subsection{Estudos anteriores}

Buscamos trabalhos por meio de palavras chaves em sites de pesquisa como Google Acadêmico, Scielo, ferramentas de buscas de grandes bibliotecas, além de checagem das referências bibliográficas nos artigos e livros dos quais já tínhamos conhecimento. Como a língua em questão não é língua oficial de nenhum país e seus estudos encontram-se dispersos, fez-se necessária uma busca ampla.

Para a coleta de referências sobre o tema, partimos de artigos já conhecidos, devido a pesquisas anteriores, e buscamos as referências bibliográficas encontradas em tais artigos. De acordo com o nome dos trabalhos tentamos encontrá-los para verificar se realmente o tema, ou pelo menos parte do trabalho, referia-se a estudos sobre a fonologia (ou mesmo sobre fenômenos fonéticos específicos que pudessem nos ajudar a entender a fonologia da língua) para incluí-los ou não na bibliografia.

Após a verificação destas fontes primárias das quais já tínhamos notícias, pesquisamos em sites de busca geral on-line, como bases de dados (graças à indicação do professor Humphrey R. Tonkin, da Universidade de Hartford) como a MLA (Modern Language Abstracts) International Bibliography ${ }^{1}$, à qual tivemos acesso graças ao convênio firmado pela USP, através da CAPES. As bases

\footnotetext{
${ }^{1}$ Disponível em: <https://www.mla.org/bibliography>.
} 
de dados disponibilizadas ao público USP podem ser consultadas no endereço $<$ http:/ /biblioteca.fflch.usp.br/basededados2>. Aplicamos o filtro "linguística" à lista geral de bases de dados, e buscamos trabalhos em todas as bases de dados disponíveis para esta área do conhecimento. São elas: Academic Search Elite $(\mathrm{EBSCO})^{2}$, Academic Search Premier ASP (EBSCO) ${ }^{3}$, Annual Reviews ${ }^{4}$, Cambridge Journals Online $(\mathrm{CJO})^{5}$, DOAJ - Directory of Open Access Journals ${ }^{6}$, Gallica Digital Library $^{7}$, JSTOR $^{8}$, LATINDEX $^{9}$, Linguistics and Language Behavior Abstracs LLBA (ProQuest) ${ }^{10}$, MUSE $^{11}$, Oxford Journals ${ }^{12}$, Persée $^{13}$, Portal CAPES ${ }^{14}$, REDALYC - Red de Revistas América Latina, Caribe, España y Portugal ${ }^{15}$, SCIELO Artigos de Periódicos ${ }^{16}$, Science Direct (Elsevier) ${ }^{17}$, SCOPUS ${ }^{18}$, Web of Science ${ }^{19}$ e WILLEY Online Library ${ }^{20}$. As plataformas, muitas vezes, geravam resultados semelhantes, por buscarem os dados nas mesmas bases, mas mesmo assim todas foram verificadas. A base na qual a busca foi mais produtiva foi a MLA (Modern Language Abstracts) International Bibliography, uma das bases de dados mais completas sobre a área de linguística, com mais de 2 milhões de referências (não só de linguística, mas também de literatura, línguas e folclore).

\footnotetext{
${ }^{2}$ Disponível em: <http:/ / web.b.ebscohost.com/ehost/search/basic?sid=74771424-125c-4264ba92-8c043b0a9c09\%40sessionmgr114\&vid=0\&hid=109>.

${ }^{3}$ Disponível em: <http://web.b.ebscohost.com/ehost/search/basic?sid=b92d9e65-7378-4cc6b84d-31a9b45885d9\%40sessionmgr110\&vid=0\&hid=109>.

${ }^{4}$ Disponível em: <http://www-annualreviews-org.ez67.periodicos.capes.gov.br/>.

${ }^{5}$ Disponível em: <http://journals-cambridge-org.ez67.periodicos.capes.gov.br/action/login>.

${ }^{6}$ Disponível em: <https://doaj.org/>.

${ }^{7}$ Disponível em: $<$ http://gallica.bnf.fr/?\&lang=EN>.

${ }^{8}$ Disponível em: <http://www.jstor.org/>.

${ }^{9}$ Disponível em: <http://www.latindex.org/>.

${ }^{10}$ Disponível em: <http://search.proquest.com/llba/index>

${ }^{11}$ Disponível em: <http:// muse-jhu-edu.ez67.periodicos.capes.gov.br/search/advanced\#firstLoad>.

${ }^{12}$ Disponível em: <http:/ / www.oxfordjournals.org.ez67.periodicos.capes.gov.br/en/>.

${ }^{13}$ Disponível em: <http://www.persee.fr/web/guest/home>.

${ }^{14}$ Disponível em: <http://www-periodicos-capes-gov-br.ez67.periodicos.capes.gov.br/>.

${ }^{15}$ Disponível em: <http://www.redalyc.org/home.oa $>$.

${ }^{16}$ Disponível em: <http://www.scielo.org/php/index.php>.

${ }^{17}$ Disponível em: <http://www.sciencedirect.com/science/journals/sub/socialscienceshumanities $>$.

${ }^{18}$ Disponível em: <http://www.scopus.com/>.

${ }^{19}$ Disponível em: <http:/ /apps.webofknowledge.com/WOS_GeneralSearch_input.do?product=WOS $\& S I D=2 D O 4 c c I I I F W w m H V 3 T a e \& s e a r c h \_m o d e=G e n e r a l S e a r c h>$.

${ }^{20}$ Disponível em: <http:// onlinelibrary-wiley-com.ez67.periodicos.capes.gov.br/advanced/search>.
} 
A Scienca Revuo ${ }^{21}$ (Revista Científica), publicação periódica, em esperanto, sobre assuntos relacionados a diversas áreas do meio científico, foi importante fonte de busca, assim como os anais do IKU ${ }^{22}$ - Internacia Kongresa Universitato (Congresso universitário internacional), que ocorre uma vez por ano, em países diferentes, desde 1951. Os arquivos on-line com os textos das apresentações disponíveis, entretanto, datam de 1998.

Como a língua aqui estudada é pouco popular no campo científico, entramos em contato, por meio eletrônico, com professores universitários e pesquisadores independentes, falantes de esperanto, e que já publicaram algo referente à língua no meio acadêmico. Os pesquisadores consultados foram: Profa. Dra. Ilona Koutny $^{23}$, Prof. Dr. Nicolau Dols Salas ${ }^{24}$, Prof. Dr. Marc van Oostendorp ${ }^{25}$, Prof. Dr. Humphrey Tonkin ${ }^{26}$, Prof. Dr. Ivan Eidt Colling ${ }^{27}$, Prof. Dr. Jouko Lindstedt ${ }^{28}$, Prof. Dr. Renato Corsetti ${ }^{29}$, Profa. Dra. Sabine Fiedler ${ }^{30}$, Prof. Dr. José Passini ${ }^{31}$, Dra. Katalin Kováts ${ }^{32}$, Usui Hiroyuki ${ }^{33}$, Bertilo Wennergren ${ }^{34}$, Dr. Marc Bavant ${ }^{35}$. Infelizmente, tivemos poucas respostas, mas que foram bastante úteis na indicação de campos de pesquisa propícios e de trabalhos específicos a serem incluídos no levantamento bibliográfico.

\footnotetext{
${ }^{21}$ Disponível em: <https://scienca-revuo.info/>.

${ }^{22}$ Disponível em: <http://www.uea.org/kongresoj/universitato $>$.

${ }^{23}$ Hungria/Polônia - Universidade Adam Mickiewicz.

${ }^{24}$ Ilhas Baleares - Universidade das Ilhas Baleares - <http:/ / www.uib.es/es/personal/ABDI2MjE/>.

${ }^{25}$ Holanda - Universidade de Leiden - <http:/ / www.vanoostendorp.nl/index.php?lan=en>.

${ }^{26}$ Inglaterra/Estados Unidos - Universidade de Hartford $<$ http:/ / uhaweb.hartford.edu/TONKIN/intro.html>.

${ }^{27}$ Brasil - Universidade Federal do Paraná - <http://www.eletrica.ufpr.br/p/professores:ivan:inicial $>$.

${ }^{28}$ Finlândia - Universidade de Helsink - <https://tuhat.halvi.helsinki.fi/portal/en/person/jslindst $>$.

${ }^{29}$ Itália - Universidade de Roma.

${ }^{30}$ Alemanha - Universidade de Leipzig - $<$ http://anglistik.philol.unileipzig.de/de/institut/linguistik/mitarbeiter/apl-prof-dr-sabine-fiedler>.

${ }^{31}$ Brasil - Universidade Federal de Juiz de Fora.

${ }^{32}$ Hungria/Holanda - pesquisadora independente.

${ }^{33}$ Japão/China - jornalista na CRI ("Ĉina Radio Internacia" - Rádio chinesa internacional, com transmissão on-line em esperanto) - <http:/ /esperanto.cri.cn/>.

${ }^{34}$ Suécia/Alemanha - gramático,

$<$ http://bertilow.com/bertilo/index.html>.

${ }^{35}$ Holanda - Universidade de Amsterdã.
} 
Os subitens a seguir contêm as referências às quais pudermos ter acesso. Comentamos, de modo enxuto, como podemos classificá-las de acordo com o tipo de material.

\subsubsection{Manuais, gramáticas, livros e dissertações}

Há duas obras gramaticais sobre o esperanto: Kalocsay \& Waringhien (1985 (1935) e Wennergren (2005). Elas tratam sobre todos os temas canônicos que usualmente aparecem nas gramáticas, e têm capítulos específicos sobre a fonologia da língua.

O único manual sobre linguística escrito em esperanto é de Wells (1989). Escrito pelo professor John Wells, da Universidade de Londres, possui um capítulo sobre Fonética, um sobre Morfologia, Sintaxe, Léxico e Semântica, e explica quais são os conceitos de cada área e o que cada uma estuda.

Pettyn (1994) é o único livro que encontramos dedicado exclusivamente à área

de Fonética e Fonologia. Versa sobre a variação fonética do esperanto e sobre bastantes fenômenos fonológicos, como assimilação, vozeamento ou desvozeamento, etc. Tem exercícios de pronúncia, e no final do livro é dito que a brochura acompanha um CD com gravações do próprio autor com exercícios de pronúncia, mas ao qual não tivemos acesso. O trabalho, porém, é de caráter mais normativo do que descritivo.

Uma única monografia foi encontrada. Trata-se de Okhuijsen (2011), dissertação de mestrado, defendida na Universidade de Amsterdã, que trata de palavras do inglês que são emprestadas para o holandês e para o esperanto, comparando os processos de empréstimos nas duas línguas. Abrange fonologia e morfologia, e, de todos os trabalhos encontrados, é o que mais se parece com o que estudamos nesta dissertação. Entretanto, tal pesquisa teve foco na semântica das palavras, e não nas adaptações fonológicas, apesar de tratar, também, da adaptação de fonemas 
no esperanto. O autor chega à conclusão de que o holandês e o esperanto têm maneiras diferentes para incorporar empréstimos, apesar de os processos entre as duas línguas serem parecidos.

\subsubsection{Artigos em livros, revistas, jornais e blogs}

Os artigos aqui listados encontram-se em revistas especializadas sobre linguística, revistas do movimento esperantista, anais de congressos (UK - Universala Kongreso "Congresso Universal”), blogs de crítica e discussão linguística, livros publicados sobre vários assuntos relacionados ao esperanto, etc.

Os trabalhos referenciados tratam de vários aspectos da fonética e fonologia do esperanto: variação fonética, fenômenos fonológicos - como elisão de segmentos -, estrutura silábica da língua, comparação de sistemas fonológicos, ditongos, consoantes geminadas, palavras emprestadas, etc.

As vogais da língua foram estudadas por Sadler (1961) e Čižikaité (2006). Sadler (1961) fez um experimento sobre vogais, inserido num quadro teórico de fonética experimental, testando a percepção de 18 falantes ao ouvir combinações CV de todas as consoantes da língua com as 5 vogais presentes no quadro fonológico do esperanto. Čižikaité (2006) comenta a evolução histórica do sistema vocálico do lituano e sua complexidade, com vogais longas e breves, além das nasais e ditongos, e compara com o sistema vocálico do esperanto. Traz uma discussão sobre as vogais $<\mathrm{e}>\mathrm{e}<\mathrm{o}>$, pois não há, em esperanto, consenso se elas devem ser pronunciadas como médias baixas ou médias altas (elas podem ser pronunciadas como algo intermediário entre as duas categorias, é claro, e há variação nas pronúncias, assim como de qualquer outro fonema).

Segmentos específicos foram estudados por Vitali (2001) e Pokrovskij (2014). O primeiro estudo refere-se às nasais e suas possíveis realizações fonéticas em esperanto. Comenta, também, fenômenos fonológicos com consoantes nasais em 
geral nas línguas. O segundo estudo discute os ditongos, e fala de fonética e fonologia. Afirma que " $\breve{u}$ " deve ter tratamento e análise diferentes de "j", mas fala principalmente sobre o Fundamento ${ }^{36}$ e como o Zamenhof descreveu essas letras/sons.

A estrutura silábica da língua foi estudada, entre outros, por Oostendorp $(1998,1999)$, que teoriza sobre o assunto à luz da teoria da otimidade e de outras teorias correntes no campo, com as quais o pesquisador trabalha. O artigo de 1999 é bem mais abrangente e comenta que os estudos sobre a fonologia da língua são normalmente deixados de lado nas teorizações mais gerais, existentes até o momento. O autor deixa claro que trabalha com a forma fonológica da palavra, e não com as realizações fonéticas possíveis (assim como fazemos nesta dissertação), uma vez que normalmente há influência da língua materna do falante. Bavant (2006b) é o trabalho mais completo sobre o tema, pois faz uma revisão da bibliografia disponível, incluindo gramáticas normativas e textos descritivocientíficos, como os próprios textos de Oostendorp supracitados. Dols Salas (2012) também se vale da teoria da otimidade para analisar as possíveis estruturas silábicas na língua, principalmente em palavras compostas. Miner (2003) discursa sobre a estrutura silábica do esperanto e especificamente sobre elisão de segmentos, a partir de um corpus formado por 105 poemas.

Alguns autores escreveram textos com descrições comparativas entre o esperanto e outras línguas. Tucker (2008) fala sobre o processo de aprendizado do esperanto pelos falantes de turco, assim como da fonologia de línguas indoeuropeias em geral e também do esperanto. O autor comenta a dificuldade que falantes de turco têm para aprender qualquer língua do ramo indo-europeu, visto que o léxico e o sistema gramatical delas normalmente é bem diferente do turco (das línguas turcomanas e fino-úgricas em geral). Entretanto, entre as línguas

\footnotetext{
${ }^{36}$ Livro que contém as regras gerais do esperanto, lançado em 1905, durante o primeiro congresso de esperanto, realizado na França.
} 
desse ramo, o esperanto ainda é de mais fácil aprendizado do que as outras línguas, como francês, inglês, alemão, etc. O autor comenta semelhanças e diferenças entre os sistemas consonantais e vocálicos do turco e do esperanto, além de comentar o sistema acentual do turco e certas dificuldades que os falantes de turco têm para aprender outras línguas. Nagata (2004) constitui pesquisa sobre percepção de cinco línguas (inglês, francês, italiano, holandês e esperanto) por falantes de japonês. Discorre sobre percepção silábica (sílabas e moras). Nagata (2008) fez uma pesquisa sobre a percepção de seis línguas (inglês, holandês, francês, italiano, japonês e esperanto) por falantes de japonês. Faz uma comparação entre as línguas e sons das línguas isoladas. A pesquisa é bastante parecida com a publicada em Nagata (2004). Colling (2012) descreve brevemente o sistema da língua portuguesa e do esperanto e compara os dois sistemas. O autor comenta problemas de aprendizado que os brasileiros enfrentam ao aprender esperanto, principalmente os que ele observou ao longo de suas aulas, ministradas na UFPR (Universidade Federal do Paraná).

Dominte (2001) realizou um estudo estatístico entre a frequência de vogais e consoantes, que lista a frequência de todos os fonemas do esperanto no corpus selecionado (prosa e poesia, textos variados, de várias épocas, originalmente escritos em esperanto e também textos traduzidos). A pesquisa foi apresentada em 1978, na Alemanha, em um congresso. Dominte chegou à conclusão de que os fonemas mais frequentes na língua são as vogais, e os menos frequentes são as africadas. A ordem geral que a pesquisa encontrou foi: a [a], o [o], i [i], e [e], n [n], 1 $[\mathrm{l}], \mathrm{r}[\mathrm{r}], \mathrm{s}[\mathrm{s}], \mathrm{t}[\mathrm{t}], \mathrm{k}[\mathrm{k}], \mathrm{d}[\mathrm{d}], \mathrm{j}[\mathrm{j}], \mathrm{u}[\mathrm{u}], \mathrm{m}[\mathrm{m}], \mathrm{p}[\mathrm{p}], \mathrm{b}[\mathrm{b}], \mathrm{v}[\mathrm{v}], \mathrm{f}[\mathrm{f}], \hat{\mathrm{g}}[\widehat{\mathrm{d}}]], \mathrm{g}[\mathrm{g}], \mathrm{c}$ $[\widehat{\mathrm{ts}}], \hat{\mathrm{c}}[\widehat{\mathrm{t} f}], \breve{\mathrm{u}}[\mathrm{w}], \hat{\mathrm{s}}\left[\int\right], \mathrm{z}[\mathrm{z}], \mathrm{h}[\mathrm{h}], \hat{\mathrm{j}}[3], \hat{\mathrm{h}}[\mathrm{x}]$.

Cadei (1983) e Sherwood (1982) escreveram considerações sobre a variação fonética possível na língua. Benczik (2005) ocupa a maior parte do texto sobre semiótica, mas fala um pouco de fonética e critica o capítulo sobre este tema de 
Kalocsay \& Waringhien (1985 (1935). Tambovtsev (2008) constitui uma tentativa de classificação do esperanto pela tipologia das línguas indo-europeias, considerando o nível fonológico.

Dols Salas (2009), inicialmente realizado como palestra, constitui um texto sobre as pesquisas em fonética e fonologia do esperanto, e defende que devem-se aplicar mais as teorias gerais da fonologia ao estudo da língua, com resultados promissores e interessantes sobre as próprias línguas naturais e a relação de línguas naturais e as planejadas. Trata também da relação da língua escrita e fenômenos naturais da língua falada.

Esperamos que trabalhos futuros possam se beneficiar deste levantamento bibliográfico, que, acima de tudo, foi muito útil para nossa própria pesquisa e nosso entendimento da área estudada.

\subsection{Sistema consonantal}

O elenco de consoantes do esperanto é bastante parecido com o do português (com as línguas indo-europeias, em geral), já que os radicais vêm, em sua maioria, do latim, além do grego e de línguas eslavas.

O alfabeto do esperanto consiste em 28 letras: $a, b, c, \hat{c}, d, e, f, g, \hat{g}, h, \hat{h}, i, j, \hat{j}$, $\mathrm{k}, \mathrm{l}, \mathrm{m}, \mathrm{n}, \mathrm{o}, \mathrm{p}, \mathrm{r}, \mathrm{s}, \hat{\mathrm{s}}, \mathrm{t}, \mathrm{u}, \mathrm{u}, \mathrm{v}, \mathrm{z}$. Somente um quarto delas não corresponde ao símbolo fonético da IPA [...]. (Colling, 2012:02)

O sistema consonantal pode ser visto na tabela 2.1. Há oclusivas (p, b, t, d, k, g), africadas (ts, dz, t $\left.\int, d_{3}\right)$, fricativas (f, v s, $\left.z, \int, 3, x, h\right)$, nasais $(m, n)$, líquidas $(\mathrm{l}, \mathrm{c})$ e aproximantes $(j, w)$. 
Tabela 2.1: Segmentos consonantais do esperanto (os símbolos à direita representam consoantes sonoras) (Colling, 2012).

\begin{tabular}{|l|llllll|}
\hline & Bilabial & $\begin{array}{l}\text { Lábio- } \\
\text { dental }\end{array}$ & $\begin{array}{l}\text { Dental } \\
\text { ou } \\
\text { alveolar }\end{array}$ & $\begin{array}{l}\text { Pós- } \\
\text { alveolar }\end{array}$ & Velar & Glotal \\
\hline $\begin{array}{l}\text { Oclusiva } \\
\text { Africada }\end{array}$ & $\mathrm{p} \mathrm{b}$ & & $\mathrm{td}$ & $\mathrm{kg}$ & \\
$\begin{array}{l}\text { Fricativa } \\
\text { Nasal }\end{array}$ & $\mathrm{m}$ & $\mathrm{f} \mathrm{v}$ & $\mathrm{s} \mathrm{z}$ & $\int 3$ & $\mathrm{x}$ & $\mathrm{h}$ \\
$\begin{array}{l}\text { Líquida } \\
\text { Aproximante }\end{array}$ & & & $\mathrm{n}$ & $\mathrm{t} d \mathrm{~d} 3$ & & \\
\hline
\end{tabular}

A maioria das letras representa a pronúncia do som, a não ser as representadas na Tabela 2.2. A existência do fonema /dz/ não é consenso entre os estudiosos, devido ao baixo número de palavras que contrastam de significado por meio do par mínimo /ts/ - /dz/.

Tabela 2.2: Fonemas do esperanto cujas representações ortográficas não correspondem ao símbolo fonético (Colling, 2012).

\begin{tabular}{|c|c|}
\hline Fonema & Representação ortográfica \\
\hline$[\mathrm{ts}]$ & $\mathrm{c}$ \\
\hline$[\mathrm{t}]$ & $\hat{\mathrm{c}}$ \\
\hline$\left[\mathrm{d}_{3}\right]$ & $\hat{\mathrm{g}}$ \\
\hline$[\mathrm{s}]$ & $\hat{\mathrm{j}}$ \\
\hline$[\mathrm{x}]$ & $\hat{\mathrm{h}}$ \\
\hline$[\mathrm{J}]$ & $\hat{\mathrm{s}}$ \\
\hline$[\mathrm{w}]$ & $\breve{\mathrm{u}}$ \\
\hline
\end{tabular}

Tal sistema consonantal se mostra dentro do padrão da maioria das línguas. Maddieson \& Disner (1984:07) afirmam que o tamanho típico de inventórios fonológicos é entre 20 e 37 segmentos (70\% das línguas estudadas pelos autores). 
Além disso, os segmentos presentes são também os mais comuns. Oclusivas são encontradas em todas línguas ${ }^{37}$ (Maddieson \& Disner, 1984 : 25); africadas são, normalmente, compostas por oclusivas e sibilantes (Maddieson \& Disner, 1984 : 40); as fricativas presentes no esperanto também estão entre as mais comuns (Maddieson \& Disner, 1984:50); entre as nasais, as mais comuns são a dentalalveolar e a bilabial; 87\% das laterais encontradas no corpus da referida pesquisa se referiam à dental-alveolar (Maddieson \& Disner, 1984:77), enquanto o tepe (o rótico presente no sistema consonantal do esperanto) foi o segundo segmento mais encontrado dessa classe (Maddieson \& Disner, 1984:79); sobre as aproximantes, os autores afirmam que /j/ e /w/ são os segmentos mais comuns (Maddieson \& Disner, 1984:91-92). Isso nos mostra que o sistema consonantal do esperanto é suficientemente internacional, ou seja, propício para uma língua planejada para tal propósito (por mais que não seja o sistema consonantal talvez ideal).

\subsection{Sistema vocálico}

Wells (1989: 18-19) fala de sistemas vocálicos nas línguas em geral, e afirma que o sistema de cinco vogais que o esperanto possui é o mais comum entre as línguas. Maddieson \& Disner (1984) também afirmam que tal sistema vocálico é o mais comum (i, e, a, o, u).

As vogais podem ser vistas na Tabela 2.3.

\footnotetext{
${ }^{37}$ Os autores citados estudaram 317 línguas, o que é um número pequeno, mas selecionaram línguas de todos os troncos linguísticos, para poder fazer análises estatísticas baseadas em exemplos que pudessem ser confiáveis para se falar de padrões gerais.
} 
Tabela 2.3: Segmentos vocálicos do esperanto (os símbolos à direita representam consoantes sonoras) (Colling, 2012).

\begin{tabular}{|c|ccc|}
\hline & Anterior & Central & Posterior \\
\hline Alta & $\mathrm{i}$ & & $\mathrm{u}$ \\
Média & $\mathrm{e}$ & & $\mathrm{o}$ \\
Baixa & & $\mathrm{a}$ & \\
\hline
\end{tabular}

Não há oposição fonológica entre vogais longas e breves. Colling (2012) nos chama a atenção para o fato de que não há diferenciação da altura das vogais médias:

Cinco são as vogais; entre as consoantes figuram as semivogais j e $\breve{u}$ [w]. Wells (1989:21) afirma que Zamenhof foi sábio ao não incluir subdivisões nas vogais médias (os contrastes / / - /o/ e / $\varepsilon /$ - /e/ não existem em esperanto) e também por manter o arredondamento dependente da anterioridade das vogais. (Colling, 2012: 02)

Em relação à realização fonética efetiva das vogais, entretanto, é bastante provável que /o/ e /e/ sejam realizados como / / / e / $\varepsilon /$, respectivamente, em determinados contextos fonológicos ou por determinados falantes da língua. Dols Salas (2012 : 40) comenta a variação fonética das pronúncias das vogais. Ele cita a nona regra do esperanto, que diz que "cada palavra é lida da maneira como é escrita"38, e explica porque isso é impossível de ser realizado. O autor comparou a realização fonética das vogais $[\mathrm{o}]$ e $[\mathrm{u}]$ de cinco falantes, estudo mostrado na Figura 2.1.

\footnotetext{
38“Ĉiu vorto estas legata, kiel ĝi estas skribita” (Dols Salas, 2012:38).
} 
(1) Vowel chart ((X=F1, Y=F2)) (single occurrences)

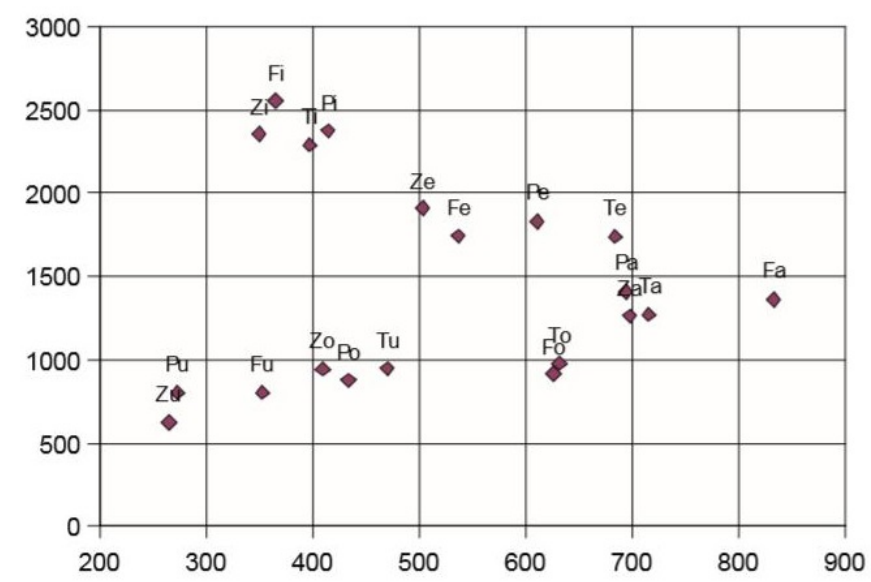

Figura 2.1: Comparação entre a realização fonética das vogais $[\mathrm{o}]$ e $[\mathrm{u}]$, pronunciadas por cinco falantes diferentes (cada sigla representa um falante).

A figura mostra que a realização fonética das duas vogais, que são fonêmicas na língua, se interpenetram, o que nos mostra que há variação na pronúncia delas.

\subsection{A estrutura silábica}

Esta seção ${ }^{39}$ tem como objetivo comentar a bibliografia disponível sobre a estrutura das sílabas em esperanto, baseando-nos em conceitos da teoria fonológica sobre as possíveis estruturações silábicas existentes nas mais variadas línguas.

Primeiramente veremos o que pode-se dizer sobre a sílaba, sua estruturação e seus constituintes, para após verificar o que já foi escrito em esperanto e sobre o esperanto em relação ao assunto. Por fim, tentaremos formular regras estruturais de acordo com a discussão feita ao longo do trabalho.

\footnotetext{
${ }^{39}$ Esta seção do texto foi publicada como artigo na revista Domínios de Lingu@gem, disponível em: <http:/ /www.seer.ufu.br/index.php/dominiosdelinguagem/article/view/31839/18489>. Há, entretanto, pequenas diferenças entre o texto publicado na revista e o que é apresentado nesta dissertação.
} 


\subsubsection{O que é sílaba?}

Blevins (1995) afirma que várias escolas de teorias fonológicas reconhecem a sílaba como item fundamental para a análise. Para ela, a sílaba pode ser entendida como a unidade estrutural que compõe melodicamente a cadeia sonora da fala, que leva em consideração o grau de sonoridade dos segmentos fonológicos para se estruturar. Em resumo, "a sílaba então é a unidade fonológica que organiza as melodias segmentais no que diz respeito à sonoridade; os segmentos silábicos são equivalentes aos picos de sonoridade dentro dessas unidades organizacionais" (Blevins, 1995 : 207).

Para confirmar a afirmação acima, a autora apresenta quatro argumentos de que a sílaba é um constituinte fonológico. São eles:

- sílaba como domínio: há certas restrições e/ou processos fonológicos que usam a sílaba como unidade de aplicação. Esses processos acontecem em um ambiente que contém um pico de sonoridade, maior que o segmento e menor que a palavra. Exemplos desses processos são a faringalização em dialetos do árabe e do berbere e processos que envolvem o acento e o tom.

- fronteira de sílaba como lugar: as sílabas correspondem às fronteiras de palavras em todas as línguas, e sem essa noção deveriam ser formuladas muitas regras para explicar fenômenos que acontecem entre as palavras.

- sílabas como estruturas de alvo: a noção de sílaba é usada em jogos linguísticos ou alvos prosódicos em processos morfológicos, como a reduplicação.

- intuição de falantes nativos: os falantes das línguas normalmente têm uma intuição bastante clara de quantas sílabas há nas palavras, e onde estão suas divisões internas. (Blevins, 1995: 207-210)

Para continuar a discussão sobre os constituintes da sílaba, a autora disserta 
sobre a noção de sonoridade, afirmando que as sílabas são formadas baseadas em algo que tem picos sonoros. De forma bastante geral, a escala de sonoridade é a seguinte: vocoides > líquidas $>$ nasais > obstruintes, que podem ainda ser divididas em várias subclassificações. Para a construção de sílabas válidas segundo essa escala, deve-se verificar que a sonoridade aumenta até o pico (núcleo) da sílaba e depois decresce.

Várias propostas foram feitas sobre a estrutura interna da sílaba, e a mais usada delas, a qual também usaremos para este trabalho, é a de ramificação binária com rima. Nesta estruturação, a sílaba se divide em ataque e rima, e esta, por sua vez, se divide em núcleo e coda (Blevins, 1995 : 212), como pode ser visto na estruturação da figura 2.2.



Figura 2.2: Constituição silábica possível segundo Blevins (1995: 216).

Uma sílaba, portanto, se constitui do núcleo e de suas margens. Zec (2007) chama a atenção para o fato de que "os segmentos que tipicamente ocorrem no núcleo são representados por $\mathrm{V}$, e aqueles tipicamente nas margens por C. V não necessariamente se refere a uma 'vogal'. Em algumas línguas, a posição V também pode ser ocupada por uma consonante [...]" (Zec, 2007:163). A autora ainda nos 
traz uma tipologia básica da estrutura da sílaba: CVC, sílaba com as três principais partes; $\mathrm{CV}$, sílaba com ataque e núcleo; VC, sílaba com núcleo e coda e V, sílaba com apenas o núcleo (Zec, 2007:163), podendo ainda os ataques e codas serem simples, com apenas um constituinte, como nos exemplos dados, ou complexos, com dois segmentos ocupando tal posição. Os constituintes da sílaba não são interdependentes, "se uma língua requer ataques, isso não significa que bana ou requeira codas, e vice-versa" (Zec, 2007:164). Na tabela 2.4 podem-se observar os possíveis formatos de sílabas existentes nas línguas.

Tabela 2.4: Tipos estruturais possíveis de formação silábica (Zec, 2007: 165).

\begin{tabular}{|l|l|l|l|l|l|}
\hline ataque & coda & $\begin{array}{l}\text { ataque } \\
\text { com- } \\
\text { plexo }\end{array}$ & $\begin{array}{l}\text { coda } \\
\text { com- } \\
\text { plexa }\end{array}$ & inventário & língua \\
\hline obrigatório & opcional & opcional & opcional & $(\mathrm{C}) \mathrm{CV}(\mathrm{C})(\mathrm{C})$ & totonaca \\
\hline obrigatório & opcional & opcional & proibida & $(\mathrm{C}) \mathrm{CV}(\mathrm{C})$ & dacota \\
\hline obrigatório & opcional & proibida & opcional & $\mathrm{CV}(\mathrm{C})(\mathrm{C})$ & klamath \\
\hline obrigatório & opcional & proibida & proibida & $\mathrm{CV}(\mathrm{C})$ & temiar \\
\hline obrigatório & proibida & opcional & - & $(\mathrm{C}) \mathrm{CV}$ & arabela \\
\hline obrigatório & proibida & proibida & - & $\mathrm{CV}$ & senufo \\
\hline opcional & opcional & opcional & opcional & $(\mathrm{C})(\mathrm{C}) \mathrm{V}(\mathrm{C})(\mathrm{C})$ & inglês \\
\hline opcional & opcional & opcional & proibida & $(\mathrm{C})(\mathrm{C}) \mathrm{V}(\mathrm{C})$ & espanhol \\
\hline opcional & opcional & proibida & opcional & $(\mathrm{C}) \mathrm{V}(\mathrm{C})(\mathrm{C})$ & finlandês \\
\hline opcional & opcional & proibida & proibida & $(\mathrm{C}) \mathrm{V}(\mathrm{C})$ & turco \\
\hline opcional & proibida & opcional & - & $(\mathrm{C})(\mathrm{C}) \mathrm{V}$ & pirahã \\
\hline opcional & proibida & proibida & - & $(\mathrm{C}) \mathrm{V}$ & fiji \\
\hline
\end{tabular}

Mas como saber, em uma sequência VCCV, se os segmentos mediais CC fazem parte de uma coda complexa da primeira sílaba (VCC.V), de um ataque complexo da segunda sílaba (V.CCV), ou ainda se de uma coda simples da primeira sílaba e um ataque simples da segunda sílaba (VC.CV)? Zec (2007) explica que os constituintes têm uma ordem para serem incorporados à sílaba, e que "a maximização do ataque é capturada pela ordenação de regras: a regra do ataque 
é sempre ordenada antes da regra da coda, então a consoante intervocálica na sequência VCV é invariavelmente incluída no ataque" (Zec, 2007 :166). É comum que a posição de ataque tenha poucas restrições segmentais nas línguas em geral, enquanto a posição de coda costuma permitir um grupo restrito de segmentos para preenchê-la (Blevins, 1995).

\subsubsection{A sílaba em esperanto}

Há poucos estudos relacionados a essa temática sobre o esperanto. Nossas principais fontes são artigos de Oostendorp (1999) e Bavant (2006b).

Bavant (2006b) fez uma compilação de vários livros que citam a noção de "sílaba" e tentam defini-la, além de ter analisado, por meio de um programa computacional, todas as palavras (mais de 47 mil) que compõem o Plena Ilustrita Vortaro (PIV - Dicionário Completo Ilustrado), para achar os constituintes possíveis da sílaba e sua frequência na língua.

\section{Ataque}

Oostendorp (1999) fez uma descrição das restrições silábicas que as palavras possuem em esperanto em posição inicial de palavra. Ele afirma que "[...] é importante observar que nem toda combinação de dois segmentos pode ser empregada em esperanto como ataque. O primeiro segmento tem que ser um elemento do grupo b, d, f, g, k, p, s, s, t, v e o segundo um elemento do grupo r, l, n" (Oostendorp, 1999:57, tradução nossa) ${ }^{40}$. A tabela a seguir, formulada pelo autor, mostra as combinações possíveis e aquelas que são ou não atestadas em palavras existentes na língua (sem considerar as sequências possíveis de consoante+semivogal):

\footnotetext{
40 "[...] it is important to observe that not every combination of two segments can serve as an Esperanto onset. The first segment always has to be an element of the set $b, d, f, g, k, p, s, \hat{s}, t, v$ and the second one an element of $r, 1, n^{\prime \prime}$.
} 
Tabela 2.5: Ataques complexos existentes em esperanto segundo Oostendorp (1999:57-58) (tabela adaptada).

\begin{tabular}{|c|c|}
\hline Ataque Complexo & Exemplos \\
\hline $\begin{array}{l}{[\mathrm{br}]} \\
{[\mathrm{bl}]} \\
{[\mathrm{bn}]}\end{array}$ & $\begin{array}{l}\text { bruna 'marrom', brako 'braço', branĉ 'galho' } \\
\text { blua 'azul', blago 'espécie de piada', bloko 'bloco' } \\
\text { não atestado }\end{array}$ \\
\hline $\begin{array}{l}{[\mathrm{dr}]} \\
{[\mathrm{dl}]} \\
{[\mathrm{dn}]}\end{array}$ & $\begin{array}{l}\text { drinki 'beber bebida alcoólica', droni 'afogar-se' } \\
\text { não atestado } \\
\text { apenas em nomes geográficos (Dnepro 'Dniepre', } \\
\text { nome de rio da Rússia e Dnestro 'Dniestre', nome de } \\
\text { rio da Ucrânia) }\end{array}$ \\
\hline $\begin{array}{l}{[\mathrm{fr}]} \\
{[\mathrm{fl}]} \\
{[\mathrm{fn}]}\end{array}$ & $\begin{array}{l}\text { franca 'francês', fraŭlo 'homem solteiro' } \\
\text { flava 'amarelo', Flandrio 'Flandres', região da Bélgica } \\
\text { não atestado }\end{array}$ \\
\hline $\begin{array}{l}\text { [gr] } \\
{[\mathrm{gl}]} \\
{[\mathrm{gn}]}\end{array}$ & $\begin{array}{l}\text { granda 'grande', griza 'cinza' } \\
\text { glaso 'copo', gliti ‘deslizar' } \\
\text { gnomo 'gnomo', gnuo 'gnu' }\end{array}$ \\
\hline $\begin{array}{l}{[\mathrm{kr}]} \\
{[\mathrm{kl}]} \\
{[\mathrm{kn}]}\end{array}$ & $\begin{array}{l}\text { kreteno 'cretino', krepo 'panqueca' } \\
\text { klera 'pessoa culta', klara 'claro' } \\
\text { knabo 'menino', knedi 'amassar' }\end{array}$ \\
\hline $\begin{array}{l}\text { [pr] } \\
{[\mathrm{pl}]} \\
{[\mathrm{pn}]}\end{array}$ & $\begin{array}{l}\text { preni 'pegar', profiti 'aproveitar' } \\
\text { plano 'plano', plori 'chorar' } \\
\text { pneŭmonio 'pneumonia' }\end{array}$ \\
\hline $\begin{array}{l}{[\mathrm{sr}]} \\
{[\mathrm{s} l]} \\
{[\mathrm{sn}]}\end{array}$ & $\begin{array}{l}\text { não atestado } \\
\text { slipo 'ficha (de cartão)', slango 'gíria' } \\
\text { snobo 'esnobe', snufi 'fungar' }\end{array}$ \\
\hline $\begin{array}{l}\text { [ŝr] } \\
{[\hat{s} l]} \\
{[\hat{s} n]} \\
\end{array}$ & $\begin{array}{l}\text { ŝraŭbo 'parafuso', ŝranko 'armário' } \\
\text { ślifi 'erodir', ślosilo 'chave' } \\
\text { snuro 'corda' }\end{array}$ \\
\hline $\begin{array}{l}\mathrm{tr}] \\
{[\mathrm{tl}]} \\
{[\mathrm{tn}]}\end{array}$ & $\begin{array}{l}\text { trajno 'trem', tri 'três' } \\
\text { não atestado (exceto em tlaspo 'espécie de erva') } \\
\text { não atestado }\end{array}$ \\
\hline $\begin{array}{l}\text { [vr] } \\
{[\mathrm{vl}]} \\
{[\mathrm{vn}]}\end{array}$ & $\begin{array}{l}\text { vrako 'destroço', vringi 'escorrer' } \\
\text { nos nomes Vladimiro e Vladivostoko } \\
\text { não atestado }\end{array}$ \\
\hline
\end{tabular}




\begin{tabular}{|l|l|}
\hline$[z r]$ & não atestado \\
{$[z l]$} & zloto 'zloty' - moeda da Polônia \\
{$[\mathrm{zn}]$} & não atestado \\
\hline
\end{tabular}

O autor elenca combinações com a o segmento /z/, mas não o cita em seu texto (como mostrado acima).

Bavant (2006b : 21) nos lembra, entretanto, que há palavras com outras combinações de ataques complexos, como $\hat{h} m$ (em ĥmero - membro de uma etnia do Camboja), ou mn (em mnemonika - mnemôniko) mas que são exceção na língua. Bavant (2006a) elencou a frequência com que os ataques aparecem em palavras da versão de 2002 do dicionário PIV. Aparecem, apenas uma vez, as seguintes combinações: [dv] (Dvino - nome de um rio), [dz] (dzeta, que possui a variante zeta - zetta, em português, prefixo numérico), [fj] (fjordo - fiorde), [gd] (Gdansko Gdańsk), [gh] (ghetto - gueto), [kŝ] (kŝatrio - membro de antiga casta indiana), [lh] (Lhaso, que possui a variante Lasao - Lhasa, capital do Tibete), [lv] (Lvovo - cidade na Ucrânia), [mb] (Mbabano - capital da Suazilândia), [nĝg] (Noĝameno - N’Djamena, capital do Chade), [pf] (pfenigo - fênique, a centésima parte de um marco alemão, antiga moeda da Alemanha), [pîs] (pŝsento - tipo de chapéu de faraós), [sb] (sbiro tipo de guarda/policial), [tb] (Tbiliso - capital da Geórgia), [tm] (tmezo - processo sintático), [tv] (tvido - tuíd, tipo de tecido escocês), que são exceção na língua, e não regra.

Outros ataques, ainda, não citados pelos autores em seus respectivos estudos, são possíveis, como [kv] (kvar - quatro) e [ks] (ksenofobo - xenofobia).

Além disso, há ataques complexos que se iniciam pelos segmentos [s] e [ $]$ ], que podem chegar a ter 3 elementos, ou que podem ter, como segundo componente do ataque, segmentos diferentes dos listados anteriormente como únicos possíveis $([\mathrm{r}, 1, \mathrm{n}])$ 
Tabela 2.6: Ataques complexos com os segmentos [s] e [ $]$ Oostendorp (1999: 63) (tabela adaptada).

\begin{tabular}{|c|c|}
\hline Ataque Complexo & Exemplos \\
\hline [sb] & somente sbiro 'tipo de guarda/policial' \\
\hline$[\mathrm{sc}][\mathrm{sts}]$ & scii 'saber', sceno 'cena' \\
\hline$[\mathrm{sf}]$ & sfero 'esfera', sfinkso 'esfinge' \\
\hline [sk] & skandi 'fazer escansão', skemo 'esquema' \\
\hline$[\mathrm{sl}]$ & slango 'gíria' \\
\hline$[\mathrm{sm}]$ & smokingo 'smoking' \\
\hline$[\mathrm{sn}]$ & snobo 'esnobe', snufi 'inspirar fortemente' \\
\hline [sp] & spezo 'gasto', sperta 'experiente' \\
\hline [st] & stelo 'estrela', stafeto 'mensageiro' \\
\hline [sv] & svingi 'balançar', svelta 'esbelta' \\
\hline [skr] & skribi 'escrever', skrupulo 'escrúpulo' \\
\hline [skl] & sklavo 'escravo' \\
\hline$[\mathrm{skv}]$ & skvamo 'escama' \\
\hline [spl] & splito 'lasca', splisi 'entrelaçar' \\
\hline [str] & strato 'rua', striko 'greve' \\
\hline$[\hat{\mathrm{s} k}]$ & ŝkopi 'baldear água', \\
\hline [ŝl] & ŝlosilo 'chave', ŝlimo 'limo' \\
\hline [ŝm] & ŝmiri 'espalhar', ŝminko 'maquiagem' \\
\hline [ŝn] & ŝnuro 'corda' \\
\hline [ŝp] & ŝparo 'economia', ŝpuro 'medida' \\
\hline [ŝr $]$ & ŝranko 'armário', ŝraŭbo 'parafuso' \\
\hline$[\hat{s} t]$ & stato 'Estado', steli 'roubar' \\
\hline$[\hat{\mathrm{s} v}]$ & ŝviti 'suar', ŝvebi 'flutuar' \\
\hline [spr] & spruci 'borrifar', sproso 'broto' \\
\hline [ŝtr] & ŝtrumpo 'meia' \\
\hline
\end{tabular}

É importante notar que tais ataques complexos só se formam com outros elementos que também podem aparecer no ataque. Nos casos com três segmentos seguidos, os dois segmentos depois do [s] e do $\left[\int\right]$ podem formar ataques complexos sozinhos, como mostrado anteriormente. 


\section{Rima}

Em esperanto o núcleo silábico é sempre uma vogal plena ([a, e, i, o, u]).

Segundo Oostendorp (1999), o estudo da estrutura da rima nas palavras em esperanto é um pouco mais complicado, pois

[...] não faz sentido estudar as rimas das últimas sílabas das palavras quando se trata da fonologia do esperanto. A razão para isto é que a maioria das palavras em esperanto termina em uma vogal gramatical; o número desses finais é pequeno e há provavelmente mais rimas possíveis do que terminações gramaticais possíveis (Oostendorp, 1999: 68, tradução nossa) ${ }^{41}$.

E ainda nos mostra na seguinte tabela quais são as terminações possíveis para a rima das sílabas (os acréscimos explicativos entre parênteses são nossos). As terminações gramaticais se referem às terminações nominais (substantivo, adjetivo, advérbio, plural, caso acusativo), às terminações verbais (passado, presente, futuro, subjuntivo, imperativo) e aos pronomes.

Tabela 2.7: Rimas possíveis em esperanto, segundo Oostendorp (1999).

\begin{tabular}{|l|l|}
\hline $\begin{array}{l}\text { Terminações } \\
\text { gramaticais }\end{array}$ & $\begin{array}{l}\text {-a (adjetivo), -aj (adjetivo plural), -ajn (adjetivo plural no } \\
\text { acusativo), -am (correlativo de tempo), -an (adjetivo no acu- } \\
\text { sativo), -as (tempo presente), aŭ (ou), -e (advérbio), -el (corre- } \\
\text { lativo de modo), -en (advérbio de direção), -es (correlativo de } \\
\text { posse), -i (verbo no infinitivo), -is (tempo passado), -o (subs- } \\
\text { tantivo), -oj (substantivo plural), -ojn (substantivo plural } \\
\text { no acusativo), -on (substantivo no acusativo), -om (correla- } \\
\text { tivo de quantidade), -os (tempo futuro), -u (imperativo), -us } \\
\text { (tempo condicional) }\end{array}$ \\
\hline $\begin{array}{l}\text { Itens de classe } \\
\text { fechada }\end{array}$ & $\begin{array}{l}\text { unu (um), du (dois), tri (três), kvar (quatro), kvin (cinco), ses } \\
\text { mil (mil); }\end{array}$
\end{tabular}

41 “[...] it does not make sense to study the rhymes of the last syllables of words when studying Esperanto phonology. The reason for this is that most Esperanto words end in a grammatical vowel; the number of these endings is small and there probably are more possible rhymes than possible grammatical endings" 
el (de dentro de), al (para), ĉe (perto de), da (de, relativo a quantidade), de (de), dum (durante), ekster (fora de), en (em), far (longe de), ĝis (até), inter (entre), je (preposição com sentido indefinido), krom (além de), kun (com), per (por meio de), plus (mais), po (à razão de), por (por), post (depois), preter (pelo lado de), pri (a respeito de), pro (por causa de), sen (sem), sub (embaixo de), super (em cima de), sur (acima), tra (através), trans (através de);

ĉar (porque), do (então), kaj (e), nek (nem), sed (mas), tamen (embora);

ke (que), kvankam (entretanto), se (se); ajn (qualquer que), nur (apenas), eĉ (até mesmo), des (tanto), tuj (logo), jes (sim), ne (não), nu (ora), ek (começo de), la (artigo definido)

Estas palavras da tabela são invariáveis, mas ainda nos sobra a possibilidade de estudar as rimas das sílabas internas dos radicais. A lógica de Oostendorp foi elencar sistematicamente os segmentos possíveis em começo de palavras para achar os ataques e aqueles possíveis em final de palavra para obter as codas, mas o autor ignora as porções mediais das palavras, o que torna o estudo parcial apenas, mas, de qualquer forma, seus resultados devem ser elencados entre as possibilidades estruturais da língua.

Em resumo, podemos ter palavras terminadas em: a, o, j, n, an, on, aj, oj, ajn, ojn, as, is, os, us, u, i, ŭ, e, en, el, es, om. Em termos de categorias segmentais, vogais, aproximantes, a líquida $l$, a fricativa $s$ e nasais, no que se refere às terminações gramaticais.

Além dessas terminações, os itens de classe fechada podem terminar em oclusivas ( $\mathrm{p} b \mathrm{t} \mathrm{d} \mathrm{k}$ ), pelo rótico $r$, pela africada $\hat{c}$ ou pela combinação de dois segmentos, st ou ns.

\section{O termo "sílaba" em obras anteriores}

Bavant (2006b) faz uma análise mais ampla, comparando vários autores que, de 
uma forma direta ou indireta, tentam definir a sílaba em esperanto, e faz ressalvas sobre as afirmações de Oostendorp (1999). Sigamos o artigo por partes para melhor entendermos as afirmações do autor. Bavant (2006b) diz que a noção de sílaba é muito pouco explorada em relação ao esperanto. A gramática mais popular do esperanto na atualidade, a Plena Manlibro de Esperanta Gramatiko (PMEG) Manual completo da gramática do esperanto - evita usar a noção de sílaba, mas há uma frase em que o autor diz que "o acento cai sempre na penúltima sílaba" (Wennergren, 2005 : apud Bavant, 2006:02). No geral, Wennergren não fala sobre sílabas acentuadas, mas sim vogais acentuadas.

O Fundamento, livro oficial da gramática do esperanto, elaborado pelo seu criador, Zamenhof (1905), usa a noção de sílaba na regra número 10 (há 16 regras gramaticais apresentadas no livro), que consiste em "o acento cai na penúltima sílaba da palavra", mas não define nem explica como fazer a separação silábica. Ainda no mesmo livro encontramos exercícios de leitura que trazem as palavras divididas por hífen, supostamente nos limites silábicos delas. Estes exercícios são os números 2 e 3, que consistem em:

§2 Ekzerco de legado.

Al. Bá-lo. Pát-ro. Nú-bo. Cé-lo. Ci-tró-no. Cén-to. Sén-to. Scé-no. Scí-o. Có-lo. Kó-lo. O-fi-cí-ro. Fa-cí-la. Lá-ca. Pa-cú-lo. Ĉar. Ĉe-mí-zo. Ĉi-ká-no. Ĉi-é-lo. Ĉu. Fe-lí-ĉa. Cí-a. Ĉ́í-a. Pro-cé-so. Sen-ĉé-sa. Ec. Eĉ. Ek. Da. Lú-do. Dén-to. Plén-di. El. En. De. Té-ni. Sen. Vé-ro. Fá-li. Fi-dé-la. Trá-fi. Gá-lo. Grán-da. Gén-to. Gíp-so. Gús-to. Lé-gi. Pá-go. Pá-ĝo. GGis. Guús-ta. Ré-ĝi. Gar-dé-no. Lón-ga. Rég-no. Síg-ni. Gvar-dí-o. Lín-gvo. GGu-á-do. Há-ro. Hi-rún-do. Há-ki. Ne-hé-la. Pac-hó-ro. Ses-hó-ra Bat-hú-fo. Hó-ro. Hó-ro. Kó-ro. Ho-lé-ro. He-mí-o. I-mí-ti. Fí-lo. Bír-do. Tró-vi. Prin-tém-po. Min. Fo-í-ro. Fe-í-no. I-el. I-am. In. Jam. Ju. Jes. Ju-ris-to. Kra-jó-no. Ma-jés-ta. Tuj. Dó-moj. Ru-í-no. Prúj-no. Ba-lá-i. Pá-laj. De-í-no. Véj-no. Pe-ré-i. Mál-plej. Jús-ta. Jus. Jé-ti. Ja-lú-za. Jur-nálo. Má-jo. Bo-ná-jo. Ká-po. Ma-kú-lo. Kés-to. Su-ké-ro. Ak-vo. Ko-ké-to. Li-kvó-ro. Pac-ká-po.

$\S 3$ Ekzerco de legado.

Lá-vi. Le-ví-lo. Pa-ró-li. Mem. Im-plí-ki. Em-ba-rá-so. Nó-mo. In-di-fe-rén-ta. In-ter-na-cí-a. Ol. He-ró-i. He-ro-í-no. Fój-no. Pí-a. Pál-pi. Ri-pé-ti. Ar-bá-ro. Sá-ma. Stá-ri. Si-gé-lo. Sis-té-mo. Pe-sí-lo. Pe-zí-lo. Sén-ti. So-fís-mo. Cipré-so. Ŝi. Pá-ŝo. Stá-lo. Ŝtá-lo. Vés-to. Véŝ-to. Dis-ŝí-ri. Ŝan-cé-li. Ta-pí-ŝo. 
Te-o-rí-o. Pa-tén-to. U-tí-la. Un-go. Plú-mo. Tu-múl-to. Plu. Lú-i. Kí-u. Ba-lá-u. Tra-ú-lo. Pe-ré-u. Ne-ú-lo. Fráŭ-lo. Paŭ-lí-no. Láŭ-di. Eŭ-ró-po. Tro-ú-zi. Ho-dí-aŭ. Vá-na. Vér-so. Sól-vi. Zór-gi. Ze-ní-to. Zo-o-lo-gí-o. A-zé-no. Me-zú-ro. Ná-zo. Tre-zó-ro. Mez-nók-to. Zú-mo. Sú-mo. Zó-no. Só-no. Pé-zo. Pé-co. Pé-so. Ne-ní-o. A-dí-aŭ. Fi-zí-ko. Ge-o-gra-fí-o. Spi-rí-to. Lip-há-ro. In-díg-ni. Ne-ní-el. Spe-gú-lo. Ŝpí-no. Né-i. Ré-e. He-ró-o. Konscí-i. Tra-e-té-ra. He-ro-é-to. Lú-e. Mó-le. Pá-le. Tra-í-re. Pa-sí-e. Me-tí-o. In-ĝe-ni-é-ro. In-sék-to. Re-sér-vi. Re-zér-vi. (Zamenhof, 1905 : 29-31)

$\mathrm{O}$ acento agudo nas palavras indica a vogal que deve ser acentuada. Segundo Bavant (2006b), pode-se concluir o seguinte destes exercícios de leitura:

- Não confunda/misture as letras c, $\hat{c}, k ; h, \hat{h} ; g, \hat{g}, s, z, c$.

- A letra h deve ser falada à parte, até mesmo depois de outra consoante: não se trata de dígrafos (pac-hó-ro, ses-hó-ra, bat-húfo).

- Vogais dobradas não equivalem a uma vogal longa (ré-e, he-ró-o, kon-scí-i).

- Os grupos vocálicos ae, oe, ue não apresentam nem ditongos nem metafonia (tra-e-té-ra, he-ro-é-to, lú-e). As vogais i e u sempre formam sílabas em contraste com j e ŭ (ba-lá-i, ru-í-no/prúj-no, in-ĝe-ni-é-ro; ba-lá-u, tra-úlo/fráŭ-lo, ĝu-á-do).

Ainda que de forma mais sutil, ainda aparecem as seguintes regras sobre silabificação:

- Cada sílaba contém precisamente uma vogal.

- Se duas vogais separam duas consoantes uma da outra, o limite silábico se encontra antes da consoante (si-gé-lo); isso também é válido se a consoante é africada (pro-cé-so, fe-lí-ĉa, pá-ĝgo).

- Se duas consoantes separam duas vogais, a primeira consoante sendo oclusiva e a segunda sendo líquida (l ou r), o limite silábico se encontra antes da oclusiva (cí-tro-no, cí-pre-so, ge-o-gra-fí-o), mas em outros casos com 
duas consoantes distintas ele se encontra após a primeira (sis-té-mo, vér-so, láŭ-di).

- Palavras derivadas não obedecem a regras específicas para a silabificação (arbá-ro, ko-ké-to, bo-ná-jo, pa-cú-lo, ju-rís-to, Paŭ-lí-no). (Bavant, 2006b : 03-04)

O próprio autor reconhece que extrapolou os exemplos para formular a penúltima regra estabelecida, pois não há nenhum exemplo com $l$.

Continuando sua análise sobre os livros em esperanto que discorrem sobre sílaba, Bavant examina a Plena Analiza Gramatiko (PAG) - Gramática analítica plena -, de Kalocsay \& Waringhien (1985 (1935). Ele diz que “com o atrativo título 'Sílabas', encontra-se apenas a seguinte informação: 'cada vogal, exceto ŭ, corresponde a uma sílaba à parte'. Segue uma definição de sílabas longas e curtas, mas nada mais sobre a definição da sílaba em si!" (Bavant, 2006b :05). Ele afirma ainda que é de conhecimento geral que o livro PAG tem a teoria de que $\breve{u}$ não é uma vogal. Sobre isso, deve-se considerar que há uma certa não uniformidade sobre como se enquadrariam, dentro de uma especificação fonológica, os grafemas $<\breve{u}>$ $(/ w /)$ e $<j>(/ j /)$, que são aproximantes. Alguns afirmam ser semivogais, outros, semiconsoantes. O importante é que tais segmentos são glides, e enquadrados como aproximantes. De fato, eles nunca aparecem sozinhos entre duas consoantes, sempre estão ao lado de uma vogal.

Como o PAG é uma obra de referência até os dias atuais sobre a gramática do esperanto (assim como o PMEG), muitos autores passivamente aceitaram a noção de sílaba presente no livro e a reproduziram. Bavant alega que pode ser o caso do livro La tuta Esperanto - O Esperanto completo - (Seppik, 1987), no qual a definição de sílaba é "sílaba é um som ou grupo de sons que é falado por meio de uma expiração" (Seppik, 1987 : apud Bavant, 2006, p. 07). Segundo Bavant (2006b), a afirmação, embora imprecisa, pelo menos informa que sílaba é um agrupamento sonoro à parte (p. 8). Seppik segue dando exemplos, e afirma que “j e ŭ não são 
vogais e por causa disso não podem formar sílabas autônomas" (Seppik, 1987:05). A separação silábica, segundo ele, "acontece geralmente segundo as mesmas regras que nas outras línguas; cit-ro-no ou ci-tro-no, prob-le-mo ou pro-ble-mo" (Seppik, 1987: 06). Essa definição (assim como as outras discutidas no artigo de Bavant) são muito mais prescritivas do que descritivas, e portanto pouco científicas, mas interessantes para analisarmos o que existe, na literatura em esperanto, sobre o assunto aqui tratado. Seppik faz ainda uma distinção entre o nível fonológico e morfológico (sem usar esses termos), pois diz que não se devem misturar afixos, radicais e terminações gramaticais (Seppik, 1987:06). Bavant afirma que esta afirmação é um absurdo, pois determina que deveríamos separar a palavra facila (fácil) como fa-ci-la, mas tranĉila (tranĉ - radical para "corte", il - afixo para formar instrumento) como tranĉ-il-a. Assim como Seppik (1987),Wüster (1923) considera que os morfemas não devem se misturar aos radicais na separação silábica de palavras compostas. Por fim, Bavant analisa o dicionário oficial da Academia de esperanto, o PIV, e chega à conclusão de que a definição nele encontrada é inútil, pois há vários contraexemplos que não são explicados por tal definição, e também cita a partitura do hino do esperanto, La Espero, que também faz diferenciação entre os níveis do radical e os afixos e outras derivações.

Bavant resume os livros e fontes analisadas na Tabela 2.8. 
Tabela 2.8: Estruturas silábicas possíveis encontradas por Bavant (2006b).

\begin{tabular}{|c|c|c|c|c|}
\hline PAG & PIV & Wüster & Seppik & La Espero \\
\hline fa-ci-la & fa-ci-la & fa-ci-la & fa-ci-la & fa-cil-a \\
\hline (falta regra) & ju-ris-to & ju-ris-to & *jur-ist-o & *jur-ist-o \\
\hline (falta regra) & $\begin{array}{l}\text { fa-ci-la-ni-ma } \\
\text { ba-na-nar-bo }\end{array}$ & $\begin{array}{l}\text { fa-cil-a-ni-ma } \\
\text { ba-nan-ar-bo }\end{array}$ & $\begin{array}{l}{ }^{*} \text { fa-cil-a-nim-a } \\
\text { ba-nan-arb-o }\end{array}$ & $\begin{array}{l}{ }^{*} \text { fa-cil-a-nim-a } \\
{ }^{*} \text { ba-nan-arb-o }\end{array}$ \\
\hline ci-tro-no & ci-tro-no & ci-tro-no & ci-tro-no aŭ cit-ro-no & ${ }^{*}$ ci-tron-o \\
\hline pa-tro & pa-tro & pa-tro & pa-tro aŭ * pat-ro & *patr-o \\
\hline (falta regra) & ak-vo & a-kvo & $? ?$ & *akv-o \\
\hline (falta regra) & lik-vo-ro & li-kvo-ro & ?? & $? ?$ \\
\hline kon-sci-i & kon-sci-i & kons-ci-i & $? ?$ & $? ?$ \\
\hline ob-sti-na & ob-sti-na & obs-ti-na & $? ?$ & obs-tin-a \\
\hline ling-vo & ling-vo & lin-gvo & $? ?$ & ${ }^{*}$ ling $\mathrm{V}-\mathrm{O}$ \\
\hline tung-ste-no & tun-gste-no & tungs-te-no & $? ?$ & $? ?$ \\
\hline
\end{tabular}

Dos livros analisados por Bavant, e pelas próprias considerações do autor, pode-se afirmar que o estudo da estrutura silábica do esperanto não tem bases firmes ou referências bibliográficas uniformes sobre o tema.

Sobre o trabalho de Oostendorp (1999), citado anteriormente, Bavant se questiona se realmente as regras postuladas podem ser consideradas corretas, uma vez que o autor não levou em consideração muitas palavras com ataques diferentes daqueles por ele elencados (palavras de baixa frequência na língua), e considerou apenas os ataques em começo de palavras, o que não engloba a totalidade de ataques que podem aparecer na porção medial das palavras também. (Bavant, $2006 \mathrm{~b}: 21)$. Como exemplo, o autor cita os ataques $t l$ e $d l$, os quais Oostendorp considera como não atestados, a não ser pela palavra tlaspo (um tipo de planta), bastante infrequente na língua. Entretanto, existem palavras como atlantiko (atlântico), atlaso (atlas), atleto (atleta), kotleto (costela - carne de porco assada, por exemplo), entre outras, que têm o ataque composto $t l$ em sua composição. 


\subsubsection{Resumo sobre a sílaba}

Vimos que a estruturação silábica segue regras que se relacionam com o grau de sonoridade dos segmentos e com a posição estrutural que eles podem ocupar. A partir disso, podemos montar uma escala para o esperanto, e tirarmos nossas primeiras conclusões sobre as possíveis sílabas que podem aparecer na língua, em palavras não derivadas, ou seja, radicais simples. A escala, segundo o grau de

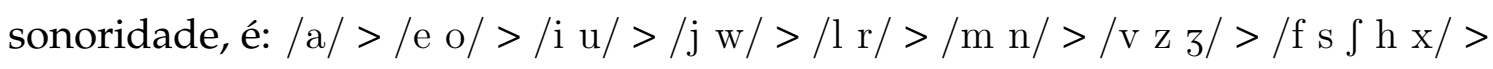
$/ \mathrm{d}_{3} />/ \mathrm{t} \int \mathrm{ts} />/ \mathrm{b} \mathrm{d} \mathrm{g/} / \mathrm{p} \mathrm{t} \mathrm{k/} \mathrm{(ortograficamente:} \mathrm{a}>\mathrm{e}$ o $>\mathrm{i} \mathrm{u}>\mathrm{ju} \breve{\mathrm{u}}>\mathrm{lr}>\mathrm{m} \mathrm{n}>$ $v z \hat{j}>$ f s $\hat{s} h \hat{h}>\hat{g}>\hat{c} c>b d g>p t k)^{42}$.

Como conclusão parcial, podemos afirmar que a estrutura silábica máxima em esperanto é $(C)(C) V(C)(C)$. Exemplos:

- Ataque e coda simples: jur.na.lo (jornal) - CVC.CV.CV

- Coda complexa: post (depois) - CVCC

- Ataque complexo: gran.da (grande) - CCVC.CV

- Sílaba sem ataque e sem coda: ĉi.e.lo (céu) - CV.V.CV

A especificação sobre quais elementos podem ou não preencher cada posição foi apresentada anteriormente. Por exemplo, além dos ataques complexos elencados por Oostendorp (1999) e citados neste trabalho, há outros, menos frequentes, como gneto (gneto, gênero arbóreo) e kŝatrio (membro de antiga casta indiana), citados por Bavant (2006b :39), também problematizados anteriormente.

Bavant (2006a) efetuou um estudo por meio de um programa computacional, utilizando a linguagem de programação perl, e listou as sílabas mais frequentes no esperanto (de acordo com o corpus presente no dicionário estudado). As dez

\footnotetext{
${ }^{42}$ Vogais baixas $>$ vogais médias $>$ vogais altas $>$ glides $>$ líquidas $>$ nasais $>$ fricativas sonoras $>$ fricativas surdas $>$ africada sonora $>$ africadas surdas $>$ oclusivas sonoras $>$ oclusivas surdas. Oostendorp (1999:59) também elenca tal escala de sonoridade, mas de forma menos especificada.
} 
primeiras da lista são: <to> (que apareceu 6.287 vezes no corpus), <0> (5.552), $<\mathrm{lo}>(4.367),<\mathrm{no}>(4302),<\mathrm{a}>(3.828),<\mathrm{ti}>(3.448),<\mathrm{do}>(3.212),<\mathrm{ro}>(3.130),<\mathrm{ko}>$ (3.062) e <ta $>$ (2.987) (Bavant, 2006a). Por estes resultados, podemos afirmar que as sílabas mais frequentes em esperanto tem o padrão V ou CV. A sílaba fechada que primeiro apareceu na lista é kon, na posição número 54, ou seja, as 53 sílabas mais frequentes são abertas, e nenhuma delas tem ataque complexo.

O ponto estrutural sobre o qual achamos menos análises foi a coda e a separação interna de vários encontros consonantais, que não se apresenta bem clara.

Bavant (2006a) afirma ainda em seu estudo que, em 4\% das palavras estudadas, o local de separação silábica na porção medial das palavras foi duvidosa, segundo os seus postulados. A palavra com maior encontro consonantal encontrada pelo autor foi angstromo, com 5 consoantes em seguida. É digno de nota, entretanto, que a entrada lexical para esta palavra no dicionário citado traz a seguinte afirmação: "angstrom/o = anstromo", ou seja, ao longo da evolução da língua o /g/ da porção medial foi elidido, possivelmente por não se enquadrar na estruturação silábica permitida. A entrada lexical de anstromo é: "Anstrom/o. Sveda fizikisto (A.J. Ångström, 1814-1874). anstromo. Unuo de longo, uzata en spektroskopio, k egala al 10-10 metroj; simb.: $\AA^{\prime \prime 43}$.

Outro ponto a ser ainda aprofundado é a possível extrassilabicidade do segmento /s/ em ataques com três elementos, como sklavo (escravo), já que a sequência $s k l$ fere a escala de sonoridade, pois a sonoridade decresce do /s/ para o /k/ e cresce do / $/$ / para o $/ 1 /$, para logo em seguida atingir o pico de sonoridade no núcleo silábico. Kla, portanto, seria uma sílaba bem formada, mas skla não. Entretanto, como mostrado anteriormente, há ataques complexos, em esperanto, que se iniciam pelas fricativas $[\mathrm{s}] \mathrm{e}[\mathrm{J}]$.

\footnotetext{
${ }^{43}$ Disponível em: <http://vortaro.net/\#anstromo>. Tradução: “Anstrom/o. Físico sueco. (A.J. Ångström, 1814-1874). anstromo. Unidade de comprimento, usada em espectrografia e igual a 10-10 metros; simb.: A."
} 


\section{A fonologia de empréstimo (Loanword pho- nology)}

Diferentes línguas possuem diferentes sistemas fonológicos, e quando esses sistemas entram em contato as não similaridades entre eles são percebidas e adaptadas pelos falantes de formas diversas.

Considera-se como empréstimo uma palavra que não esteja presente no léxico da L1 (língua materna) e seja adaptada de um item lexical proveniente de uma outra língua, cujo sistema fonológico o falante pode conhecer profundamente ou de forma apenas superficial.

Calabrese \& Wetzels (2009: 01) explicam que os empréstimos acontecem para preencher lacunas vocabulares na língua de origem dos falantes, e os motivos são diversos.

Speakers borrow words from other languages to fill gaps in their own lexical inventory. The reasons for such lexical gaps vary greatly: cultural innovation may introduce objects or actions that do not have a name in the native language; native words may be perceived as non-prestigious; names of foreign cities, institutions, and political figures which were once unknown may have entered the public eye; new words may be introduced for play, etc. (Calabrese \& Wetzels, 2009)

Estudos específicos sobre essa área são recentes. Calabrese \& Wetzels (2009: 01) afirmam que na primeira década dos anos 2000 houve um crescente interesse sobre o tema entre os fonólogos.

As pesquisas da área de Fonologia de Empréstimo foram intensificadas baseadas na Teoria de Restrição e Estratégias de Reparo (Paradis, 1988) e na Teoria da Otimidade (Prince \& Smolensky, 1993), que são modelos de fonologia com bases em restrições (Kang, 2011:02). 
Quando um fone não está presente na língua que está emprestando a palavra, ele é substituído pelo que for mais "próximo", "mais parecido". Mas como decidir isso? O segmento [y] do francês, por exemplo, é adaptado como [u], [i] ou ainda mesmo [ju] por diferentes línguas (Kang, 2011:08). Essa variação pode depender da natureza da língua que empresta e da que toma emprestado. As pesquisas apontam para o fato de que tanto fatores fonológicos como fonéticos (assim como morfológicos, semânticos e ortográficos) são importantes para os resultados obtidos nas adaptações (Kang, 2011 :12).

\subsection{Diferentes linhas de estudo e análise}

Kang (2011) faz uma compilação da literatura criada até então na área, e identifica padrões emergentes de linhas de estudo (baseados em restrições, que não explicam as adaptações como um todo, mas como elas acontecem no geral):

- The too-many-solutions problem: dada uma estrutura do input estrangeiro violada, sempre há mais de um meio lógico de reparo da estrutura, mas os falantes sempre seguem um padrão de adaptação, mesmo sem terem consciência disso.

O havaiano, por exemplo, não tem, em seu inventário fonológico, a oclusiva vozeada /b/, mas em palavras provenientes do inglês esse fonema é sistematicamente adaptado como /p/ - como em boulder (inglês) que se transforma em [polu'ka:] -, e não como /m/, o que seria possível (considerando traços segmentais semelhantes entre os fones), ou qualquer outro segmento (Adler, 2006, apud Kang (2011:02)).

Outro exemplo de adaptação que possibilita várias escolhas é a adaptação de padrões silábicos. Quando uma língua que não permite ataques complexos empresta uma palavra que tenha uma estrutura $C_{1} C_{2} V$, a restrição fonotática 
pode ser satisfeita de duas formas: (i) eliminando uma das consoantes - gerando uma estrutura $C_{1} \mathrm{~V}$ ou $C_{2} \mathrm{~V}$ - como acontece com palavras do francês adaptadas para o vietnamita (crème se torna [kem]) ou (ii) colocando uma vogal epentética na frente do ataque complexo $\left(\mathrm{v}_{1} C_{2} \mathrm{~V}\right)$ ou entre as consoantes do ataque $\left(C_{1} v C_{2} V\right)$. Broselow (2006, apud Kang (2011:02)) nos fornece dados desse tipo de adaptação da palavra Christmas, do inglês, que no japonês é adaptada como [kurisumasu] e no havaiano como [kalikimaki].

- Divergent repair: estratégias de reparo para as palavras emprestadas que diferem das exigências fonotáticas das palavras nativas.

Na língua tailandesa, por exemplo, as sílabas em fim de palavras devem ser pesadas, e essa condição é satisfeita por uma parada glotal nas palavras nativas, como em [ $\left.\mathrm{p}^{\mathrm{h}} \mathrm{rá}\right]$ - [ $\mathrm{p}^{\mathrm{h}}$ rá $\left.^{\mathrm{P}}\right]$ (macaco), mas para palavras emprestadas do inglês isso não ocorre, e a restrição é satisfeita pelo alongamento das vogais, como coma, que é adaptada como [ $\left.\mathrm{k}^{\mathrm{h}} \overline{\mathrm{O}}: \mathrm{m} \hat{\mathrm{r}} \mathrm{]}\right]$, ou seja, as palavras emprestadas têm uma solução para uma restrição fonotática que diverge da que é usada nas palavras nativas.

Outro exemplo é como a restrição da sequência de uma obstruinte seguida por uma nasal é solucionada em coreano. Em palavras nativas, a nasalização é usada, como / kuk-mul/ (sopa), que se transforma em [kuymul]. Entretanto, palavras adaptadas do inglês recebem uma vogal epentética entre os dois segmentos, como picnic, que, em coreano, é adaptada como [ $\mathrm{p}^{\mathrm{h}} \mathrm{ik}^{\mathrm{h}}$ inik].

- Unnecessary Repair: quando ocorre adaptação mesmo sem que as estruturas precisem ser reparadas, uma vez que elas não violam as restrições fonotáticas da língua.

Isso acontece, por exemplo, no coreano, que permite oclusivas desvozeadas na posição de coda, mas que adapta palavras do inglês com essa característica 
por meio de epêntese vocálica, como $c u t$, que, em coreano, se torna $\left[k^{\mathrm{h}} \Lambda \mathrm{t}^{\mathrm{h}} \mathrm{i}\right]$ (que varia com a forma $\left[\mathrm{k}^{\mathrm{h}} \mathrm{t} \mathrm{t}\right]$ ) (Kang, 2003, apud Kang (2011:03)).

- Diferential importation: uma estrutura que não é permitida na língua é aceita excepcionalmente para a palavra emprestada.

Entretanto, algumas restrições são mais facilmente "violadas" do que outras. Segundo Adler (2006, apud Kang (2011)), em havaiano, a palavra inglesa truck é adaptada como [kə'lakə], mas há uma versão "menos havaiana" da palavra, [tə'lakə], na qual o segmento /t/ do inglês não é adaptado. A variante ['krakə], entretanto, não é possível, apesar de o segmento /t/ ser adaptado como $/ \mathrm{k} /$, pois a permanência do ataque complexo parece ser menos aceitável do que a permanência do segmento / $t$ /.

- Retreat to the unmarked: situação em que a palavra emprestada se adapta às restrições que não são do léxico nativo da língua que a empresta.

O húngaro não exige que sílabas sejam pesadas (Kertész, 2003, apud Kang (2011:04)), mas palavras adaptadas parecem seguir essa exigência, como em shock, que, em húngaro, passui a forma [sokk] (com uma obstruinte desvozeada geminada no fim da palavra).

Kang (2011 : 04-07) segue dando explicações de interpretação para modelos emergentes (que não se excluem mutuamente, ou seja, as categorias não são rígidas):

- Native phonology: a fonologia da língua nativa (a língua que está tomando emprestada a palavra) é majoritária ao decidir quais segmentos são ou não relevantes para serem mantidos.

Zuraw (2000) demonstrates that the variable application of nasal substitution in loanwords in Tagalog is a direct reflection of statistical tendencies in the native lexicon. It has also been argued that the default accentuation 
in loanwords in Tokyo Japanese has a direct correlate in native phonology as a covert default in the lexicon as a whole (Kubozono 2006). (Kang, 2011:04)

Outro exemplo é a adaptação de nomes e verbos ingleses no cantonês, pois verbos são normalmente adaptados como palavras monossilábicas e nomes como palavras bissilábicas, o que também é observado na língua nativa em análises estatísticas (Luke \& Lau, 2008, apud Kang (2011:04)).

- Default setting of UG: alguns estudiosos atribuem os modelos emergentes de adaptação a cenários default da Gramática Universal (como já mencionado acima no tópico Retreat to the unmarked).

- Adaptation as perception: a adaptação ocorre por meio da percepção fonêmica da palavra estrangeira.

This approach breaks away from the assumption that the input to the production grammar in loanword adaptation faithfully retains the phonetic and/or phonological structure of the source language input (cf. Jacobs \& Gussenhoven 2000, LaCharité \& Paradis 2005). This view provides a solution to many puzzling adaptations, such as unnecessary repair or divergent repair, where the adaptation pattern seems to contradict the production grammar of the borrowing language. (Kang, 2011:05)

Alguns estudiosos afirmam que essa é apenas uma das fases da adaptação, enquanto outros acreditam que a adaptação se dá, como um todo, durante a percepção da fala (Kang, 2011:06).

- Perceptual similarity: assim como a anterior, toma como base percepção e fatores fonéticos, mas acrescenta que por mais que a percepção do input estrangeiro seja total, certos segmentos não podem ser inteiramente adaptados à língua que os empresta.

Kabak and Idsardi (2007, apud Kang (2011:06)) observaram isso em palavras do inglês adaptadas no coreano. Os falantes de coreano percebiam a 
diferença entre $[\mathrm{gm}]$ e $[\mathrm{km}]$ (ataques complexos não permitidos em coreano) e [gvm] e [kvm] (os mesmos ataques complexos com a vogal epentética). Ou seja, por mais que os ataques complexos sejam percebidos de forma correta, eles não podem ser inseridos na língua, pois violam suas restrições fonotáticas.

- Grammar-external factors: autores propõem que fatores sociolinguísticos ou extragramaticais influenciam o padrão de adaptação das palavras, como o nível de bilinguismo da comunidade ("the higher the level of bilingualism, the more likely the adaptation will refer to phonological representations over phonetic representations of the input language" (Heffernan 2007, apud Kang (2011:07))).

A história das relações políticas entre os países e o prestígio social das línguas também influenciam os empréstimos. Friesner (2009) estudou palavras emprestadas pelo romeno provenientes do turco e do francês. O contato entre turco e romeno se deu do século XIV ao século XVIII, principalmente por causa da expansão do império turco; muitas palavras provenientes do turco, entretanto, não são mais usadas no romeno, pois houve um esforço consciente de intelectuais romenos para eliminar essas palavras da língua, uma vez que a base lexical do romeno é composta principalmente por radicais latinos e os empréstimos turcos eram considerados "impuros" (Friesner, 2009 : 117-118). Já o contato com a língua francesa se deu mais tardiamente, durante o século XIX. Ao contrário do que aconteceu com os empréstimos turcos, as palavras provenientes do francês eram bem recebidas, pois essa língua era considerada "a língua do intelectualismo e da sofisticação" (Friesner, 2009:118), e tais empréstimos (assim como as palavras provenientes do italiano) foram usados para inserir radicais latinos em substituição aos empréstimos turcos que haviam sido feitos em séculos passados. 


\subsection{Fonética ou Fonologia}

Uma discussão importante sobre a adaptação é se ela se dá, majoritariamente, por meio da fonética ou por meio da fonologia da L2 (língua da qual os empréstimos provêm).

With respect to the input to the adaptation process, some argue that the input is the phonological representation of the source language, devoid of redundant phonetic details (Paradis \& LaCharite 1997, Shinohara 2004, LaCharité \& Paradis 2005). This view, referred to here as the "phonological input" view, predicts uniform adaptation of a source language phoneme across different contexts (i.e. phonemic uniformity). Others assume that the input is the acoustic representation of the source language, including all subphonemic phonetic details of the source language sounds (Silverman 1992, Yip 1993, Peperkamp 2005, Iverson \& Lee 2006, Peperkamp et al. 2008). The latter view, referred to here as the "phonetic input" view, predicts that a given phoneme of the source language can be adapted differently in different segmental contexts depending on its surface phonetic characteristics in the input language. (Kang, 2011:11)

Calabrese \& Wetzels (2009) usam os termos nativização através da produção (nativization-through-production) e nativização através da percepção (nativization-throughperception $)^{1}$ para explicar as duas possibilidades de análise.

No primeiro caso, assume-se que um falante bilíngue, que conhece tanto a língua que vai receber o empréstimo quanto a língua da qual o empréstimo provém, é o responsável pela adaptação.

Nesse caso, a suposição comum é que o falante recupera a representação subjacente da palavra emprestada do seu dicionário mental (o armazenamento de memória de longo prazo para itens lexicais) para L2 e gera sua representação superficial enquanto falante de L1. Se a representação superficial da palavra é gerada ao usar o sistema fonológico ou, mais geralmente, o sistema gramatical de L1, a palavra sofre adaptações e ajustes e é nativizada de acordo com a gramática de L1. (Menezes, 2013:57)

Nesse cenário, importa o que é mais próximo em termos de traços fonológicos, o que nem sempre é o que é mais próximo foneticamente (Chang, 2008 : 44).

\footnotetext{
${ }^{1}$ Os termos encontram-se traduzidos dessa forma em Menezes (2013).
} 
No segundo caso, o falante não conhece, ou conhece muito pouco, a língua da qual vem o empréstimo. A palavra terá que ser aprendida, e durante o processo de aprendizado é provável que a adaptação ocorra por meio da percepção, uma vez que o falante não conhece o sistema fonológico da L2.

Alguns autores afirmam que todas as adaptações de palavras são processadas por meio da aproximação fonética, e que o conhecimento da fonologia da L2 não é importante para a adaptação (Chang, 2008 :43-44). As duas linhas de pensamento, entretanto, não se excluem, e podem ser usadas juntas para analisar os dados que os pesquisadores têm em mãos (Calabrese \& Wetzels, 2009: 09).

Chang (2008) apresenta dados do birmanês para argumentar que as duas linhas de racionício podem ser úteis na interpretação da adaptação de palavras inglesas na referida língua.

A interpretação de adaptação por meio da fonologia é observada na adaptação de alofones do inglês que correspondem a fonemas do birmanês e de fonemas do inglês que correspondem a alofones do birmanês (Chang, 2008:46). O segmento alofônico $\left[\mathrm{p}^{\mathrm{h}}\right]$ do inglês é adaptado como /p/ no birmanês, apesar da língua ter $/ \mathrm{p}^{\mathrm{h}}$ / como fonema. Este fonema, por sua vez, é usado para adaptar o fonema /f/ do inglês. O esquema de adaptação é resumido na Figura 3.1.

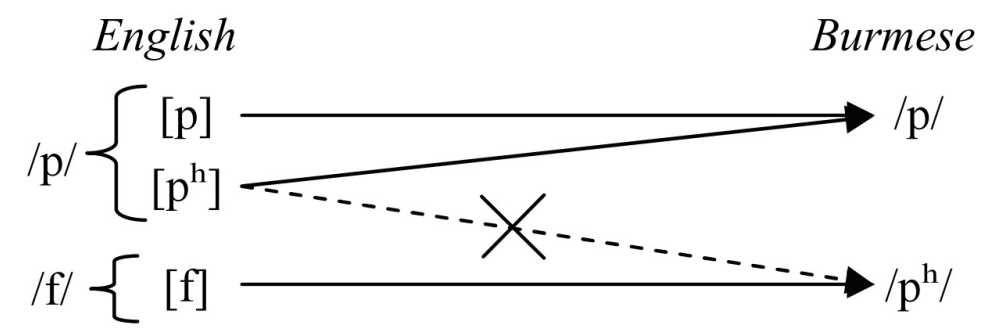

Figura 3.1: Manutenção de distinções fonêmicas na adaptação de palavras do inglês no birmanês (Chang, 2008:48). 
Exemplos dessa adaptação, presentes na Figura 3.2, deixam mais claro como se dá o processo. Podemos observar que o fonema /p/, do inglês, que tem duas realizações alofônicas - $[\mathrm{p}]$ e $\left[\mathrm{p}^{\mathrm{h}}\right]$ - é adaptado unicamente como /p/ no birmanês, enquanto o fone $/ \mathrm{f} /$, do inglês, é adaptado como $/ \mathrm{p}^{\mathrm{h}} /$.

\begin{tabular}{|c|c|c|c|c|c|c|c|}
\hline \multirow[t]{4}{*}{ (1) } & penguin & $>$ & [pĩ.gWĨ ] & b. & Poland & $>$ & [pòù.lã ] \\
\hline & c. plastic & $>$ & [pə.la?.sə.tı?] & d. & police & $>$ & [pə.lei?] \\
\hline & Japan & $>$ & [dz̧ح.pã ] & f. & computer & $>$ & [kòũ .pjù.tà] \\
\hline & g. champagne & $>$ & [Sã .péî́] & h. & ball pen & $>$ & [bó.pĩ ] \\
\hline \multirow[t]{4}{*}{ (2) } & file & $>$ & [p $\mathrm{p}^{\mathrm{h}}$ àĩ $]$ & b. & four & $>$ & [p óóu] \\
\hline & film & $>$ & [p $\mathrm{p}^{\mathrm{h}}$ ๖.IĨ $]$ & d. & feeling & $>$ & [p $\mathrm{p}^{\mathrm{h}}$.̀.IĨ $]$ \\
\hline & Finland & $>$ & 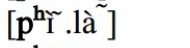 & f. & Philippines & $>$ & [p $\mathrm{p}^{\mathrm{h}}$ ìlı?.pàĩ ] \\
\hline & g. phone & $>$ & [p óữ $]$ & h. & coffee & $>$ & [kò.p $\left.\mathrm{p}_{\mathrm{i}}^{\mathrm{h}}\right]$ \\
\hline
\end{tabular}

Figura 3.2: Dados de adaptação dos fonemas /p/ e /f/ do inglês para os fonemas /p/ e /ph / do birmanês (Chang, $2008: 46)$.

Ou seja, a informação de categorias fonológicas da L2 está sendo levada em consideração. Se o processo se desse por aproximação perceptual/acústica, poderíamos encontrar dados em que a realização fonética de $/ \mathrm{p}^{\mathrm{h}} /$ do inglês levasse à adaptação de palavras com esse mesmo segmento no birmanês, o que não acontece.

Entretanto, outros dados mostram que os falantes levam em consideração detalhes fonéticos que não são fonêmicos nem na língua inglesa e nem na birmanesa (Chang, 2008 :49). Estruturas silábicas da primeira, por exemplo, são adaptadas diferentemente na última dependendo do contexto fônico (Chang, 2008:50-51). Logo, o autor demonstra que as duas formas de adaptação (fonológica e fonética) estão presentes no processo de empréstimo lexical de palavras do inglês para o birmanês. 


\subsection{Influência da ortografia}

O meio pelo qual a palavra é emprestada, se pela escrita ou pela fala, também influencia a adaptação. Por isso, outro aspecto chave desenvolvido pela teoria é a relação entre adaptação por meio da fonética ou por meio da ortografia, levando em consideração um conjunto grande de fatores para que a adaptação seja feita, e não apenas a fonética ou a fonologia (ao dar preferência a uma ou outra), como afirmam alguns pesquisadores. Kenstowicz \& Suchato (2006) afirmam que

\footnotetext{
A pessoa que adapta não é um recipiente passivo do módulo da percepção da fala, mas exerce controle ativo em relação à gramática nativa ao modelar o empréstimo tanto quanto possível, partindo do conhecimento implícito da similaridade fonética para chegar a adaptações moduladas que carecem de um precedente no sistema nativo. (Kenstowicz \& Suchato, 2006:02) (tradução nossa)
}

Esse ponto de vista é mais intermediário, e procura buscar em mais de um campo a explicação para a modulação final da palavra na língua que a toma emprestada.

Vendelin \& Peperkamp (2006) fizeram um estudo das palavras inglesas adaptadas no francês para investigar a influência da ortografia no processo de empréstimo. Para tanto, elas apresentaram palavras aos falantes de francês (bilíngues, que eram também falantes de inglês) apenas oralmente durante a primeira metade da pesquisa, e na outra metade incluíram a amostra visual da palavra ortograficamente escrita. Verificou-se que a adaptação das palavras que foram apresentadas também escritas sofreram clara influência da ortografia, pois foram observados ajustes a partir do modo como os franceses costumam ler as palavras em inglês. Os resultados mostraram, portanto, que houve sensibilidade mediante a presença ou a ausência da representação escrita.

A intenção desse estudo foi abrir o campo de pesquisa para outros fatores de influenciação fora a fonética e a fonologia, amplamente estudadas pelos pesquisa- 
dores da área, os quais deixam o fator ortográfico normalmente marginalizado, ou usam-no para explicar aquilo que não pode ser explicado pelas estruturas fonológicas da língua.

Segundo Vendelin \& Peperkamp (2006), a ortografia pode influenciar os empréstimos de duas maneiras distintas:

- 1. Algumas adaptações são claramente de "leitura", ou seja, são pronunciadas como se fossem palavras nativas da língua que as empresta. Um exemplo é a palavra francesa cul-de-sac [kytsak] que é adaptada em inglês como [kıldəsaek], que claramente não provém da forma como a palavra é pronunciada, mas sim da ortografia, ou seja, os ingleses leem a sequência de grafemas como leriam qualquer outra palavra do inglês.

- 2. Pode haver certo grau de estandardização na maneira como a língua que está emprestando lê os grafemas da língua fonte, ou seja, da qual a palavra emprestada provém. Quando as crianças francesas aprendem inglês na escola, lhes é ensinado que o grafema do inglês $<u>$ em palavras como "but" deve ser pronunciado como a vogal francesa /œ/, e que o grafema do inglês $<00\rangle$, presente em palavras como "book" deve ser pronunciado como a vogal francesa /u/. Quando adultos, provavelmente esse esquema grafema-fonema influencia as adaptações que sejam requeridas aos falantes.

Roth (1980:168) afirma que a lexicografia brasileira aportuguesa "ortograficamente os anglicismos mais comuns ora conforme a ortografia inglesa, ora conforme a pronúncia do inglês, ora conforme o uso já consagrado", indicando a possibilidade de adaptação por meio da ortografia ou da pronúncia. Isso também pode ser visto em palavras adaptadas do francês, como afirma Menezes (2013:67). A palavra fricot [fRi'ko], do francês, foi adaptada no português como fricote [fri'kət $\left.\int \mathrm{I}\right]$, uma vez que a forma nativizada se assemelha à forma escrita da palavra, enquanto 
a palavra tricot [tri'ko] foi adaptada como tricô [tri'ko], que se assemelha à forma fonética.

Todas as linhas de análise expostas neste capítulo têm evidências baseadas em estudos de casos específicos. Não há um só modo, portanto, para analisar a adaptação de empréstimos. Deve-se levar em conta as características das L1 e da L2, o grau de bilinguismo dos falantes, as questões sociolinguísticas e históricas, e verificar qual é a melhor explicação para o fenômeno de adaptação estudado. 


\section{Dados e análise}

Neste capítulo descrevemos o meio pelo qual montamos o corpus (anexo ao fim do trabalho) e analisamos os dados encontrados.

\subsection{Metodologia}

Para entender como selecionamos as palavras para a análise desta pesquisa, vejamos como o léxico do esperanto se comporta diante da necessidade de formação de novas palavras.

Oostendorp (1998) nos chama a atenção para um fato interessante em relação à distinção de palavras nativas e emprestadas:

Nesta língua [esperanto] não faz sentido distinguir diacronicamente palavras "nativas" e palavras "emprestadas". Aproximadamente $99 \%$ do léxico foi derivado, de uma forma ou de outra, do léxico de morfemas de outras línguas, e neste sentido todas as palavras configuram um empréstimo. (tradução nossa)

O autor ignora a distinção entre palavras oficiais (aquelas que estavam no projeto inicial do esperanto, e foram cunhadas pelo organizador da língua L. L. Zamenhof) e neologismos. Consideremos que essa afirmação de Oostendorp se refere aos empréstimos das raízes, uma vez que depois de ser adaptado na língua o radical pode formar novas palavras (pela composição com outros radicais ou afixos, por exemplo) que são características da língua.

O projeto da língua (Unua libro - Primeiro livro), publicado em 1887, possuía um vocabulário de um pouco mais de 900 verbetes. Em 1893 foi publicado o Universala Vortaro (Dicionário Universal) que, em 1905, foi aceito como parte do 
Fundamento de Esperanto ${ }^{1}$, com cerca de 2.600 entradas lexicais. O Plena Vortaro (Dicionário Completo), de 1954, possuía 7.866 entradas lexicais, enquanto o PIV, publicado em 1970, tinha 16.000 (Wells, 1989, p. 55). O Nova PIV, de 2005, por sua vez, possuía 17.000 (Dias, 2009).

Percebe-se, dessa forma, que o léxico da língua é gradativamente aumentado. Enquanto novas palavras passam a ser usadas, outras se tornam arcaicas (Dias, 2009:81).

A formação de palavras em esperanto pela junção de dois ou mais radicais (e/ou morfemas) da língua é um processo bastante produtivo. Segundo Wells (1989), a língua aqui estudada tem caráter extremamente aglutinante, mas também apresenta processos flexionais e isolantes (Wells, 1989:29-30).

Como podemos observar pelo crescimento de entradas lexicais nos dicionários da língua ao longo dos anos, novas palavras são incorporadas ao léxico. Entretanto, nem todas são empréstimos, pois os processos de formação de novas palavras no esperanto são variados:

É preciso verificar que nem todas as novas palavras são empréstimos, sendo várias delas recombinações entre radicais já existentes para abarcar novos conceitos. Interessa saber também sobre a maneira com que se formam os neologismos, e, principalmente, é preciso pesquisar de quais línguas-fonte eles estão surgindo com maior frequência, devido à distribuição ampla de seus falantes no globo e devido à diversidade de línguas-fonte do esperanto original. (Dias, 2009:17)

Os processos pelos quais novas palavras podem ser formadas são:

- Composição.

Em uma palavra complexa, com mais de um radical, cada elemento acrescenta um significado semântico à palavra. Esse padrão morfológico é o mais usado para compor novas palavras em muitas línguas (Booij, 2012 :75).

\footnotetext{
${ }^{1}$ Este livro foi publicado depois do primeiro congresso de esperanto, que ocorreu na França. O conteúdo dele, que passou a ser a norma oficial da língua, foi votado em assembleia pelos presentes no congresso.
} 


\author{
vizitĉambro (vizito+ĉambro) \\ sala de estar (visita+cômodo) \\ petveturi (peto+veturi) \\ viajar de carona (pedido+viajar)
}

\title{
- Derivação.
}

Palavras derivadas envolvem afixos, e essa categoria é abundante em esperanto. No livro Fundamento de esperanto há uma lista de exemplos que envolvem o mesmo radical e vários afixos da língua:

\begin{abstract}
Sano, sana, sane, sani, sanu, saniga, saneco, sanilo, sanigi, sanigi i, sanejo, sanisto, sanulo, malsano, malsana, malsane, malsani, malsanulo, malsaniga, malsanigi i, malsaneta, malsanema, malsanulejo, malsanulisto, malsanero, malsaneraro, sanigebla, sanigisto, sanigilo, resanigi, resaniĝanto, sanigilejo, sanigejo, malsanemulo, sanilaro, malsanaro, malsanulido, nesana, malsanado, sanulajo, malsaneco, malsanemeco, saniginda, sanilujo, sanigilujo, remalsano, remalsaniĝo, malsanulino, sanigista, sanigilista, sanilista, malsanulista k.t.p ${ }^{2}$ (Zamenhof, 1905).
\end{abstract}

Os afixos se dividem em sufixos e prefixos. Os prefixos da língua são: $b o-$ (parentesco por casamento); dis- (dispersão, disseminação); ek- (começo de

\footnotetext{
${ }^{2}$ Sano - saúde, sana - saudável, sane - saudavelmente, sani - estar com saúde, sanu - esteja com saúde, saniga - que torna saudável, saneco - sanidade, sanilo - instrumento para saúde (um remédio ou praticar exercícios, por exemplo), sanigi - tornar saudável, saniĝi - tornar-se saudável, sanejo lugar de saúde, sanisto - profissional da saúde, sanulo - pessoa que é saudável, malsano - doença, malsana - doente, malsane - doentemente, malsani - estar com doença, malsanulo - pessoa que é doente, malsaniga - que torna doente, malsaniĝi - tornar-se doente, malsaneta - um pouco doente, malsanema - tendência à doença, malsanulejo - lugar de doentes, malsanulisto - profissional do doente, malsanero - uma parte da doença, malsaneraro - conjunto de partes da doença, sanigebla - possível de tornar saudável, sanigisto - profissional do processo de tornar saudável, sanigilo instrumento para tornar saudável, resanigi - tornar saudável novamente, resaniĝanto - aquele que está se tornando saudável novamente, sanigilejo - lugar de instrumentos para tornar saudável, sanigejo - lugar de tornar saudável, malsanemulo - pessoa que tem tendência à doença, sanilaro conjunto de instrumentos para saúde, malsanaro - conjunto de doenças, malsanulido - filho de uma pessoa que é doente, nesana - não saudável, malsanado - processo contínuo de doença, sanulajo - coisa de pessoa saudável, malsaneco - fraqueza, característica da doença, malsanemeco tendência à fraqueza, saniginda - que merece se tornar saudável, sanilujo - recipiente para guardar instrumentos de saúde, sanigilujo - recipiente para guardar instrumentos que tornam saudável, remalsano - doença reincidente, remalsanigho - tornar-se doente novamente, malsanulino - mulher que é doente, sanigista - profissional do processo de tornar saudável, sanigilista - profissional dos instrumentos que tornam saudável, sanilista - profissional dos instrumentos de saúde, malsanulista - profissional de pessoas que são doentes, k.t.p.
} 
ação); eks- (ex, algo antigo); ge- (ambos os sexos); mal- (ideia contrária, antônimo); mis- (de forma imprópria, errada); pra (há muito tempo, primitivo); re- (repetição) (Wennergren, 2005 : 588-600).

Os sufixos são mais numerosos: âc (qualidade má, sem valor); ad (ação contínua); $a \hat{j}$ (coisa concreta); an (membro, que pertence a um grupo); ar (coletivo); $\hat{c} j$ (cria apelido carinhoso em nomes masculinos); $e b l$ (que se pode fazer); ec (qualidade ou estado, ideia abstrata); eg (aumentativo); ej (lugar); em (tendência natural, inclinação); end (que deve ser feito); er (fragmento, pedaço pequeno); estr (pessoa que dirige ou governa); et (diminutivo); id (filhote, descendente); ig (causativo - transforma verbos intransitivos em transitivos, e pode ser usado com nomes também); iĝg (tornar-se o que a raíz indica); il (instrumento); in (feminino); ind (que merece ser feito); ing (recipiente parcial); ism (sistema, doutrina); ist (profissão, ocupação contínua); nj (cria apelido carinhoso em nomes femininos); obl (multiplicação); on (divisão); op (grupo com certo número de membros); $u j$ (recipiente total); $u l$ (pessoa com tal característica); um (significado livre, cada palavra com esse sufixo deve ser aprendida individualmente) (Wennergren, 2005: 540-588).

- Ampliação semântica de palavra já existente.

Uma palavra já existente na língua passa a designar um novo objeto, como a palavra muso, que, originalmente, significava apenas o animal rato, mas passou, também, a significar um item do computador, o mouse.

- Mudança de significado.

Esse processo acontece quando uma palavra perde seu significado original e passa a ser reconhecida somente pelo seu novo significado, como komputi que, originalmente, significava medir, e depois passou a fazer parte da palavra komputilo (computador), e não mais é reconhecida pelo significado original. 
Outro exemplo é a palavra gufujo. Gufo é um tipo de ave, e o afixo $u j$ significa "recipiente total", mas a palavra derivada não significa "lugar de aves", e sim um lugar tranquilo durante o Internacia Junulara Kongreso (IJK - Congresso internacional da juventude) e outros eventos, onde os participantes conversam em voz baixa e tomam bebidas não alcoólicas.

- Abreviações.

Quando a palavra é composta pelas letras ou sílabas iniciais de mais de uma palavra. Em esperanto, os nomes das letras são lidos com $<0>$ depois delas, já que são substantivos.

A palavra mojosa é a abreviação de "moderna juna stilo" (estilo moderno jovem), e significa legal.

Dias (2009:74) cita o exemplo da palavra aidoso, leitura soletrada da palavra aids (a.i.do.so).

- Empréstimos.

Por fim, um processo possível para a criação de novas palavras é emprestar raízes de outras línguas. As palavras que compõem o corpus desta pesquisa estão enquadradas nesse tipo.

Quando uma palavra nova é incorporada na língua por meio de empréstimo lexical, passa a se comportar como qualquer outra. Vacapo (WhatsApp), que é um substantivo, pode ser usado, por exemplo, como adjetivo (vacapa, do WhatsApp), advérbio (vacape, pelo WhatsApp, com o WhatsApp), verbo conjugado (mi vacapas, eu "whatsappeio"), etc.

A análise das adaptações fonológicas que fazemos, entretanto, se atém apenas às raízes, e não às possíveis composições e devirações da palavra. 


\subsection{Fontes}

Nosso corpus foi formado por palavras encontradas nos periódicos denominados Kontakto e Esperanto, além de palavras de uma lista terminológica sobre tecnologia, e, ainda, palavras listadas como não dicionarizadas no blog ${ }^{3}$ do professor emérito John C. Wells, da University College London. O parâmetro para decidir quais palavras incluir na pesquisa foi a não presença delas no dicionário oficial da língua, o PIV (Plena Ilustrita Vortaro - Dicionário Ilustrado Completo), para nos certificarmos de que são palavras novas. Encontramos, entretanto, palavras que não parecem ser novas na língua (como varno, proveniente do sânscrito), mas que foram incluídas no corpus, mesmo assim.

Kontakto é a revista oficial da Tutmonda Esperantista Junulara Organizo (TEJO - Organização Mundial da Juventude Esperantista), lançada em 1963, enviada a assinantes em mais de 90 países; tal revista tem como alvo o público jovem e traz em suas matérias sempre assuntos polêmicos e recentes. Sua periodicidade é bimestral.

Esperanto é a revista oficial da Universala Esperanto-Asocio (UEA - Associação Universal de Esperanto), e tem periodicidade mensal (mas não há publicação em agosto, por decisão editorial interna, portanto são 11 edições por ano, e não 12). Sua primeira publicação foi em 1905, mas houve interrupções das edições nos períodos entre 1914/15, 1941/42 e 1946/47. A revista é enviada a leitores em 115 países ${ }^{4}$.

Os arquivos das revistas que foram utilizados (publicações entre os anos de 2004 e 2014) foram baixados do site oficial da $\mathrm{UEA}^{5}$, transformados em arquivos com extensão $\cdot \mathrm{txt}^{6}$, e aplicados a um programa computacional para gerar uma

\footnotetext{
${ }^{3}<$ http://vortaro-blogo.blogspot.com.br/2009/09/nepivaj-vortoj-i.html>.

${ }^{4}$ Informações da página oficial da revista: <http://www.uea.org/revuoj/esperanto >.

${ }^{5}<$ http://www.uea.org/>.

${ }^{6}$ Por meio do site $<\mathrm{http}: / /$ convertonlinefree.com/PDFToTXTEN.aspx>.
} 
lista de palavras presente nos arquivos. A linguagem utilizada foi Python. Foi feito um script para abrir os arquivos em txt e foi considerada como palavra tudo que estivesse entre dois espaços em branco.

Assim, tivemos como resultado final uma lista com todas as palavras presentes nos 183 arquivos das revistas (algumas edições da revista Kontakto eram duplas, então alguns anos tinham apenas 05 exemplares, em vez de 06). Por mais que as palavras se repetissem várias vezes nas revistas, elas apareceram uma vez apenas na lista criada, o que facilitou o processo por busca de palavras novas.

Após a formação da lista, verificamos, ordenadamente, quais seriam as possíveis novas palavras. A conversão para arquivos .txt causou problemas, uma vez que nem sempre as palavras foram lidas corretamente na conversão, e muitas vezes duas ou mais palavras ficaram sem espaço em branco entre elas. Os caracteres $\hat{c}, \hat{g}, \hat{h}, \hat{j}, \hat{s}$ e $\breve{u}$ não foram convertidos corretamente em muitos arquivos, e, portanto, corrigimos o problema manualmente.

Durante a formação da lista, se alguma palavra aparecesse junto a um ponto final, por exemplo, era considerada como uma nova ocorrência, por mais que se tenha tido o cuidado, durante o processo, de se excluir a pontuação e os números da listagem. Por esses e outros motivos, a lista gerada foi bastante grande.

Além desses problemas de ordem técnica, deve-se lembrar que a composição e a derivação são processos de formação de palavras bastante profícuos em esperanto. Por isso, sequências longas com o mesmo radical compunham a lista? .

\footnotetext{
${ }^{7}$ Exemplos com os radicais akcept- (aceitar) e inform- (informar): akcepta, akceptadi, akceptado, akceptanta, akceptante, akceptantino, akceptata, akceptebla, akcepteblajo, akcepteble, akceptebleco, akceptebli, akcepteblo, akceptema, akceptemo, akceptigi, akceptigo, akceptinda, akceptindo, akceptinta, akceptita, akceptite, akceptitita, akceptiĝi, akceptiĝo, akceptota; informa, informada, informadi, informadika, informadikisto, informadiko, informagado, informagentejo, informaktivulo, informametabolo, informanonco, informanta, informante, informanto, informaradiostacio, informaranĝo, informaro, informartikolo, informata, informativo, informbezono, informbroŝuro, informbudo, informbulteno, informcela, informcele, informcentro, informdistribuo, informe, informeca, informeto, informevojaĝo, informfako, informfilmeto, informflua, informfluo, informfolio, informfonto, informfoto, informigita, informilaro, informilero, informinterŝanĝo, informisto, informita, informite, informiteco, informiva, informiĝema, informiĝinta, informiĝinte, informiĝo, informjaro, informkajero, informkampanjo, informkesto, informkiso, informkunsido, informlaboro,
} 
Uma vez que o parâmetro para seleção das palavras era a não dicionarização oficial delas, foi feito um cruzamento entre os dados da lista criada e os dados da versão do PIV de $1975^{8}$. Cerca de 8.000 itens foram eliminados da lista nessa verificação. Para "limpar" ainda mais a lista, retiramos as conjugações verbais e terminações nominais repetidas, para que o resultado fosse apenas substantivos, adjetivos ou advérbios simples ou verbos no infinitivo. As terminações nominais aj (adjetivo plural), an (adjetivo no caso acusativo) e ajn (adjetivo plural no acusativo) foram substituídas por a (adjetivo); oj (substantivo plural), on (substantivo no caso acusativo) e ojn (substantivo plural no acusativo) foram substituídas por $o$ (substantivo); en (advérbio no acusativo, indicando direção) foi substituído por $e$ (advérbio); as terminações verbais is (passado), os (futuro), as (presente), us (condicional) e $u$ (imperativo) foram substituídas por $i$ (infinitivo). O resultado foi uma lista com cerca de 142.000 itens, nas formas de verbos no infinitivo e de nomes no nominativo singular.

Procurar cada palavra em seu contexto de uso nas revistas seria um trabalho muito grande e impossível de se fazer em tempo tão curto. Entretanto, para verificarmos se a palavra é realmente usada em esperanto, procuramos na internet possíveis usos de cada uma. As palavras só foram incluídas no corpus quando encontramos, em sites de busca, usos efetivos dela.

A lista terminológica usada foi selecionada pois, ao longo do processo de verificação das palavras da lista criada, percebeu-se que grande parte delas pertencia ao campo semântico relacionado à tecnologia. Tal lista ${ }^{9}$ é constituída por palavras informletero, informlibro, informmaterialo, informoceano, informoficejo, informofonto, informofoto, informohava, informoplena, informorgano, informoriça, informoservo, informpanelo, informparolo, informpaĝo, informperado, informpetanto, informpeto, informplena, informpolitiko, informportalo, informprilaborado, informprogramo, informprospekto, informrespondeca, informreto, informrimedaro, informriĉa, informriĉe, informriĉeco, informrolo, informservo, informserĉanta, informsesio, informsistemo, informsocio, informstando, informstrategio, informtabulo, informtago, informtaŭga, informteknologio, informteksto, informtema, informtrudulo, informvarbado, informvespero, informvojaĝo, informĉeno.

${ }^{8}$ Cedida a nós pelo esperantista Túlio Flores, cujo dicionário está disponível neste link: <vortaro.esperanto.org.br $>$.

${ }^{9}$ Disponível em: <http:/ / komputeko.net/Komputeko-ENEO.pdf $>$. 
em inglês e esperanto relacionadas a todas as áreas da computação, com cerca de 7.800 terminações, e foi publicada como livro (Nevelsteen, 2012).

As palavras provenientes do blog do professor John C. Wells foram verificadas após indicação pessoal de outros falantes da língua.

Após a definição do corpus, analisamos as palavras para verificar quais foram os processos de adaptação e buscar um possível padrão entre eles. As palavras foram separadas por língua de origem (apesar de a grande maioria ser do inglês) para melhor organização.

Os itens referentes a nomes de lugares, línguas, povos, etc. estão separados, ao fim do corpus. Apesar de tais dados serem passíveis de análise e comuns nos corpus de trabalhos referentes à fonologia de empréstimo (Calabrese \& Wetzels, 2009), decidimos separá-los pela particularidade da língua que aqui estudamos: a não localização geográfica de uma comunidade de falantes uniforme. Ou seja, tais palavras podem até ser usadas amplamente, mas também podem ser usadas apenas localmente. Considere-se, por exemplo, que houve um congresso de esperanto em tal ou qual cidade, e por isso seu nome foi adaptado à língua. Pode ser que a palavra tenha sido usada apenas durante a divulgação do congresso e a ocorrência do mesmo, não sendo amplamente usada posteriormente.

\subsection{Análise dos dados}

Foram coletadas palavras de 13 línguas diferentes: árabe (04), chinês (02), coreano (01), espanhol (02), francês (01), inglês (37), japonês (10), komi (01), português (03), russo (01), turco (02), sânscrito (01) e suaíli (01). O corpus completo encontra-se ao fim desta dissertação.

As próximas seções descrevem as mudanças que ocorreram durante a adaptação das palavras. Nas tabelas de dados encontra-se um índice subscrito depois de cada palavra, que se refere ao número de cada item do corpus completo, e é usado 
ao longo do texto para os comentários tecidos sobre eles.

Algumas palavras aparecem recorrentemente em seções diferentes, pois em cada subitem a seguir procuramos analisar um fenômeno por vez, e, em algumas palavras, adaptações de vários tipos podem ser observadas.

\subsubsection{Consoantes}

As palavras do corpus cuja língua de origem tem consoantes presentes no inventório do esperanto permitem que a adaptação ocorra sem mudanças. Em blogo $_{17}$ ['blogo], proveniente de blog ['blog], do inglês, por exemplo, quase não há modificações. Os segmentos consonantais [b], [l] e [g], presentes nas duas línguas, foram mantidos na adaptação. O mesmo se dá com a palavra Salso 9 ['salso], originada da palavra Salsa ['salsa], do espanhol e tabasami 66 [taba'sami], do suaíli tabasamu [taba'samu].

Observemos, entretanto, adaptação de consoantes que não estão presentes no sistema consonantal do esperanto:

Tabela 4.1: Adaptação de $\left[\mathrm{t}_{6}\right],\left[\mathrm{t}_{6}^{\mathrm{h}}\right]$ e $\left[\mathrm{t}^{\mathrm{h}}\right]$.

\begin{tabular}{|c|c|c|}
\hline Esperanto & Chinês & Glosa \\
\hline 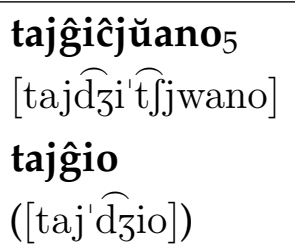 & $\begin{array}{l}<\text { tàijíquán } \\
{\left[\mathrm{t}^{\mathrm{h}}{ }^{\mathrm{ajt}} \text { ait }^{\mathrm{h}}{ }_{\mathrm{wan}}\right]}\end{array}$ & tai chi chuan \\
\hline $\begin{array}{l}\text { vejĉio }_{6} \\
\text { [vej'tfio] }\end{array}$ & $\begin{array}{l}<\text { wéiqí } \\
{\left[\text { wejt }^{\mathrm{h}} \mathrm{i}\right]}\end{array}$ & goo \\
\hline Esperanto & Japonês & Glosa \\
\hline $\begin{array}{l}\text { peĉakuĉo }_{53} \\
\text { [petfa'kutfo] }\end{array}$ & $\begin{array}{l}<\text { pechakucha } \\
\text { [petcakutca] }\end{array}$ & "pecha kucha" \\
\hline Esperanto & Komi & Glosa \\
\hline
\end{tabular}




\begin{tabular}{|c|c|c|}
\hline 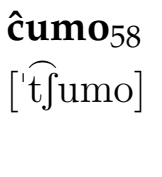 & $\begin{array}{l}<\text { чум } \\
\text { [ ţum] }\end{array}$ & $\begin{array}{l}\text { tipo de moradia de } \\
\text { povos nômades da Si- } \\
\text { béria }\end{array}$ \\
\hline
\end{tabular}

Tanto [tc] quanto $\left[\mathrm{t}_{6}^{\mathrm{h}}\right]$ são adaptados como [t $\left.\widehat{\mathrm{t} \int}\right]$ nos itens 6,53 e 58.

No item 5 , há os segmentos do chinês $\left[\mathrm{t}_{6}\right]$ e $\left[\mathrm{t}_{6}^{\mathrm{h}}\right]$, que são fonemas na língua. A sequência [ $\mathrm{t}^{\mathrm{h}}$ aitcii-] (pronúncia do chinês) é adaptada como [tajd $\widehat{J}_{3} \mathrm{i}-$ em esperanto, o que mostra que houve vozeamento da africada alveo-palatal surda [ $\mathrm{t}_{6}$ ] para a africada sonora $\left[\mathrm{d}_{3}\right]$. A ortografia pode ter sido influente nesse caso, pois o pinyin, sistema oficial de transliteração do mandarim, usa o grafema $<j>$ para representar a adaptação da africada [t6], não aspirada, e o grafema $<q>$ para representar a africada $\left[\mathrm{t}_{6}^{\mathrm{h}}\right]$, aspirada.

Pode-se também observar, no item 5 , a adaptação do segmento [ $\left.\mathrm{t}^{\mathrm{h}}\right]$ para a oclusiva sem aspiração [t], ou seja, houve apenas a queda da aspiração.

Tabela 4.2: Adaptação de $[6]$ e $[s]$ para $\left[\int\right]$.

\begin{tabular}{|c|c|c|}
\hline Esperanto & Japonês & Glosa \\
\hline hibakuŝo $_{49}$ & $<$ hibakusha & pessoa que sobrevi- \\
\hline [hiba'kufo] & [çibakuca] & $\begin{array}{l}\text { veu aos ataques de } \\
\text { bomba atômica que o }\end{array}$ \\
\hline & & Japão sofreu em 1945 \\
\hline ŝogio $_{56}$ & $<$ shoogi & shôgui \\
\hline 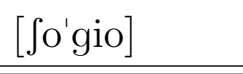 & [60:9i] & \\
\hline Esperanto & Russo & Glosa \\
\hline matrjoŝlko $_{62}$ & < матрёшка & boneca tipicamente \\
\hline [ma'trjo $\left.\int k o\right]$ & [me'trjoske] & russa \\
\hline
\end{tabular}

A fricativa retroflexa surda [6] e a fricativa alveo-palatal surda [s] foram adaptadas para a fricativa pós-alveolar surda [ $]$. Nesse caso, observa-se a manutenção do não vozeamento e a adaptação do ponto de articulação para o que estaria mais próximo entre as possibilidades do sistema fonológico do esperanto. 
Tabela 4.3: Adaptação de $[\mathrm{w}]$ para $[\mathrm{v}]$.

\begin{tabular}{|c|c|c|}
\hline Esperanto & Árabe & Glosa \\
\hline $\operatorname{divano}_{1}$ & $<$ diwân & divã \\
\hline [di'vano] & [di:'wa:n] & \\
\hline Esperanto & Chinês & Glosa \\
\hline 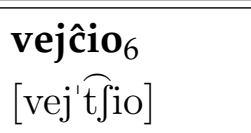 & $\begin{array}{l}<\text { wéiqí } \\
{\left[\text { wejtc }^{\mathrm{h}} \mathrm{i} \text { ] }\right.}\end{array}$ & goo \\
\hline Esperanto & Inglês & Glosa \\
\hline Tvitero $_{42}$ & $<$ Twitter & Twitter \\
\hline [tvi'tero] & ['twitər] & \\
\hline Vacapo $_{44}$ & $<$ WhatsApp & WhatsApp \\
\hline [va'tsapo] & ['wptsæp] & \\
\hline vifio $_{45}$ & $<w i-f i$ & wi-fi \\
\hline [vi'fio] & ['wajfaj] & \\
\hline Vikipedio $_{46}$ & $<$ Wikipedia & Wikipedia \\
\hline [vikipe'dio] & [wıki'pi:diə] & \\
\hline Vindozo $_{47}$ & $<$ Windows & Windows \\
\hline [vin'dozo] & [windəwz] & \\
\hline
\end{tabular}

O fonema / w /, representado ortograficamento como $\breve{u}$, não é comum em início de sílabas. No PIV, apenas a palavra ŭato (watt) e a onomatopeia $\breve{u} a$ ! (choro de bebê) estão presentes.

A maior parte das ocorrências se deu em início de palavra, a não ser pelos itens 1 e 42. No item 1, proveniente do árabe, a língua poderia aceitar a forma *diŭano, uma vez que ŭa é uma sequência de sons já existente, mesmo que rara. No item 42, todavia, realmente há uma violação das caracterizações das combinações possíveis em esperanto, uma vez que a sequência $\breve{u} i$ não existe, e por isso a forma *Tŭitero não seria possível.

Tabela 4.4: Manutenção de [w] para [w] - ortograficamente representado como ŭ em esperanto.

\begin{tabular}{|ll|}
\hline Esperanto $\quad$ Chinês & Glosa \\
\hline
\end{tabular}




\begin{tabular}{|c|c|c|}
\hline $\begin{array}{l}\text { tajôgiĉjŭano }_{5} \\
{\left[\text { tajd }_{3}{ }^{\prime} \text { t'fjwano] }\right.}\end{array}$ & $\begin{array}{l}<\text { tàijíquán } \\
{\left[\mathrm{t}^{\mathrm{h}} \text { ajtcitc }^{\mathrm{h}} \text { wan }\right]}\end{array}$ & tai chi chuan \\
\hline Esperanto & Coreano & Glosa \\
\hline $\begin{array}{l}\text { ŭonbulismo }_{7} \\
{[\text { wonbu'lismo] }}\end{array}$ & $\begin{array}{l}<\text { Wŏn Buddhism } \\
{[\mathrm{w} \wedge \operatorname{nbul}(\text { gjo) }]}\end{array}$ & Wŏn Buddhism \\
\hline
\end{tabular}

No item 07 vemos uma sequência que não existe em outras palavras na língua: ŭon. Como explicitado no capítulo 3, uma estrutura pode ser permitida excepcionalmente para a adaptação de alguma palavra (Diferential importation, Kang (2011)), o que parece ocorrer neste caso.

Houve apenas um caso de mudança de vozeamento do segmento, no item 41 do corpus, a palavra tezaŭro ([te'zawro]), do inglês thesaurus ([0I'sər'əs] $]$ ), no qual o segmento $[\mathrm{s}]$ foi adaptado como $[\mathrm{z}]$ em esperanto, ou seja, houve um vozeamento de uma consoante surda.

\subsubsection{Vogais}

Não há vogais longas como fonemas em esperanto. Na tabela a seguir podemos ver a adaptação de vogais longas provenientes do árabe, inglês e japonês.

Tabela 4.5: Adaptação de vogais longas.

\begin{tabular}{|c|c|c|}
\hline Esperanto & Árabe & Glosa \\
\hline $\operatorname{divano}_{1}$ & $<$ diwân & divã \\
\hline [di'vano] & [di:'wa:n] & \\
\hline falaflo $_{2}$ & $<$ filfil (substantivo) / & falafel \\
\hline [fa'laflo] & falfala (verbo) & \\
\hline & [fa'la:fil] & \\
\hline$\hat{\text { gihado }}_{3}$ & $<$ jihâd & jihad \\
\hline [ $\widehat{\mathrm{d}}_{3} \mathrm{i}^{\prime}$ hado] & {$\left[\widehat{d}_{3} i^{\prime} h a: d\right]$} & \\
\hline
\end{tabular}




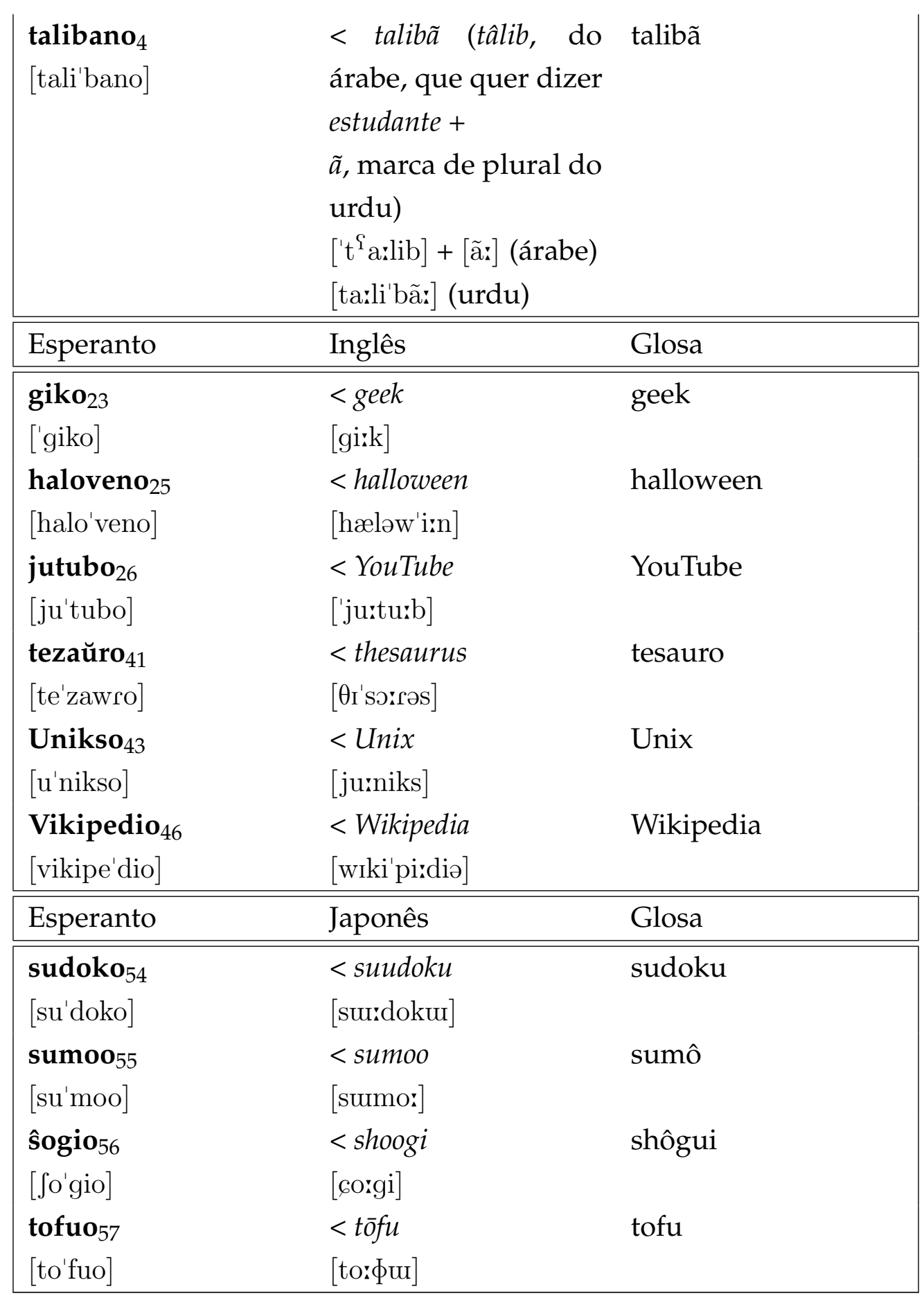

Na maioria dos casos, a vogal longa foi simplesmente adaptada para uma vogal breve idêntica à vogal da forma fonética da língua de origem (como nos itens 1, 2, 3, 4 - mas neste item houve a manutenção da nasalidade -, 23, 26, 56 e 57).

Nos exemplos de adaptação do japonês, podemos observar a mudança do 
grau de arredondamento da vogal não arredondada [u] para a vogal arredondada $[u]$, nos itens 54, 55 e 57, acompanhando a vogal usada para a transliteração romanizada.

Pode-se observar, também, a influência da ortografia nas adaptações (tal influência será mais detalhada na seção 4.3.5). O item 25 tem uma sequência gráfica $<$ ee> $([i \mathrm{i}])$ que é adaptada como <e> em esperanto. O item 41 tem uma sequência de grafemas <au> (э:) que se mantém na adaptação como <aŭ>, enquanto o item 43 tem um grafema único na ortografia, $<u>$, expresso por um ditongo na forma fonética (ju:), que se mantém como grafema único em esperanto (Unikso). O item 46 tem a vogal [i: na forma fonética e [e] na forma ortográfica, e a palavra adaptada em esperanto preservou a vogal da ortografia.

Sobre o item 57, Wennergren (2005) afirma que há a palavra toŭfuo, mas que as variantes tofuo ou tohuo são preferíveis (a forma toŭfuo está presente no PIV). O ditongo < oŭ> seria uma forma de preservar o alongamento da vogal da língua de origem.

A vogal nasal longa na palavra 4 mantém a nasalidade no esperanto por meio da consoante alveolar nasal $[n]$. Como essa vogal é a marca morfológica de plural do urdu, talvez a manutenção da nasalidade se explique pelo peso morfológico do segmento na língua de origem, ou pela possibilidade de o termo ter se internacionalizado já na forma plural.

Como já comentado, a língua da qual se coletou mais dados foi o inglês. Por isso, uma das únicas correspondências de adaptação de segmento em vários contextos que pudemos fazer é a que mostramos na seguinte tabela:

Tabela 4.6: Adaptação do segmento [æ] do inglês para [a] no esperanto.

\begin{tabular}{|ll|}
\hline Esperanto & Inglês \\
\hline
\end{tabular}




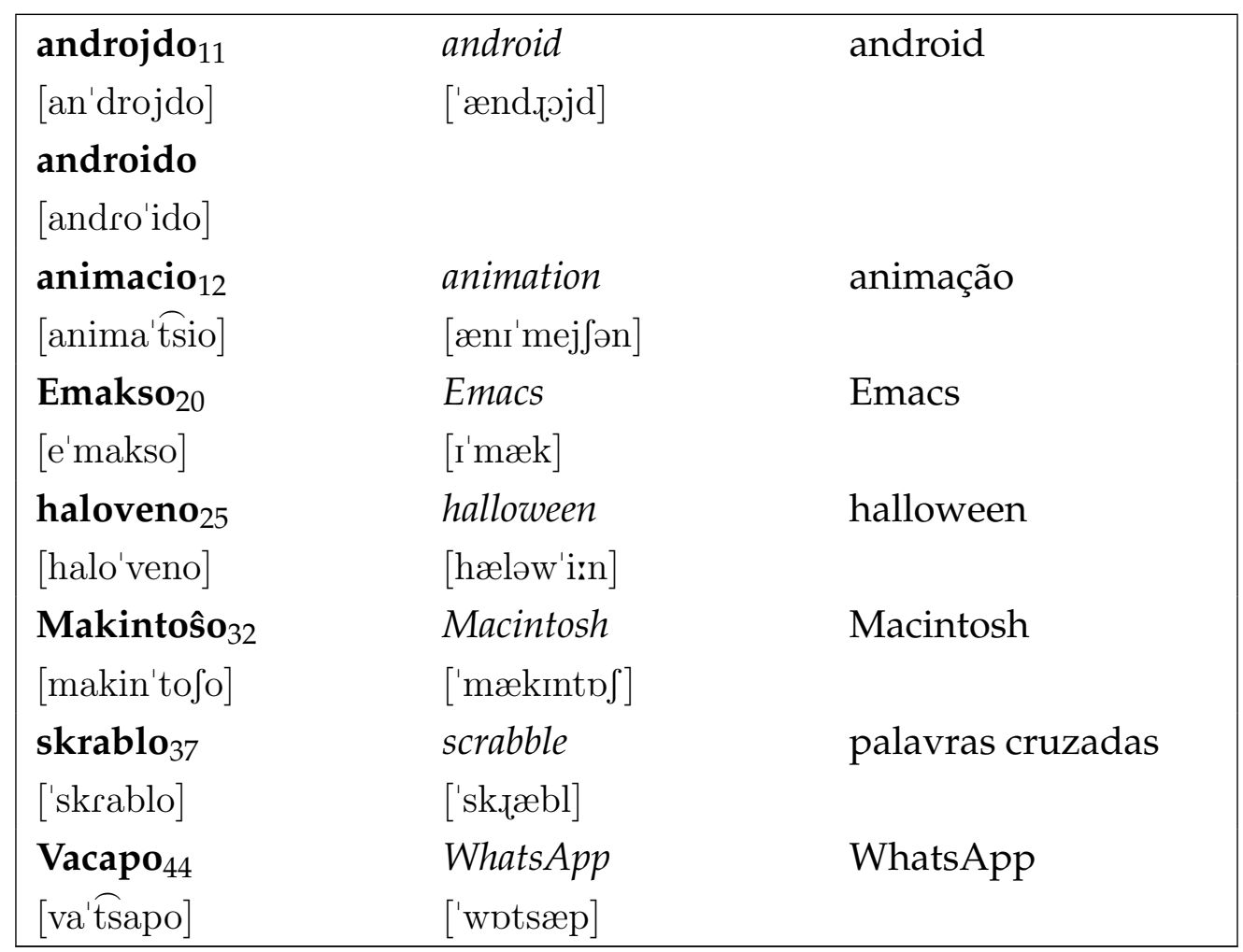

Nesta tabela observamos exemplos de adaptação da vogal baixa anterior não arredondada [æ] para a também baixa anterior não arredondada [a] em contextos de início e de meio de palavra. As duas vogais são bastante próximas, e portanto a adaptação se dá sem grandes contrastes.

\subsubsection{Estrutura silábica}

Bavant (2006a), em seu estudo computacional sobre as sílabas em esperanto, demonstrou que os tipos silábicos mais frequentes na língua são CV ou V. Esse padrão se manteve nas palavras emprestadas.

Na seção seguinte veremos como ataques complexos foram adaptados. Em seguida, explicitamos as adaptações das rimas, especificamente da parte final das raízes. 


\section{Ataques complexos}

Os ataques complexos das palavras originais que não violavam nenhuma restrição do esperanto foram mantidos na adaptação, como podemos ver nos itens a seguir:

Tabela 4.7: Palavras adaptadas com ataque complexo sem modificação.

\begin{tabular}{|c|c|c|}
\hline Esperanto & Inglês & Glosa \\
\hline an[dr]ojdo 11 & $<$ an[dr]oid & android \\
\hline [an'drojdo] & ['ænd.ðjd] & \\
\hline \multirow{2}{*}{\multicolumn{3}{|c|}{$\begin{array}{l}\text { an[dr]oido } \\
\text { [andro'ido] }\end{array}$}} \\
\hline & & \\
\hline $\operatorname{asem}[\mathbf{b l}] \mathbf{i}_{14}$ & $<\operatorname{assem}[b l] e$ & traduzir para uma lín- \\
\hline [a'sembli] & [ə'sembl] & gua de programação \\
\hline$[\mathrm{bl}] \operatorname{logo}_{17}$ & $<[b l] \log$ & blog \\
\hline ['blogo] & ['blog] & \\
\hline [Sk]ajpo 36 & $<$ [Sk]ype & Skype \\
\hline ['skajpo] & ['skajp] & \\
\hline$[\mathbf{s k r}] \mathbf{a b l o} 37$ & $<$ [scr]abble & palavras cruzadas \\
\hline ['skrablo] & ['sk.ææbl] & \\
\hline [sk]iflo 38 & $<$ [sk]iffle & ritmo musical \\
\hline ['skiflo] & ['skif'l] & \\
\hline [spl]ajno 39 & $<$ [spl]ine & função matemática \\
\hline ['splajno] & [splajn] & \\
\hline Esperanto & Russo & Glosa \\
\hline ma[tr]joŝko 62 & < матрёшка & boneca tipicamente \\
\hline$\left[\mathrm{ma}^{\prime} \operatorname{trjo} \mathrm{k} \mathrm{ko}\right]$ & [me'trjoskə] & russa \\
\hline
\end{tabular}

Como visto na seção 2.5.2, os ataques complexos presentes nessa tabela são permitidos na língua. Nos casos em que o ataque tem três elementos consonantais, como nos itens 37 e 39, a primeira consoante é /s / , o que também é permitido.

Houve apenas uma mudança de segmento nos ataques complexos do corpus. Na seção 4.3.1 comentamos, sobre a Tabela 4.3, a adaptação do segmento [w] para 
[v], já que manter a sequência fônica, como no inglês, criaria um alinhamento de sons que não ocorre em esperanto nessa posição silábica. O ataque complexo [tv], apesar de raro, ocorre em outra palavra, também em início de sílaba, em tvido (tuíd, tipo de tecido escocês), portanto é uma sequência já existente.

\section{Rima: adaptação da parte final dos radicais e a influência da morfologia}

O fato de a língua aqui estudada ser planejada nos traz problemáticas diferentes em relação as outras línguas. O Fundamento de Esperanto (Zamenhof, 1905), livro que traz as regras da língua e que foi aprovado em assembleia durante o primeiro congresso de esperanto, em 1905, dita quais estruturas podem ou não ser aceitas na língua. Não há explicitação formal das regras fonológicas, mas pode-se observar padrões pelas palavras presentes nesse primeiro livro.

A influência da gramática pode ser observada na adaptação da parte final das raízes. Todos os substantivos na língua devem ter a terminação $<0>$. Portanto, se alguma palavra for adaptada e a raiz na língua de origem terminar em consoante, o processo mais simples é acrescentar a vogal morfológica $<0>$ ao fim da raiz, como pode ser observado na seguinte tabela:

Tabela 4.8: Acréscimo da vogal /o/ ao fim de palavras que terminam em consoante.

\begin{tabular}{|c|c|c|}
\hline Esperanto & Árabe & Glosa \\
\hline divano $_{1}$ & $<$ diwân & divã \\
\hline [di'vano] & [di:'wa:n] & \\
\hline$\hat{\text { gihado }}_{3}$ & $<$ jihâd & jihad \\
\hline [Ấ3i'hado] & {$\left[\widehat{d}_{3} i^{\prime} h a: d\right]$} & \\
\hline talibano $_{4}$ & $<$ talibã & talibã \\
\hline \multirow[t]{2}{*}{ [tali'bano] } & {$\left[{ }^{\mathrm{f}}{ }^{\mathrm{a}} \mathrm{a} l i b\right]+\left[\tilde{a}_{\mathbf{i}}\right]$ (árabe) } & \\
\hline & [ta:li'bã:] (urdu) & \\
\hline Esperanto & Chinês & Glosa \\
\hline
\end{tabular}




\begin{tabular}{|c|c|c|}
\hline 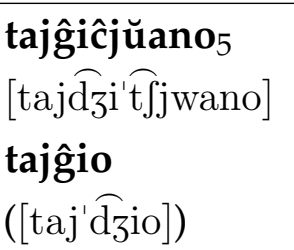 & $\begin{array}{l}<\text { tàijíquán } \\
{\left[\mathrm{t}^{\mathrm{h}} \text { ajtcitc }^{\mathrm{h}} \text { wan] }\right.}\end{array}$ & tai chi chuan \\
\hline Esperanto & Francês & Glosa \\
\hline $\begin{array}{l}\text { suveniro }_{10} \\
{\left[\text { suve'niro] }^{-}\right.}\end{array}$ & $\begin{array}{l}<\text { souvenir } \\
\text { [suv'nir] }\end{array}$ & suvenir \\
\hline Esperanto & Inglês & Glosa \\
\hline $\begin{array}{l}\text { androjdo }_{11} \\
\text { [an'drojdo] } \\
\text { androido } \\
\text { [andro'ido] }\end{array}$ & $\begin{array}{l}<\text { android } \\
\text { ['ænd.ðjd] }\end{array}$ & android \\
\hline $\begin{array}{l}\text { bito }_{16} \\
\text { ['bito] }\end{array}$ & $\begin{array}{l}<\text { bit } \\
{[\text { 'bit }]}\end{array}$ & bit \\
\hline $\mathbf{b l o g}_{17}$ & $<$ blog & blog \\
\hline ['blogo] & ['blog] & \\
\hline dizajno $_{19}$ & $<$ design & design \\
\hline [di'zajno] & [di'zajn] & \\
\hline Emakso $_{20}$ & $<$ Emacs & Emacs \\
\hline [e'makso] & [I'mæk] & \\
\hline fejsbuko $_{21}$ & $<$ facebook & facebook \\
\hline [fejs'buko] & ['fejsbvk] & \\
\hline $\operatorname{giko}_{23}$ & $<$ geek & geek \\
\hline ['giko] & [girk] & \\
\hline haloveno $_{25}$ & $<$ halloween & halloween \\
\hline [halo'veno] & [hæləw'i:n] & \\
\hline iPodo $_{27}$ & $<i P o d$ & iPod \\
\hline [i'podo] & ['ajppd] & \\
\hline kibernetiko $_{28}$ & $<$ cybernetics & cibernética \\
\hline [kiberne'tiko] & [sajbə'netrks] & \\
\hline kilobito $_{29}$ & $<$ kilobit & kilobit \\
\hline [kilo'bito] & ['kiləbit] & \\
\hline Linukso $_{30}$ & $<\operatorname{Linux}$ & Linux \\
\hline [li'nukso] & ['linəks] & \\
\hline
\end{tabular}




\begin{tabular}{|c|c|c|}
\hline $\begin{array}{l}\text { Makintoŝo } 32 \\
{[\text { makin'tofo] }}\end{array}$ & $\begin{array}{l}<\text { Macintosh } \\
\text { ['mækintof] }\end{array}$ & Macintosh \\
\hline $\begin{array}{l}\text { Tvitero }_{42} \\
\text { [tvi'tero] }\end{array}$ & $\begin{array}{l}<\text { Twitter } \\
\text { ['twitər] }\end{array}$ & Twitter \\
\hline $\begin{array}{l}\text { Unikso }_{43} \\
\text { [u'nikso] }\end{array}$ & $\begin{array}{l}<\text { Unix } \\
\text { [ju:niks] }\end{array}$ & Unix \\
\hline $\begin{array}{l}\text { Vacapo }_{44} \\
\text { [va'tsapo] }\end{array}$ & $\begin{array}{l}<\text { WhatsApp } \\
\text { ['wotsæp] }\end{array}$ & WhatsApp \\
\hline $\begin{array}{l}\text { Vindozo }_{47} \\
\text { [vin'dozo] }\end{array}$ & $\begin{array}{l}<\text { Windows } \\
{[\text { windəwz }]}\end{array}$ & Windows \\
\hline Esperanto & Turco & Glosa \\
\hline buzuko $_{63}$ & $<b u z u k$ & bouzouki \\
\hline [bu'zuko] & [bu'zuk] & \\
\hline orkuto $_{64}$ & $<$ orkut & orkut \\
\hline [or'kuto] & [or'kut] & \\
\hline
\end{tabular}

Nesses casos, percebe-se que o segmento consonantal final foi mantido, e a sílaba final passou a ter uma estrutura aberta, terminando em vogal. As consoantes finais presentes nessas palavras são oclusivas ([p d t k $]$ ), fricativas $\left(\left[\begin{array}{lll}s & \mathrm{z}\end{array}\right]\right)$, a nasal $([\mathrm{n}])$ e um rótico $([\mathrm{r}])$. O tipo de consoante, entretanto, nesse caso, não é relevante, pois há a exigência morfológica de que tais palavras terminem pela vogal gramatical $<0\rangle$, assim como se a palavra terminar em vogal, como visto nas tabelas $4.10,4.11$ e 4.12 .

No livro referido (Zamenhof, 1905), por exemplo, podemos ver processos de adaptação similares. Na seção de exercícios de leitura, após cada trecho, há um vocabulário com as palavras usadas no texto (em esperanto), seguidas por suas versões em cinco línguas (francês, inglês, alemão, russo e polonês, que são as línguas pelas quais a gramática do esperanto foi previamente apresentada no livro). Podemos ver adaptações de radicais das línguas supracitadas (ou das línguas que lhes deram origem, em geral, já que é sabido que Zamenhof adaptou radicais do latim, do grego e de línguas eslavas): 
besto ['besto] animal (francês) | beast ['bisst] (inglês) | Thier ${ }^{10}$ (alemão) | животное ${ }^{11}$ (russo) | zwierzę (polonês).

monato [mo'nato] mois (francês) | month (inglês) | Monat (alemão) ['mo:nat] | мсяцъ (russo) | miesiąc (polonês).

(Zamenhof, 1905:32-33)(as transcrições fonéticas e destaques em negrito são nossos)

Como não fazemos um trabalho etimológico mais acurado nesta dissertação, não sabemos se as palavras em negrito foram realmente provenientes de tais línguas, mas pretendemos, apenas, mostrar a similaridade entre os processos de adaptação atuais e os do início da língua.

Esse, todavia, não é o único processo pelo qual a vogal <o> é adaptada ao fim do radical. Ao invés de acréscimo, pode haver elisão do último segmento consonantal, como pode ser visto nos seguintes dados:

Tabela 4.9: Elisão do segmento consonantal final.

\begin{tabular}{|c|c|c|}
\hline Esperanto & Inglês & Glosa \\
\hline animacio $_{12}$ & $<$ animation & animação \\
\hline [anima'tsio] & [ænı'mej」ən] & \\
\hline tezaŭro $_{41}$ & $<$ thesaurus & tipo de dicionário \\
\hline [te'zawro] & {$[\theta$ I'sว:‘วs] } & \\
\hline
\end{tabular}

Os dados de manutenção do segmento consonantal são mais numerosos do que os dados de apagamento. Durante a adaptação, segmentos não são apagados arbitrariamente, como afirma Kentowicz (2003a, apud Menezes (2013:74)), havendo uma tendência à preservação das estruturas.

O acréscimo do $<0>$ final é evidenciado como realmente morfológico, pois itens de classe fechada, como preposições e conjunções, podem terminar em consoante (como mostrado na Tabela 2.7).

\footnotetext{
${ }^{10}$ Grafia da época.

${ }^{11}$ Grafia como apresentada no livro original.
} 
Em relação às raízes terminadas em consoante, portanto, pudemos observar dois padrões de adaptação: manter ou elidir a consoante final. Os dois dados nos quais a elisão ocorre, vistos na tabela acima, têm particularidades. O item 12 é uma palavra um tanto quanto longa, com cinco vogais (e, portanto, cinco núcleos silábicos em esperanto), e a elisão da consoante nasal final torna a palavra mais curta, já que se a consoante fosse mantida, e após ela fosse acrescentada a vogal morfológica $<0>$, o resultado seria animaciono, ou seja, teria uma sílaba a mais. Além disso, a sequência <ono> poderia ser confundida com uma terminação morfológica derivativa, uma vez que <on> representa um sufixo que indica divisão (tri - três; triono - um terço). O item 41 está listado como proveniente do inglês, mas a palavra tem a mesma forma que tinha no latim. Neste caso, o $<$ us $>$ indica terminação de nominativo singular em latim, portanto, poderíamos considerar que o que foi adaptado foi a raiz da palavra (thesaur), sem a terminação de caso.

A seguir, expomos três tabelas com dados de adaptação da parte final das raízes quando terminadas em vogal (a terceira tabela retrata palavras que têm uma vogal final na ortografia mas não na forma fonética).

Tabela 4.10: Mudança da vogal final para /o/.

\begin{tabular}{|c|c|c|}
\hline Esperanto & Espanhol & Glosa \\
\hline Salso $_{9}$ & $<$ Salsa & Salsa \\
\hline ['salso] & ['salsa] & \\
\hline Esperanto & Inglês & Glosa \\
\hline gavo $_{24}$ & $<j a v a$ & Java, linguagem de \\
\hline ['d $\widehat{d}_{3}$ avo $]$ & ['d $\left.\widehat{d}_{3} \mathrm{av} \partial\right]$ & programação \\
\hline \multicolumn{3}{|l|}{ javo } \\
\hline \multicolumn{3}{|l|}{ ['javo] } \\
\hline Vikipedio $_{46}$ & $<$ Wikipedia & Wikipedia \\
\hline [vikipe'dio] & [wrki'pirdiə] & \\
\hline Esperanto & Japonês & Glosa \\
\hline
\end{tabular}




\begin{tabular}{|c|c|c|}
\hline $\begin{array}{l}\text { hibakuŝo } \\
\text { hiba'kufo] } \\
\text { [hiba' }\end{array}$ & $\begin{array}{l}\text { < hibakusha } \\
\text { [çibakuca] }\end{array}$ & $\begin{array}{l}\text { pessoa que sobrevi- } \\
\text { veu aos ataques de } \\
\text { bomba atômica que o } \\
\text { Japão sofreu em } 1945\end{array}$ \\
\hline karaoko $_{50}$ & $<$ karaoke & karaokê \\
\hline [kara'oko] & [karaoke] & \\
\hline peĉakuĉo 53 & $<$ pechakucha & "pecha kucha" \\
\hline [pet $\left.{ }^{\prime} a^{\prime} k u t \int o\right]$ & [petcakutca] & \\
\hline sudoko $_{54}$ & $<$ suudoku & sudoku \\
\hline [su'doko] & [su:doku] & \\
\hline Esperanto & Português & Glosa \\
\hline kajpirinjo $_{59}$ & < caipirinha & caipirinha \\
\hline [kajpi'rinjo] & [kajpi'rige] & \\
\hline kaŝaso $_{60}$ & $<$ cachaça & cachaça \\
\hline [ka'Jaso] & [ka'fase] & \\
\hline pandero $_{61}$ & $<$ pandeiro & pandeiro \\
\hline [pan'dero] & [pẽn'derv] & \\
\hline Esperanto & Russo & Glosa \\
\hline $\begin{array}{l}\text { matrjoŝko }_{62} \\
{[\text { ma'trjofko] }}\end{array}$ & $\begin{array}{l}\text { < матрёшка } \\
\text { [me'trjoskə] }\end{array}$ & matriosca \\
\hline Esperanto & Sânscrito & Glosa \\
\hline $\begin{array}{l}\text { varno }_{65} \\
\text { ['varno] }\end{array}$ & $\begin{array}{l}<\text { varna } \\
\text { ['varne] }\end{array}$ & $\begin{array}{l}\text { sistema de castas do } \\
\text { hinduísmo }\end{array}$ \\
\hline
\end{tabular}

Nos casos observados nessa tabela, a última vogal da palavra é modificada e adaptada como $<0>$. O item 50 , do japonês, aparece nessa e na próxima tabela, pois há, em esperanto, as variantes karaoko $_{50}$ [kara'oko] e karaokeo 50 [karao'keo]. Nesta, há a manutenção da vogal final e o acréscimo de $\langle 0\rangle$, naquela, a adaptação da vogal final.

Houve a eliminação do ditongo no item 61 (pandero 61 [pan'dero] - pandeiro [pẽn'derv]). Nesse caso, a influência da forma fonética foi importante, uma vez que o ditongo <ei> é pronunciado como [e]. A forma pandejro seria possível, mas a versão da palavra sem o ditongo é a que foi encontrada. O item 59 demonstra a 
manutenção do ditongo presente na língua de origem para a forma em esperanto (kajpirinjo59 [kajpi'sinjo] - caipirinha [kajpi'rige]), uma vez que não é possível a pronúncia [kapi'rine].

Na tabela seguinte apresentamos casos em que, em vez de adaptação da vogal final, há a manutenção dela como se apresenta na língua de origem e o acréscimo de $<$ o $>$ logo após ela.

Tabela 4.11: Manutenção da vogal final e acréscimo de /o/.

\begin{tabular}{|c|c|c|}
\hline Esperanto & Chinês & Glosa \\
\hline $\begin{array}{l}\text { vejĉíio }_{6} \\
\text { [vej'tfio] }\end{array}$ & $\begin{array}{l}<\text { wéiqí } \\
{\left[\text { wejtc }^{\mathrm{h}} \mathrm{i}\right]}\end{array}$ & goo \\
\hline Esperanto & Espanhol & Glosa \\
\hline  & 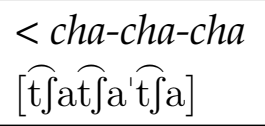 & chá-chá-chá \\
\hline Esperanto & Inglês & Glosa \\
\hline lobio $_{31}$ & $<$ lobby & lobismo \\
\hline [lo'bio] & ['lobi] & \\
\hline rumio $_{35}$ & $<$ rummy & jogo de cartas \\
\hline [ru'mio] & ['əə⿸尸I $]$ ou & \\
\hline & ['. $\mathrm{\prime} \Lambda \mathrm{mI}]$ & \\
\hline vifio $_{45}$ & $<w i-f i$ & wi-fi \\
\hline [vi'fio] & ['wajfaj] & \\
\hline Esperanto & Japonês & Glosa \\
\hline karaokeo $_{50}$ & $<$ karaoke & karaokê \\
\hline [karao'keo] & [karaoke] & \\
\hline mangao $_{51}$ & $<\operatorname{mang} a$ & mangá \\
\hline [man'gao] & [mayga] & \\
\hline origamio $_{52}$ & $<$ origami & origâmi \\
\hline [origa'mio] & [origami] & \\
\hline sumoo $_{55}$ & $<$ sumoo & sumô \\
\hline [su'moo] & [sumo: $]$ & \\
\hline ŝogio $_{56}$ & $<$ shoogi & shôgui \\
\hline [ Jo'gio] & [6o:gi] & \\
\hline
\end{tabular}




\begin{tabular}{|lll|} 
tofuo $_{57}$ & $<$ tōfu & tofu \\
{$[$ to'fuo $]$} & {$[$ to: $\Phi u]$} & \\
\hline
\end{tabular}

No item 8, apesar de haver a manutenção da vogal final, uma sílaba da palavra original é eliminada. Como se trata do nome de uma dança, que tem uma forte conotação onomatopaica, a eliminação da sílaba pode ter se dado pela fato de a simples repetição dual da sílaba [ [ $\int \mathrm{t}$ a já expressar o significado desejado.

Do inglês, temos uma palavra que é uma sigla: wi-fi 45 ['wajfaj]. A manutenção da vogal, nesse caso, pode ter ocorrido graças ao processo de formação da palavra na língua de origem, uma vez que, em siglas, normalmente cada letra tem um significado próprio, e, portanto, modificar uma das letras seria perder informações importantes de seu significado. De qualquer forma, verifica-se neste item a influência da ortografia, na adaptação das vogais.

A próxima tabela reúne dados de palavras que têm uma vogal ortograficamente marcada, mas que não é pronunciada, de fato.

Tabela 4.12: Palavras que tem, na língua de origem, uma vogal final marcada ortograficamente, mas que não são pronunciadas.

\begin{tabular}{|c|c|c|}
\hline Esperanto & Inglês & Glosa \\
\hline asembli $_{14}$ & $<$ assemble & traduzir para uma lín- \\
\hline [a'sembli] & [ə'sembl] & gua de programação \\
\hline bajto $_{15}$ & $<$ byte & conjunto de 8 bits \\
\hline ['bajto] & ['bajt] & \\
\hline kiberspaco $_{18}$ & $<$ cyberspace & espaço virtual \\
\hline [kiberspatso] & ['sajbəspejs] & \\
\hline gigabajto $_{22}$ & $<$ gigabyte & 1 bilhão de bytes \\
\hline [giga'bajto] & ['gigəbajt] & \\
\hline jutubo $_{26}$ & < YouTube & YouTube \\
\hline [ju'tubo] & ['justurb] & \\
\hline megabajto $_{33}$ & $<$ megabyte & 1 milhão de bytes \\
\hline [mega'bajto] & [megəbajt] & \\
\hline
\end{tabular}




\begin{tabular}{|c|c|c|}
\hline Skajpo 36 & $<$ Skype & Skype \\
\hline ['skajpo] & ['skajp] & \\
\hline skrablo $_{37}$ & < scrabble & palavras cruzadas \\
\hline ['skrablo] & ['sk.ðæbl] & \\
\hline skiflo $_{38}$ & < skiffle & ritmo musical \\
\hline ['skiflo] & ['skif $\left.{ }^{\ominus} l\right]$ & \\
\hline splajno $_{39}$ & < spline & função matemática \\
\hline ['splajno] & [splajn] & \\
\hline terabajto $_{40}$ & $<$ terabyte & 1 trilhão de bytes \\
\hline [tera'bajto] & [terəbajt] & \\
\hline
\end{tabular}

Nesses casos, e difícil avaliar se o que ocorreu foi a mudança da vogal final ortográfica ou o acréscimo de $<0>$ pelo fato de a raiz terminar em consoante (na forma fonética). Por isso, decidimos separar estes itens da adaptação como manutenção ou mudança da vogal final.

\subsubsection{Adaptação por meio da fonética}

Como explicado no capítulo 3, as palavras podem ter uma adaptação mais parecida com a forma fonológica/fonética ou mais parecida com a forma ortográfica da língua de origem.

Nesta seção, são comentadas as palavras que, em sua forma final em esperanto, se assemelham mais à forma falada da L2, e, na seção seguinte, as palavras que se parecem mais com a forma ortográfica.

Tabela 4.13: Palavras que se parecem mais com a forma fonética do que com a forma ortográfica da L2.

\begin{tabular}{|c|c|c|}
\hline Esperanto & Espanhol & Glosa \\
\hline  &  & chá-chá-chá \\
\hline Esperanto & Inglês & Glosa \\
\hline $\begin{array}{l}\text { androjdo } \\
\text { [an'drojdo] }\end{array}$ & $\begin{array}{l}\text { < android } \\
\text { ['ænd_əojd] }\end{array}$ & android \\
\hline
\end{tabular}




\begin{tabular}{|c|c|c|}
\hline bajto $_{15}$ & $<$ byte & conjunto de 8 bits \\
\hline ['bajto] & ['bajt] & \\
\hline dizajno $_{19}$ & $<$ design & design \\
\hline [di'zajno] & [di'zajn] & \\
\hline fejsbuko $_{21}$ & $<$ facebook & facebook \\
\hline [fejs'buko] & ['fejsbək] & \\
\hline gigabajto $_{22}$ & $<$ gigabyte & 1 bilhão de bytes \\
\hline [giga'bajto] & ['gigəbajt] & \\
\hline giko $_{23}$ & $<$ geek & geek \\
\hline ['giko] & [girk] & \\
\hline$\hat{\operatorname{gavo}}_{24}$ & $<j a v a$ & Java \\
\hline ['d]zavo] & ['d子avə] & \\
\hline megabajto $_{33}$ & $<$ megabyte & 1 milhão de bytes \\
\hline [mega'bajto] & [megəbajt] & \\
\hline Skajpo $_{36}$ & $<$ Skype & Skype \\
\hline ['skajpo] & ['skajp] & \\
\hline splajno $_{39}$ & $<$ spline & função matemática \\
\hline ['splajno] & [splajn] & \\
\hline terabajto $_{40}$ & $<$ terabyte & 1 trilhão de bytes \\
\hline [tera'bajto] & [terəbajt] & \\
\hline Esperanto & Português & Glosa \\
\hline kaŝaso $_{60}$ & $<$ cachaça & cachaça \\
\hline [ka'faso] & [ka'Jase] & \\
\hline pandero $_{61}$ & $<$ pandeiro & pandeiro \\
\hline [pan'dero] & [pẽn'derv] & \\
\hline
\end{tabular}

Nos itens 15, 19, 21, 22, 33, 36, 39 e 40 há, nas palavras em esperanto, um ditongo presente na forma fonética do inglês, mas representado apenas por um grafema na forma ortográfica, ou seja, provavelmente a forma fonética foi influente para a adaptação. No item 11, há uma sequência gráfica de duas vogais (<oi>), que gerou duas formas em esperanto: androjdo 11 [an'drojdo] (presente nesta última tabela) e androido 11 [andro'ido] (listado na tabela seguinte). No primeiro caso, a sequência fônica foi tratada como ditongo, como na forma fonética; no segundo, gerou um hiato, provavelmente influenciado pela forma ortográfica. Processo 


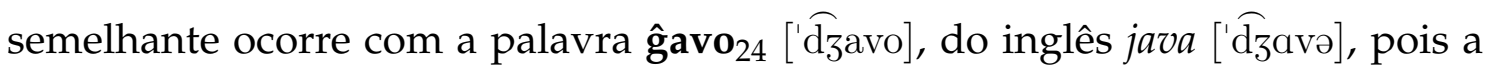
primeira consoante da palavra se assemelha à forma fonética do vocábulo em inglês, mas há também a variante javo ${ }_{24}$ ['javo], elencada na tabela seguinte, em que a primeira consoante baseia-se na forma ortográfica, e não na fonética.

No caso de Skajpo 36 ['skajpo] devemos considerar que as palavras skapo (caule) e skipo (equipe) já existem na língua, então a eliminação de um dos elementos do ditongo geraria uma duplicação semântica da sequência gráfica. O mesmo

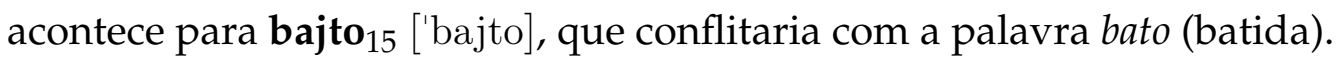

A palavra pandero 61 [pan'dero], proveniente do português pandeiro [pẽn'derv] mostra uma simplificação do ditongo, presente na ortografia, mas que não é pronunciado. A forma pandejro poderia ser criada em esperanto, considerando-se a ortografia, mas observa-se, nesse caso, também a influência da forma fonética.

A escolha da vogal $<\mathrm{i}>$ em vez de $<\mathrm{e}>$, no item 23 , também nos leva a crer que a pronúncia da palavra influenciou a forma em esperanto, giko 23 ['giko]. Entretanto, para além da forma fonética, devemos considerar, mais uma vez, palavras já existentes na língua, pois a palavra geko (lagartixa) já existe.

Os itens 8 e 60 mostram a adaptação da africada [ $[\mathrm{t}]$ (do espanhol) e da fricativa [s] (do português), que se mantêm na forma fonética em esperanto, gerando a

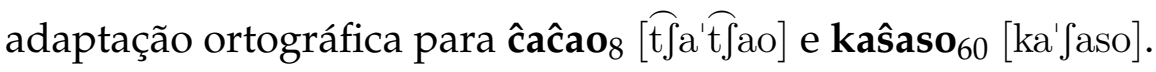

\subsubsection{Adaptação por meio da ortografia}

Como afirmam Vendelin \& Peperkamp (2006), algumas adaptações podem ocorrer pelo processo de "leitura" da palavra de origem, ou seja, os falantes leem a palavra como se ela estivesse escrita na língua a ser adaptada. Dessa forma, as estruturas ortográficas tendem a ser mantidas, em detrimento das estruturas fonéticas. 
Tabela 4.14: Palavras que se parecem mais com a forma ortográfica do que com a forma fonética da L2.

\begin{tabular}{|c|c|c|}
\hline Esperanto & Inglês & Glosa \\
\hline androido $_{11}$ & $<$ android & android \\
\hline [andro'ido] & ['ænd.əjd] & \\
\hline $\operatorname{animacio}_{12}$ & $<$ animation & animação \\
\hline [anima'tsio] & [ænı'mejfən] & \\
\hline ciberspaco $_{18}$ & $<$ cyberspace & espaço virtual \\
\hline [ [tsiberspatso] & ['sajbəspejs] & \\
\hline \multirow{2}{*}{\multicolumn{3}{|c|}{$\begin{array}{l}\text { kiberspaco } \\
\text { [kiberspatso] }\end{array}$}} \\
\hline & & \\
\hline Emakso $_{20}$ & $<$ Emacs & Emacs \\
\hline [e'makso] & [I'mæk] & \\
\hline javo $_{24}$ & $<j a v a$ & Java \\
\hline ['javo] & [' $\left.\mathrm{d}_{3} \mathrm{av} \partial\right]$ & \\
\hline haloveno $_{25}$ & $<$ halloween & halloween \\
\hline [halo'veno] & [hæləw'inn] & \\
\hline iPodo $_{27}$ & $<$ iPod & iPod \\
\hline [i'podo] & ['ajpod] & \\
\hline kibernetiko $_{28}$ & $<$ cybernetics & cibernética \\
\hline [kiberne'tiko] & [sajbə'netıks] & \\
\hline Makintoŝo $_{32}$ & $<$ Macintosh & Macintosh \\
\hline [makin'tofo] & ['mækintof] & \\
\hline skiflo $_{38}$ & < skiffle & ritmo musical \\
\hline ['skiflo] & {$\left[\right.$ 'skif $\left.^{\ominus} \mathrm{l}\right]$} & \\
\hline Unikso $_{43}$ & $<$ Unix & Unix \\
\hline [u'nikso] & [ju:niks] & \\
\hline vifio $_{45}$ & $<w i-f i$ & wi-fi \\
\hline [vi'fio] & ['wajfaj] & \\
\hline
\end{tabular}

A ausência de ditongos nas palavras 11 ([droi] - com dois núcleos silábicos $<[\operatorname{droj}]), 12([\mathrm{a}]<[\mathrm{ej}]), 25([\mathrm{o}]<[$ əəw]), $27([\mathrm{i}]<[\mathrm{aj}]), 43([\mathrm{u}]<[\mathrm{ju}])$ e $45([\mathrm{i}]<[\mathrm{aj}])$ nos indica que houve influência da ortografia, pois o ditongo, presente na forma fonética das palavras em inglês, não está marcado ortograficamente nas palavras 
em esperanto.

Sobre as vogais, podemos ainda notar que nos itens 20 e 25 foi escolhida a vogal [e], presente na ortografia das palavras em inglês, em vez de [I] e [ir], e que nas palavras 27 e 32 houve a escolha de [o] para a adaptação de [p], mantendo-se o grau de anterioridade da vogal, em detrimento da altura.

Duas consoantes não pronunciadas na forma fonética foram mantidas na palavra em esperanto: $<\mathrm{r}>$, em ciberspaco 18 [țiberspatso] $(<\text { cyberspace ['sajbəspejs] })^{12}$ $\mathrm{e}<\mathrm{s}>$ em Emakso 20 [e'makso] $(<$ Emacs [I'mæk]).

Por fim, no item 38 vemos a manutenção da sequência ortográfica <ffle>, que, na forma fonética da língua de origem, apresenta-se como [fl].

\subsubsection{Palavras em variação sincrônica e propostas intencionais de novas palavras}

Como Kang (2011 : 02) comenta, um dos padrões de análise para o empréstimo de palavras é o Grammar-external factors, ou seja, fatores para além da gramática da língua. Esse é um fator importante para a adaptação de radicais novos e aceitação de novas palavras em esperanto. A comunidade linguística costuma discutir bastante sobre os possíveis processos de adaptação e aceitação de novos radicais, seja por meio de redes sociais, por listas de e-mails ou durante congressos.

De qualquer forma, o que vale, é claro, é o uso real da palavra pelos falantes. Facebook, por exemplo, foi adaptada de duas formas: vizaghlibro e fejsbuko. A primeira é uma adaptação semântica direta das palavras inglesas face (rosto, vizaĝo em esperanto) e book (livro, libro, em esperanto). Muitos defendem que não é necessário introduzir um novo radical na língua, uma vez que pode se usar duas palavras já existentes para compor o sentido novo que se quer expressar. Parecenos, entretanto, que a variante fejsbuko é mais amplamente usada pelos falantes.

\footnotetext{
${ }^{12}$ Pronúncia britânica.
} 
Em nosso corpus encontram-se outras palavras que têm duas variantes na língua, mas nestes casos as duas são resultado de adaptações fonológicas:



2. androjdo [an'drojdo] ou androido [andro'ido], do inglês android ['ændððjd],

3. ciberspaco [țiberspatso] ou kiberspaco [kiberspatso], do inglês cyberspace ['sajbəspejs],

4. gavo [' $\left.\widehat{\mathrm{d}}_{3} \mathrm{avo}\right]$ ou javo ['javo], do inglês java [' $\widehat{\mathrm{d}}_{3} \mathrm{av}$ ],

5. karaoko [kara'oko] ou karaokeo [karao'keo], do japonês karaoke [karaoke].

O primeiro par de palavras, proveniente da palavra chinesa tàijíquán [ $\mathrm{t}^{\mathrm{h}} \mathrm{ajtcit}_{6}{ }^{\mathrm{h}} \mathrm{wan}$ ] é, na verdade, uma versão completa e outra abreviada do termo chinês, pois é um radical composto, então tajĝio ([taj' $\widehat{\text { zzio }}]$ ) seria a adaptação apenas de tàijí [t ${ }^{\mathrm{h}}$ aitcii] (que, por sua vez, também é um composto, pois em chinês cada sílaba é um morfema). Nos outros casos há variação da adaptação fonológica, como já comentado nas seções anteriores.

Também pelo fato de a língua ser planejada, novas palavras são propostas intencionalmente, o que não costuma acontecer nas outras línguas. A palavra tabasami significa "sorrir". Existe a palavra "rideti"13 em esperanto, mas por achar que tal palavra não expressava exatamente o sentido semântico desejado, um usuário específico propôs o uso da palavra, cujo radical provém do suaíli. Depende da comunidade de falantes usar ou não a palavra, é claro ${ }^{14}$.

\subsubsection{Topônimos}

Como explicado na seção 4.2, separamos os nomes de lugares, línguas, povos, etc. ao fim do corpus, não os incluindo na análise. Todavia, fazemos, nesta seção, brevíssimos comentários sobre eles.

\footnotetext{
${ }^{13}$ Esta palavra significa, literalmente, o diminutivo de "rir", o que não é "sorrir", exatamente. Alguns usam também a palavra "smajli", proveniente da palavra inglesa smile.

${ }^{14}$ Uma pesquisa rápida on-line indica que, aparentemente, a palavra está sendo usada de fato.
} 
Como visto na seção anterior, há palavras que têm duas formas em variação, e alguns itens referentes a topônimos também apresentam esse comportamento, como visto na seguinte tabela.

Tabela 4.15: Topônimos que apresentam duas formas em esperanto.

\begin{tabular}{|c|c|c|}
\hline Esperanto & L2 & Glosa \\
\hline $\begin{array}{l}\text { Katmanduo }_{107} \\
{[\text { katman'duo] }} \\
\text { Katmando } \\
\text { [ka'tmando] }\end{array}$ & < Kāthamādaum & cidade no Nepal \\
\hline $\begin{array}{l}\text { Kazaĥio }_{108} \\
{[\text { kaza'hio] }} \\
\text { Kazaĥstano } \\
\text { [kaza'hstano] }\end{array}$ & $<$ Казахстан & Cazaquistão \\
\hline $\begin{array}{l}\text { Kievo }_{111} \\
{[\text { ki'evo] }} \\
\text { Kijivo } \\
\text { [kij'ivo] }\end{array}$ & $<$ Киев & cidade na Ucrânia \\
\hline $\begin{array}{l}\text { volgio }_{174} \\
{[\text { vol'gio] }} \\
\text { volgo } \\
\text { ['volgo] }\end{array}$ & < Волга & rio na Rússia \\
\hline
\end{tabular}

As palavras 107 e 174 apresentam uma variação vocálica final que parece ter explicação parecida com a que vimos sobre a Tabela 4.10 e a Tabela 4.11. Para analisar os itens 108 e 111 seria preciso verificar a transliteração das palavras e suas formas fonéticas na L2, e como tais palavras não foram o foco de nossa descrição, tal verificação não foi feita.

Outro caso interessante é o da palavra Brajtono 78 ([braj'tono]), proveniente da palavra inglesa Brighton, que apresenta um ditongo (<aj>) não presente na forma ortográfica da L2, portanto deve ter ocorrido influência da forma fonética, da mesma forma que vimos na Tabela 4.13. 


\section{Considerações finais}

Os dados coletados foram muito dispersos para que pudéssemos chegar a conclusões em relação a padrões de adaptação. Seria preciso verificar especificações das línguas de origem, estudando uma quantidade maior de dados para cada língua, em pares (inglês-esperanto, japonês-esperanto, português-esperanto, etc.).

Uma distinção importante para a fonologia de empréstimo, a relação entre a adaptação por meio da fonética ou da fonologia, não pôde ser verificada nesta pesquisa, pela diversidade dos dados. Para analisar o input da língua de origem, é preciso grande variedade de palavras, verificar, com cuidado, a estrutura fonológica e fonética da língua de origem, e as comparar com a língua alvo. Nosso corpus reuniu palavras de línguas diferentes, muitas vezes em quantidade bastante baixa (apenas um ou dois itens, por exemplo). Sendo assim, mais do que chegar a conclusões sobre como a adaptação ocorre, procuramos descrever os casos particulares que encontramos.

As consoantes das línguas de origem que diferiam das possibilidades presentes no sistema consonantal do esperanto foram adaptadas por segmentos foneticamente semelhantes.

Em relação às vogais, pudemos observar que há uma tendência para que vogais longas sejam adaptadas como vogais breves, em detrimento de um possível ditongo, que marcaria o alongamento da vogal na língua de origem.

Sobre a estrutura silábica, vimos que a morfologia deve ser, necessariamente, considerada nas adaptações de nomes, no que se refere à parte final da raiz. Em palavras terminadas em consoantes na língua de origem, na maioria dos casos o segmento foi mantido ao invés de ser apagado. Quando terminadas em vogal, houve um equilíbrio nos dados sobre mudar a vogal para $<0>$ ou mantê-la e 
acrescentar a marcação morfológica depois dela.

Por fim, expusemos também a variabilidade entre adaptações baseadas mais na forma fonética da palavra ou mais na forma ortográfica, além de palavras que têm mais de uma variante de adaptação em esperanto ou que foram introduzidas na língua de forma intencional.

Comentamos ainda, de forma breve, algumas adaptações observadas nos nomes de cidades, países, etc.

Dissertar sobre uma língua planejada é um desafio no meio científico linguístico, tanto pela pouca aceitação de tais línguas como objetos de estudos quanto pela falta de teorização sobre o assunto.

Procuramos mostrar, entre outras coisas, que o esperanto é uma língua efetivamente usada, e não uma utopia, como alguns pensam. Stria (2016) afirma que “Contrary to popular belief, Esperanto has a dynamically interacting and growing community. It is used among many thousands of speakers" (Stria, 2016:112). A autora, em sua tese de doutorado, argumenta que o esperanto é uma língua natural, com suas peculiaridades, é claro, mas ainda assim uma língua corrente e real: "Sociolinguistically, Esperanto presents a special case. It shows some similarity to pidgins, creoles, minority and revitalised languages as well as diaspora languages, yet remains a unique type of speech community. (Stria, 2016:114)".

Do ponto de vista tipológico, Stria (2016) afirma que

Manaris et. al (2006) have demonstrated that Esperanto exhibits statistical proportions similar to other European languages (English, French, German, Italian and Spanish [...]. Parkvall (2010) shows that Esperanto shares most typological features with Indo-European languages of Europe (around 75\% and less than $70 \%$ for the most related Russian). However, its features in comparison with languages of the world as a whole are similar in $54 \%$. (Stria, 2016:112-113)

Ou seja, o esperanto é uma língua com base indo-europeia, o que já foi comentado nesta dissertação, graças às raízes escolhidas por Zamenhof para compor as 
palavras iniciais da língua. Assim sendo, seu aprendizado é mais fácil para falantes de línguas do ramo indo-europeu do que para falantes de línguas afro-asiáticas ou fino-úgricas, por exemplo (o que não impede o seu aprendizado por falantes de línguas desses troncos linguísticos, é claro).

No que se refere ao crescimento do léxico com a incorporação de novas palavras, pudemos mostrar que é um processo vigente na língua, assim como em qualquer outra língua natural. O corpus aqui apresentado não se pretende exaustivo, uma vez que foi ancorado apenas em dados escritos e limitados a fontes específicas.

Esperamos que a explanação sobre o que é uma língua planejada, sobre a comunidade de falantes do esperanto e sobre dados linguísticos específicos tenha sido um importante passo inicial para a discussão do assunto de forma mais séria e metodológica. 


\section{Referências Bibliográficas}

ABRAHAMSEN, JARDAR EGGESBØ, "Compound stress in a norwegian variety of esperanto", Nordic Journal of Linguistics, volume 38(02):245-284, 2015.

Albrow, MARTIN, “Nacionalidade e identidade na era global”, in: BARRoso, JOÃo Rodrigues (Ed.), "Globalização e identidade nacional”, 19-37, São Paulo: Atlas, 1999.

ANDERSON, BENEDICT, Comunidades imaginadas: reflexões sobre a origem e a difusão do nacionalismo, São Paulo: Editora Companhia das Letras, 2008.

ASSIS, MACHADO DE, "Instinto de nacionalidade", in: "Machado de Assis: crítica, notícia da atual literatura brasileira", São Paulo: Agir, 1959 [1873].

BARANDOVSKÁ-FRANK, VERA, "Slaviconlangs", in: "Scienca Prelegsesio de AIS San Marino", 2015.

BAVANT, MARC, "Perkomputila silaba analizo de la vortproviso de piv 2002", 2006a.

URL http://kursoj.pagesperso-orange.fr/studoj/silab.htm

BAVANT, MARC, "Silabo kaj silabado", Lingva Kritiko: Studoj kaj notoj pri la Internacia Lingvo, Esperantologio Interreta, 2006b.

URL http://lingvakritiko.com/2006/12/20/silabo-kaj-silabado/

BENCZIK, VILMOS, “Skriba kaj voĉa esperanto: La internacia lingvo en semiotika spegulo", in: WANDEL, AMRI (Ed.), "IKU 58: Internacia Kongresa Universitato", 43-53, Rotterdã: Universala Esperanto-Asocio, 2005.

URL http: //www . uea.org/pdf/IKU/IKU2005.pdf

BERGEN, BENJAMIN K, "Nativization processes in 11 esperanto", Journal of Child Language, volume 28(03):575-595, 2001.

URL http://dx.doi .org/10.1017/S0305000901004779

BHAtiA, TEJ K. \& RitChiE, William C. (Eds.), The handbook of bilingualism and multilingualism, Oxford: Blackwell Publishing Ltd, 2013. 
BÍRÓ, TAMÁS, "Yiddish influence in hungarian, esperanto and modern hebrew", On the Boundaries of Phonology and Phonetics: A Festschrift Presented to Tjeerd de Graaf, 123-145, 2004.

URL http://www.let.rug.nl/〜gilbers/onderzoek/bundel/bundel2004ed2. pdf\#page $=123$

Blanke, DetleV, “The term "planned language"", Esperanto, Interlinguistics, and Planned Language, volume 5:1-20, 1997.

BlANKE, DetLEV, "Causes of the relative success of esperanto", Language Problems and Language Planning, volume 33(3):251-266, 2009.

Blevins, Juliette, "The syllable in phonological theory", in: GoldSMith, JoHN A. (Ed.), "The Handbook of Phonological Theory", Blackwell Publishers, 1995.

URL http://ww.blackwellreference.com/public/tocnode?id= g9780631201267_chunk_g97806312012678

BOOIJ, GEERT, The grammar of words: An introduction to linguistic morphology, Oxford: Oxford University Press, 2012.

CADEI, BATTISTA, “Esperanto kiel parola lingvo", Espero Katolika, (80):52-55; 8991, 1983.

URL http: //www.esperokatolika.org/ek19811985/ek1983_03.htm\#6

CAlabrese, Andrea \& Wetzels, W. LeO, Loan phonology, volume 307, Amsterdam/Philadelphia: John Benjamins Publishing, 2009.

CHANG, CHARles B., "Phonetics vs. phonology in loanword adaptation: Revisiting the role of the bilingual", Annual Meeting of the Berkeley Linguistics Society, volume 34(1):43-54, 2008.

URL http://linguistics.berkeley.edu/phonlab/annual_report/ documents/2008/chang_bls34.pdf

COLLING, IVAN EIDT, "Comparação entre os sistemas fonéticos do esperanto e do português", Cadernos da Semana de Letras, 140, 2012.

URL http://www.semanadeletras.ufpr.br/wp-content/uploads/2013/05/ Semana_de_Letras_2012_Volume2_trabalhoscompletos. pdf\#page $=145$

CORSETti, RenAtO, "Andrea diras "ti-ta”. disaj observoj pri la kreoliĝo de esperanto", Esperanto, volume 87(04):63-64, 1994. 
CORSETTI, RENATO, “Esperanto kaj kreolaj lingvoj: komunaj kaj malkomunaj trajtoj en la kreoliĝo", in: KOŠECKÝ, STANISLAV (Ed.), "Multkulturaj familioj de nuntempa Eŭropo: aktoj de la seminario okazinta 01-02.08.1996", 11-36, Bratislava: Esprima, 1996a.

CORSETti, RENATO, "A mother tongue spoken mainly by fathers", Language problems and language planning, volume 20(3):263-273, 1996b.

Corsetti, Renato, Pinto, Maria A \& Tolomeo, Maria, "Regularizing the regular: The phenomenon of overregularization in esperanto-speaking children", Language problems and language planning, volume 28(3):261-282, 2004.

URL http://dx.doi.org/10.1075/lplp.28.3.04cor

Dias, Alberto EMERSOn Werneck, Renovação lexical do esperanto: mecanismos de formação de neologismos, Tese de Mestrado, Universidade de Brasília, Brasília, 2009.

DOBRZYŃSKI, ROMAN, Bona Espero: idealo kaj realo, Martin: Stano Marček, 2008.

DOls SAlas, NicOlaU, "Perspektivoj en fonologia kaj fonetika esplorado de esperanto", in: VERGARA, JOsÉ ANTONIO (Ed.), "IKU 62: Internacia Kongresa Universitato", 24-47, Rotterdã: Universala Esperanto-Asocio, 2009.

URL http: //www .uea.org/pdf/IKU/IKU2009.pdf

DOLS SAlAS, NiCOLAU, "Phonology and morphology and the limits of freedom in an artificial language", 2012.

URL http://www.researchgate.net/publication/236852906_Phonology_ morphology_and_the_limits_of_freedom_in_an_artificial_language

DOMINTE, CONSTANTIN, "Fonemstatistikaj rimarkoj pri esperanto", in: FIEDLER, SABINE \& LIU, HAITAO (Eds.), “Festlibro omaĝe al la 60-jariĝo de Detlev Blanke/Festschrift für Detlev Blanke zum 60", 337-345, Prague, Czech Republic: Kava-Pech, 2001.

URL http://www.lingviko.net/db/23_Dominte.htm

DULIĈENKO, ALEKSANDR, En la serĉado de la mondolingvo aŭ interlingvistiko por ĉiuj, Kaliningrado: Sezonoj, 2006.

EAgleton, Terry, A ideia de cultura, São Paulo: Editora Unesp, 2005.

ECO, UMBerTO, A procura da língua perfeita, Lisboa: Editorial Presença, 1996. 
Featherstone, MiKe, "Cultura global: introdução”, in: FeAtherstone, MiKe (Ed.), "Cultura global nacionalismo, globalização e modernidade", Petrópolis: Vozes, 1999.

FRIESNER, MICHAEL L., “The adaptation of romanian loanwords from turkish and french", in: CAlabrese, Andrea \& Wetzels, W LeO (Eds.), "Loan phonology", volume 307, 115-129, Amsterdam/Philadelphia: John Benjamins Publishing, 2009.

GOBBO, FEDERICO, Adpositional Grammars. A multilingual grammar formalism for NLP., Tese de Doutoramento, Università degli Studi dell'insubria, Itália, 2009.

HANNERZ, UlF, Transnational connections: Culture, people, places, Londres/Nova Iorque: Routledge, 1996.

HERRING, JOSHUA, "Syntactic and lexical changes in esperanto: A quantitative and corpus-based survey", 2005.

URL http://cllt.osu.edu/mclc/paper/syntactic_herrring.pdf

IANNI, OCTAVIO, “Globalização: novo paradigma das ciências sociais", Estudos avançados, volume 8(21):147-163, 1994.

URL http://dx.doi.org/10.1590/S0103-40141994000200009

KAlocsay, KÁlmán \& WARINGHIEN, GASTON, Plena analiza gramatiko de Esperanto, Roterdã: Universala Esperanto-Asocio, 1985 (1935).

KANG, YOONJUNG, "Loanword phonology", The Blackwell companion to phonology, volume 4:1003-1026, 2011.

Kenstowicz, Michael \& Suchato, AtiWOng, "Issues in loanword adaptation: A case study from thai", Lingua, volume 116(7):921-949, 2006.

URL http://web.mit.edu/ linguistics/people/faculty/kenstowicz/ loanword_adaptation.pdf

KORĴENKOV, AleKSANDER, Homarano: La vivo, verkoj kaj ideoj de d-ro L. L. Zamenhof, Kaliningrado: Sezonoj, 2011.

LAROCA, MARIA NAZARÉ DE CARVALHO, O caráter verbo-nominal do aspecto em esperanto, Tese de Doutoramento, Instituto de Letras da Universidade Federal Fluminense, Niterói, 2009.

URL

http://www.bdtd.ndc.uff.br/tde_arquivos/23/

TDE-2009-10-01T114108Z-2234/Publico/TESE\%20Maria\%20Laroca.pdf 
LiNDSTEDT, JOUKO, “Kreoliĝo kaj spontanea ŝanĝiĝo de esperanto", Manuscript, University of Helsinki, 1997.

LINDSTEDT, JOUKO, "Native esperanto as a test case for natural language", SKY Journal of Linguistics, volume 19:47-55, 2006.

URL http://www.linguistics.fi/julkaisut/SKY2006_1/1FK60.1.5. LINDSTEDT .pdf

LINDSTEDT, JOUKO, "Esperanto as a family language", Linguas francas: La véhicularité linguistique pour vivre, travailler et étudier, 69-80, 2010.

MAdDIESON, IAN \& DiSNer, SANDRA FERRARI, Patterns of sounds, Cambridge: Cambridge university press, 1984.

MAZUR, DAN, Esperantistas: uma viagem em quadrinhos no mundo dos falantes nativos de esperanto, São Paulo: Associação Paulista de Esperanto, 2015.

Menezes, ManUele BANDeirA, A adaptação de empréstimos recentes no papiamentu moderno, Tese de Mestrado, Universidade de São Paulo, São Paulo, 2013.

MiNER, KEN, “Limigoj al esperanta elizio”, 2003.

URL http://www.sunflower.com/〜miner/LIMIGOJ_package/limigoj.html

NAGATA, HiRoshi, "Esperantaj parolsonoj perceptitaj de japanlingvanoj”, Scienca Revuo, volume 55(196):13-24, 2004.

URL https://scienca-revuo.info//article/view/867/846

NAgAtA, Hiroshi, "Perceptita simileco de parolsonoj de esperanto kaj aliaj kvar lingvoj ce japanlingvanoj", Scienca Revuo, volume 59(213):85-94, 2008.

URL https://scienca-revuo.info//article/view/518/497

Nevelsteen, Yves, Komputeko: prikomputila terminoteko, Partizánske: Espero, 2012.

OKhuijsen, Guido, A Comparison between English Loan Words in Dutch and their Esperanto Equivalents, Tese de Mestrado, Universiteit van Amsterdam, 2011.

URL http://dare.uva.nl/cgi/arno/show.cgi?fid=345847

OOSTENDORP, MARC VAN, "A note on exceptional syllable structure in esperanto", in: BRUYN, A \& ARENDS, JTG (Eds.), "Mengelwerk voor Muysken: voor Pieter C. Muysken bij zijn afscheid van de Universiteit van Amsterdam", 98-101, 
Amsterdam: Instituut voor Algemene Taalwetenschap, 1998.

URL http://www . vanoostendorp.nl/interlinguistiek/esse.html

OOSTENDORP, MARC VAN, "Syllable structure in esperanto as an instantiation of universal phonology", Esperantologio/Esperanto Studies, volume 1:52-80, 1999. URL http://www.cb.uu.se/esperanto/oostendorp.pdf

OOSTEndorp, MARC VAN, "Constructed language and linguistic theory", Association Belgique de Linguistique, 2000.

OOstendorp, MARC VAN, “Constructed languages”, Serious Science, 2016.

URL http: //serious-science.org/constructed-languages-6242

PARADIS, CAROLE, "Towards a theory of constraint violations", Mc Gill working papers in linguistics, volume 5(1):1-43, 1988.

PetTyn, ANDRZEJ, La Esperanto-fonetiko en praktiko: elektitaj parolsonoj kune kun praktikaj ekzercoj, Milanówek: edição do autor, 1994.

POKROVSKIJ, SERGIO, “Duonvokaloj kaj diftongoj”, Lingva Kritiko: Studoj kaj notoj pri la Internacia Lingvo, Esperantologio Interreta, 2014.

URL http://lingvakritiko.com/2014/01/21/duonvokaloj-kaj-diftongoj/

Prince, AlAN \& SMOLENSKY, PAUl, Optimality Theory: Constraint interaction in generative grammar, Oxford: Blackwell-Wiley, 1993.

Roth, WolfGANG, "O empréstimo como problema da lingüística comparada”, ALFA: Revista de Linguística, volume 24:157-177, 1980.

URL http://seer.fclar.unesp.br/alfa/article/view/3620/3389

SADLER, VICTOR, "Effect of succeeding vowel on consonant recognition in noise", Language and Speech, volume 4(2):133-138, 1961.

SEPPIK, HENRIK, La tuta Esperanto, Budapest: HEA, 1987.

URL http://www .esperanto.mv.ru/Seppik/lec01.html

SHERWOOD, BRUCE ARNe, "Variation in esperanto", Studies in the Linguistic Sciences, volume 12(1):183-196, 1982.

Smith, Anthony D., "Para uma cultura global?”, in: Featherstone, Mike (Ed.), "Cultura global nacionalismo, globalização e modernidade", 18-205, Petrópolis: Vozes, 1999. 
STRIA, IDA, Towards a linguistic worldview for artificial languages, Tese de Doutoramento, Uniwersytet im. Adam Mickiewicz, Polônia, 2016.

URL http: //hdl.handle.net/10593/14392

Sutton, GEOFFrey, Concise Encyclopedia of the Original Literature of Esperanto, 1887-2007, New York: Mondial, 2008.

TAMBOVTSEV, YURI, “Typological proximity of esperanto to the classical language taxa of the indo-european family", California Linguistic Notes(CLN), (33):1-44, 2008.

URL http://english.fullerton.edu/publications/clnArchives/pdf/ Tambovtsev-Esperanto.pdf

TiHomirov, Konstantin, “Slavaj lingvoj”, in: NoskovÁ, KATARínA \& BALÁž, PEter (Eds.), "Modernaj edukaj metodoj kaj teknologioj: aplikoj de esperanto en scienco kaj tekniko", 199-213, Modre: Espero, 2013.

TUCKer, Gerald, "ĉu turkoj povas lerni esperanton?", Scienca Revuo, volume 59(213):61-74, 2008.

URL https://scienca-revuo.info//article/view/516/495

C̆IŽIKAITÉ, AIDA, “La vokala sistemo de la litova lingvo kaj esperanto”, Scienca Revuo, volume 57(207):210-223, 2006.

URL https://scienca-revuo.info//article/view/1949/1928

VENDELIN, INGA \& PEPERKAMP, SHARON, "The influence of orthography on loanword adaptations", Lingua, volume 116(7):996-1007, 2006.

URL http: //www. Iscp.net/persons/peperkamp/Vendelin_Peperkamp_(2006) _The_influence_of_orthography_on_loanword_adaptations.pdf

VERSTEEGH, KEES, "Esperanto as a first language: language acquisition with a restricted input", Linguistics, volume 31(3):539-555, 1993.

VitAli, DANiEle, “La nazaloj de la internacia lingvo”, in: FiedLer, SABINE \& LiU, HAITAO (Eds.), “Festlibro omaĝe al la 60-jariĝo de Detlev Blanke/Festschrift für Detlev Blanke zum 60", 326-336, Prague, Czech Republic: Kava-Pech, 2001.

URL http://www .esperantic.org/dosieroj/file/22_Vitali.pdf

WELLS, JOHN, Lingvistikaj aspektoj de esperanto, Roterdã: Universala EsperantoAsocio, 1989. 
Wennergren, Bertilo, Plena Manlibro de Esperanta Gramatiko, Sacramento/California: Esperanto-Ligo por Norda Ameriko, 2005.

URL http: //bertilow.com/pmeg/

WÜSTER, E., “Die silbentrennung der wörter und lie aussprache des selbstlaute im esperanto", Germana Esperantisto, 1923.

ZAMENHOF, LEYZER LUDWIK, Unua Libro, Warsaw: edição do autor, 1887.

ZAMENHOF, LEYZER LUDWIK, Fundamento de Esperanto, Warsaw: edição do autor, 1905.

URL http: //www .akademio-de-esperanto.org/fundamento/

ZEC, DrAGA, “The syllable”, in: LACY, PAul DE (Ed.), “The Cambridge Handbook of Phonology", Cambridge: Cambridge University Press, 2007.

ZOUZALÍK, VÁClAV, "La novslava lingvo”, in: NOSKOVÁ, KATARÍNA \& BALÁŽ, PETER (Eds.), "Modernaj edukaj metodoj kaj teknologioj: aplikoj de esperanto en scienco kaj tekniko", 229-232, Modre: Espero, 2013. 


\section{Corpus}

A descrição detalhada sobre a seleção para as palavras deste corpus se encontra na seção 4.2 .

$\mathrm{Na}$ primeira coluna se encontram as palavras em esperanto, seguidas pela palavra da qual foram adaptadas, seu significado em português e, por último, a informação de onde a palavra foi coletada.

O termo "revistas" indica que o vocábulo foi retirado da lista de palavras feita a partir dos arquivos das revistas Kontakto e Esperanto. "Komputeko" remete à lista terminológica sobre computação, e "vortaro-blogo" ao blog${ }^{1}$ do professor emétiro John C. Wells, da University College London.

Os itens estão listados em ordem alfabética (assim como as línguas). As palavras de 01 a 04 são provenientes do árabe; 05 e 06 do chinês; 07 do coreano; 08 e 09 do espanhol; 10 do francês; de 11 a 47 do inglês; 48 a 57 do japonês; 58 do komi; 59 a 61 do português; 62 do russo; 63 e 64 do turco; 65 do sânscrito; 66 do suaíli.

Algumas palavas não tiveram sua origem identificada (itens 67 a 72).

Por último, estão listados os nomes de lugares, línguas, povos e de um asteroide, por ordem alfabética, mas sem separação por línguas, pois essas palavras não foram detalhadamente analisadas, como explicado na seção 4.2.

\section{Palavras provenientes do ÁRABE}

1.

\begin{tabular}{|l|l|l|l|}
\hline Palavra & Etimologia & Significado & Fonte \\
\hline $\begin{array}{l}\text { divano } \\
{[\text { di'vano }]}\end{array}$ & $\begin{array}{l}<\text { diwân } \\
{[\text { dir'wa:n }]}\end{array}$ & divã & revistas \\
\hline
\end{tabular}

2.

\begin{tabular}{|l|l|l|l|}
\hline Palavra & Etimologia & Significado & Fonte \\
\hline falaflo & $<$ filfil (substantivo) & falafel, bolinho & revistas \\
[fa'laflo] & / falfala (verbo) & feito de grão-de- & \\
& [fa'lasfil $]$ & bico & \\
\hline
\end{tabular}

3.

\begin{tabular}{|c|c|c|c|}
\hline Palavra & Etimologia & Significado & Fonte \\
\hline $\begin{array}{l}\text { gihado } \\
{\left[\widehat{d}_{3} i^{\prime} h a d o\right]}\end{array}$ & $\begin{array}{l}<j i h a ̂ d \\
{\left[\mathrm{~d}_{3} i^{\prime} h a: d\right]}\end{array}$ & $\begin{array}{l}\text { jihad, conceito da } \\
\text { religião islâmica }\end{array}$ & revistas \\
\hline
\end{tabular}

\footnotetext{
${ }^{1}<$ http://vortaro-blogo.blogspot.com.br/2009/09/nepivaj-vortoj-i.html>.
} 


\begin{tabular}{|c|c|c|c|}
\hline Palavra & Etimologia & Significado & Fonte \\
\hline $\begin{array}{l}\text { talibano } \\
\text { [tali'bano] }\end{array}$ & $\begin{array}{l}<\text { talibã (tâlib, do } \\
\text { árabe, que quer di- } \\
\text { zer estudante }+ \\
\tilde{a}, \text { marca de plural } \\
\text { do urdu) } \\
{\left[\text { 't }{ }^{\text {arlib }]+}+\text { [ã:] }\right.} \\
\text { (árabe) } \\
\text { [ta:li'bã:] (urdu) }\end{array}$ & $\begin{array}{l}\text { talibã, movimento } \\
\text { fundamentalista is- } \\
\text { lâmico }\end{array}$ & revistas \\
\hline
\end{tabular}

\section{Palavras provenientes do CHINÊS}

\begin{tabular}{|c|c|c|c|}
\hline Palavra & Etimologia & Significado & Fonte \\
\hline  & $\begin{array}{l}<\text { tàijíquán } \\
{\left[\mathrm{t}^{\mathrm{h}} \text { ajtcitc }^{\mathrm{h}} \mathrm{wan}\right]}\end{array}$ & $\begin{array}{l}\text { tai chi chuan, arte } \\
\text { marcial }\end{array}$ & revistas \\
\hline
\end{tabular}

\begin{tabular}{|c|c|c|c|}
\hline Palavra & Etimologia & Significado & Fonte \\
\hline $\begin{array}{l}\text { vejĉio (sinônimo } \\
\text { de } g o o, \text { palavra de } \\
\text { origem japonesa) } \\
\text { [vej'tfio] }\end{array}$ & $\begin{array}{l}<\text { wéiqí } \\
{\left[\text { wejtc }^{\mathrm{h}} \mathrm{i}\right]}\end{array}$ & $\begin{array}{l}\text { goo, jogo de tabu- } \\
\text { leiro }\end{array}$ & revistas \\
\hline
\end{tabular}

\section{Palavra proveniente do COREANO}

\begin{tabular}{|l|l|l|l|}
\hline 7. Palavra & Etimologia & Significado & Fonte \\
\hline $\begin{array}{l}\text { úonbulismo } \\
\text { [wonbu'lismo }]\end{array}$ & $\begin{array}{l}<\text { Wŏn Buddhism } \\
{[\text { wınbul }(\text { gjo })]}\end{array}$ & $\begin{array}{l}\text { Wŏn Buddhism, re- } \\
\text { ligião coreana }\end{array}$ & revistas \\
\hline
\end{tabular}

\section{Palavras provenientes do ESPANHOL}

8.

\begin{tabular}{|c|c|c|c|}
\hline Palavra & Etimologia & Significado & Fonte \\
\hline $\begin{array}{l}\text { ĉaĉao } \\
{[\overbrace{\left.\mathrm{t} \int \mathrm{a}^{\prime} \mathrm{t} \int \mathrm{ao}\right]}}\end{array}$ & $\begin{array}{l}<\operatorname{cha}-\operatorname{cha} \text {-cha } \\
{\left[\overparen{\left.\mathrm{t} \int \mathrm{at} \int \mathrm{a} \int \mathrm{t} \int \mathrm{a}\right]}\right.}\end{array}$ & $\begin{array}{l}\text { chá-chá-chá, ritmo } \\
\text { musical }\end{array}$ & $\begin{array}{l}\text { vortaro- } \\
\text { blogo }\end{array}$ \\
\hline
\end{tabular}


9.

\begin{tabular}{|l|l|l|l|}
\hline Palavra & Etimologia & Significado & Fonte \\
\hline $\begin{array}{l}\text { Salso } \\
\text { ['salso] }\end{array}$ & $\begin{array}{l}<\text { Salsa } \\
{[\text { 'salsa }]}\end{array}$ & $\begin{array}{l}\text { Salsa, ritmo musi- } \\
\text { cal }\end{array}$ & revistas \\
\hline
\end{tabular}

\section{Palavra proveniente do FRANCÊS}

10.

\begin{tabular}{|l|l|l|l|}
\hline Palavra & Etimologia & Significado & Fonte \\
\hline $\begin{array}{l}\text { suveniro } \\
\text { [suve'niro }]\end{array}$ & $\begin{array}{l}\text { < souvenir } \\
{[\text { suv'nir }]}\end{array}$ & $\begin{array}{l}\text { suvenir, objeto que } \\
\text { serve como lem- } \\
\text { brança de algo }\end{array}$ & revistas \\
\hline
\end{tabular}

\section{Palavras provenientes do INGLÊS}

\begin{tabular}{|l|l|l|l|}
\hline Palavra & Etimologia & Significado & Fonte \\
\hline $\begin{array}{l}\text { androjdo } \\
{[\text { an'drojdo }]} \\
\text { androido } \\
{[\text { andro'ido }]}\end{array}$ & $\begin{array}{l}<\text { android } \\
{[' æ n d r o j d]}\end{array}$ & $\begin{array}{l}\text { android, tipo de } \\
\text { sistema operacio- } \\
\text { nal }\end{array}$ & \\
\hline
\end{tabular}

12.

\begin{tabular}{|l|l|l|l|}
\hline Palavra & Etimologia & Significado & Fonte \\
\hline $\begin{array}{l}\text { animacio } \\
{[\text { anima'țio }]}\end{array}$ & $\begin{array}{l}\text { <animation } \\
{[æ n \text { 'mej]ən }]}\end{array}$ & $\begin{array}{l}\text { animação (sequên- } \\
\text { cia de vídeo ani- } \\
\text { mada) }\end{array}$ & revistas \\
\hline
\end{tabular}

\begin{tabular}{|c|c|c|c|}
\hline Palavra & Etimologia & Significado & Fonte \\
\hline $\begin{array}{l}\text { askio } \\
\text { [as'kio] }\end{array}$ & $\begin{array}{l}<A S C I I \\
{[\text { 'æski] }}\end{array}$ & $\begin{array}{l}\text { ASCII, abreviação } \\
\text { de American Stan- } \\
\text { dard Code for Infor- } \\
\text { mation Interchange }\end{array}$ & Komputeko \\
\hline
\end{tabular}

Esta palavra (askio) está dicionarizada, mas só nos atentamos para isso após a formação do corpus e escrita da análise. Por isso, ela foi aqui mantida para não prejudicar a estruturação enumerativa já feita anteriormente. 
14.

\begin{tabular}{|l|l|l|l|}
\hline Palavra & Etimologia & Significado & Fonte \\
\hline asembli & $<$ assemble & traduzir para uma & Komputeko \\
[a'sembli $]$ & lóngua de progra- & \\
& & $\begin{array}{l}\text { mação, com símbo- } \\
\text { los e nomes especí- } \\
\end{array}$ & \\
& & ficos da língua & \\
\hline
\end{tabular}

15.

\begin{tabular}{|l|l|l|l|}
\hline Palavra & Etimologia & Significado & Fonte \\
\hline $\begin{array}{l}\text { bajto } \\
\text { ['bajto] }\end{array}$ & $\begin{array}{l}<\text { byte } \\
{[\text { 'bajt] }}\end{array}$ & conjunto de 8 bits & Komputeko \\
\hline
\end{tabular}

\begin{tabular}{|c|c|c|c|}
\hline Palavra & Etimologia & Significado & Fonte \\
\hline $\begin{array}{l}\text { bito } \\
\text { ['bito] }\end{array}$ & $\begin{array}{l}<\text { bit } \\
\text { ['bit] }\end{array}$ & $\begin{array}{l}\text { bit, unidade fun- } \\
\text { damental de infor- } \\
\text { mação que um sis- } \\
\text { tema digital pode } \\
\text { armazenar }\end{array}$ & Komputeko \\
\hline
\end{tabular}

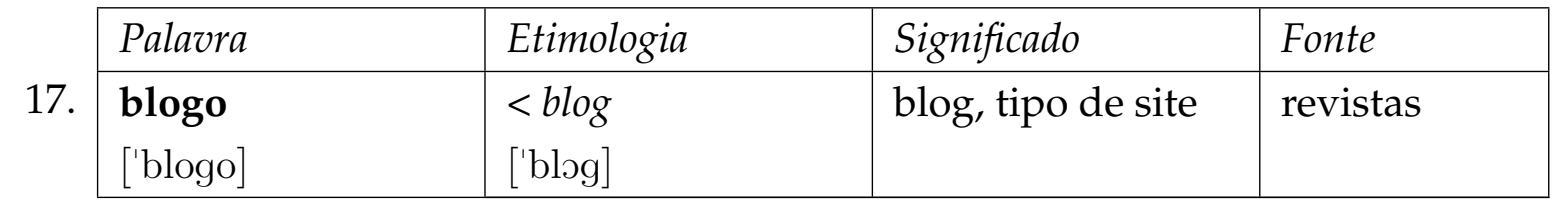

\begin{tabular}{|l|l|l|l|}
\hline Palavra & Etimologia & Significado & Fonte \\
\hline $\begin{array}{l}\text { ciberspaco } \\
{\left[\begin{array}{l}\text { tsiberspatso] } \\
\text { kiberspaco } \\
{[\text { kiberspatso] }}\end{array}\right.}\end{array}$ & <cyberspace & espaço virtual & Komputeko \\
\hline
\end{tabular}

\begin{tabular}{|l|l|l|l|}
\hline Palavra & Etimologia & Significado & Fonte \\
\cline { 2 - 3 } & $\begin{array}{l}<\text { design } \\
\text { [di'zajno }]\end{array}$ & $\begin{array}{l}\text { design, concepção } \\
\text { de produtos }\end{array}$ & Komputeko \\
\hline
\end{tabular}

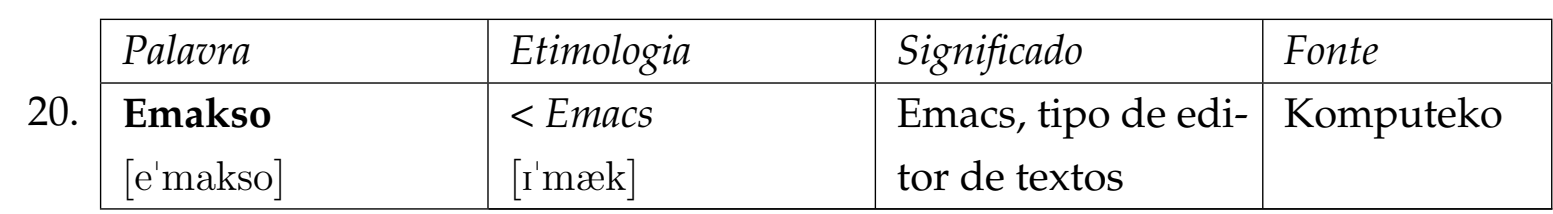

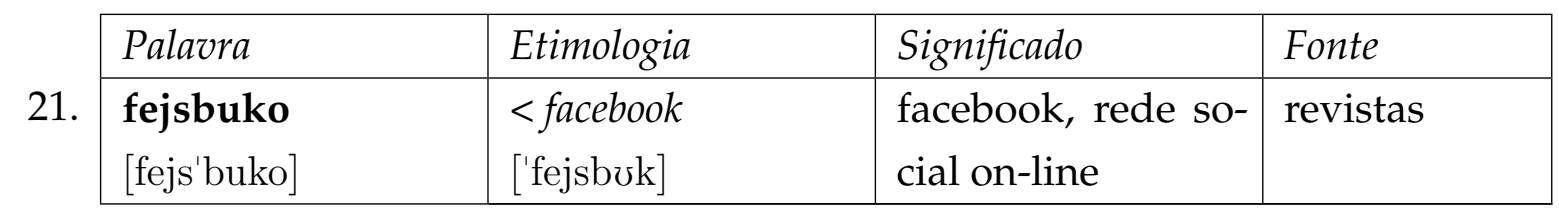




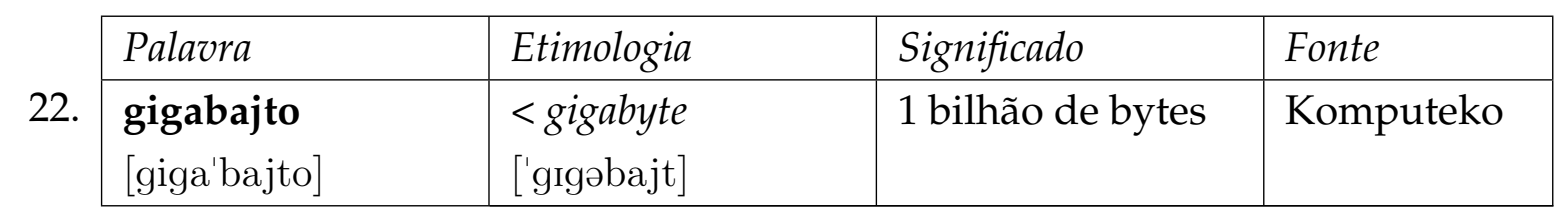

\begin{tabular}{|c|c|c|c|}
\hline Palavra & Etimologia & Significado & Fonte \\
\hline $\begin{array}{l}\text { giko } \\
\text { ['giko] }\end{array}$ & $\begin{array}{l}<\text { geek } \\
{[\text { girk }]}\end{array}$ & $\begin{array}{l}\text { geek, pessoas que } \\
\text { têm um interesse } \\
\text { especial em tecno- } \\
\text { logia, história em } \\
\text { quadrinhos, jogos } \\
\text { de tabuleiro e ele- } \\
\text { trônicos, etc. }\end{array}$ & revistas \\
\hline
\end{tabular}

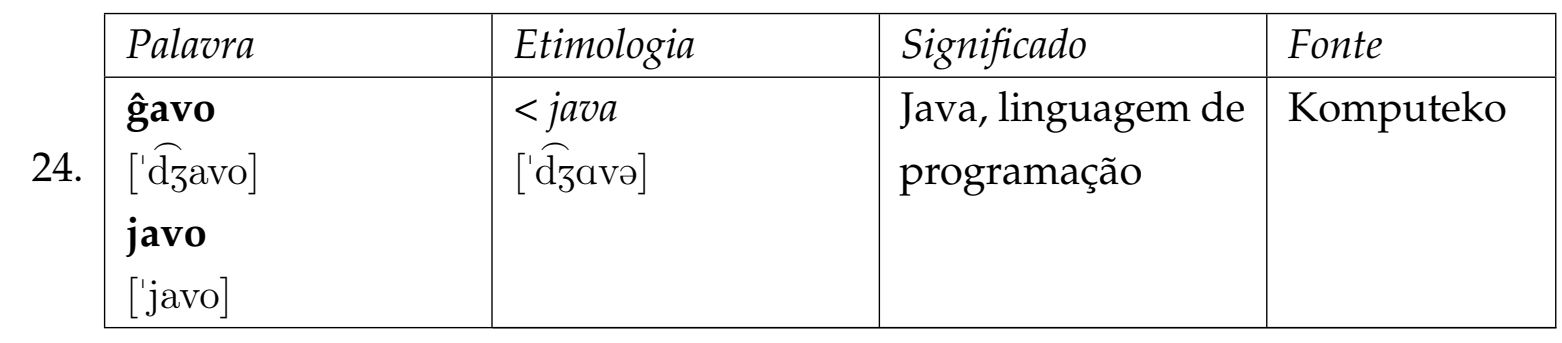

\begin{tabular}{|l|l|l|l|}
\hline Palavra & Etimologia & Significado & Fonte \\
\cline { 2 - 3 } & $\begin{array}{l}<\text { halloween } \\
{[\text { hæləow'inn }]}\end{array}$ & $\begin{array}{l}\text { halloween, festa tí- } \\
\text { pica do dia das bru- } \\
\text { xas }\end{array}$ & revistas \\
\hline
\end{tabular}



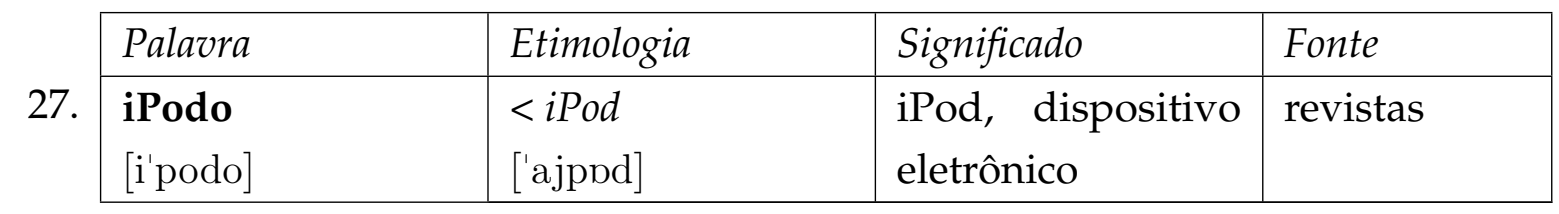




\begin{tabular}{|l|l|l|l|}
\hline Palavra & Etimologia & Significado & Fonte \\
\hline kibernetiko & <cybernetics & cibernética, "es- & Komputeko \\
[kiberne'tiko $]$ & tudbə'netrks $]$ & $\begin{array}{l}\text { de comunicação } \\
\text { e controle nas }\end{array}$ & \\
& & $\begin{array}{l}\text { eáquinas e nos } \\
\text { seres vivos"2 }\end{array}$ & \\
\hline
\end{tabular}

\begin{tabular}{|c|c|c|c|c|}
\hline & Palavra & Etimologia & Significado & Fonte \\
\hline 29. & $\begin{array}{l}\text { kilobito } \\
\text { [kilo'bito] }\end{array}$ & $\begin{array}{l}<\text { kilobit } \\
\text { ['kıləbit] }\end{array}$ & kilobit, mil bytes & Komputeko \\
\hline
\end{tabular}

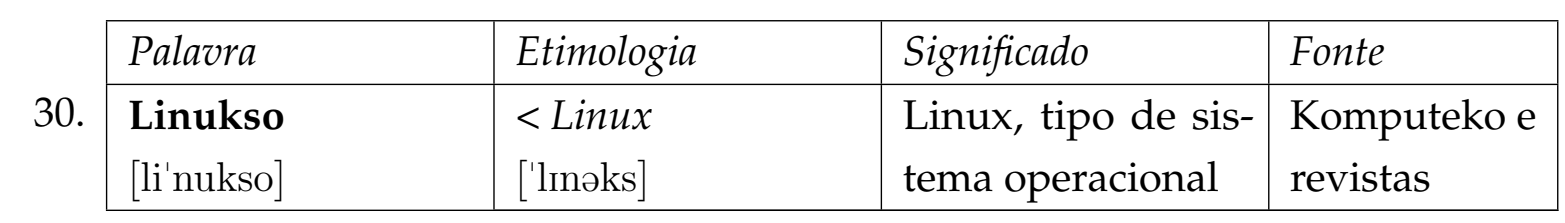

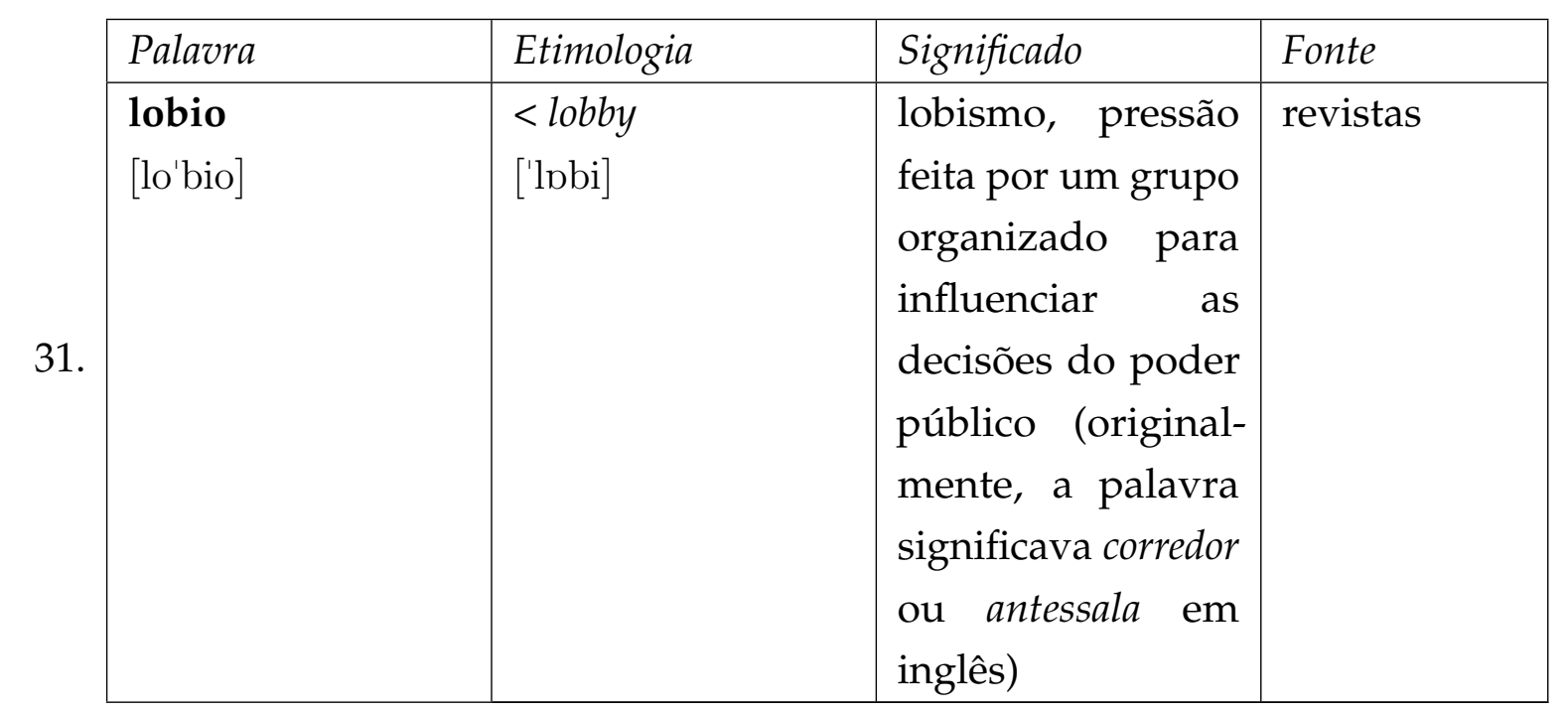

\begin{tabular}{|c|c|c|c|c|}
\hline & Palavra & Etimologia & Significado & Fonte \\
\hline 32. & $\begin{array}{l}\text { Makintoŝo } \\
{[\text { makin'tofo] }}\end{array}$ & $\begin{array}{l}<\text { Macintosh } \\
{[\text { 'mækintof] }}\end{array}$ & $\begin{array}{l}\text { Macintosh, tipo de } \\
\text { computador }\end{array}$ & Komputeko \\
\hline
\end{tabular}

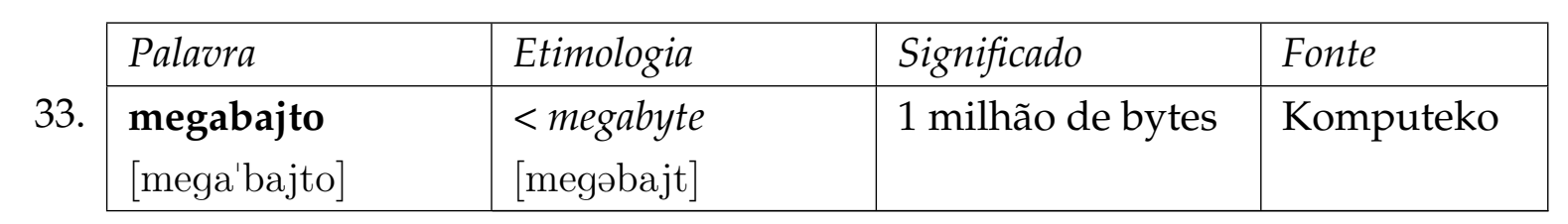

\begin{tabular}{|l|l|l|l|}
\hline Palavra & Etimologia & Significado & Fonte \\
\cline { 2 - 2 } & $\begin{array}{l}<o k \\
{[\text { ow'kej] }}\end{array}$ & $\begin{array}{l}\text { advérbio, que sig- } \\
\text { nifica “tudo bem" }\end{array}$ & revistas \\
\hline ['okej] & & \\
\hline
\end{tabular}




\begin{tabular}{|l|l|l|l|}
\hline Palavra & Etimologia & Significado & Fonte \\
\hline $\begin{array}{l}\text { rumio } \\
{[\text { ru'mio }]}\end{array}$ & $\begin{array}{l}<\text { rummy } \\
{[' \mathrm{r} \ni \mathrm{mI}] \text { ou }} \\
{[' \mathrm{\prime} \Lambda \mathrm{mI}]}\end{array}$ & jogo de cartas & revistas \\
\hline
\end{tabular}

\begin{tabular}{|l|l|l|l|}
\hline Palavra & Etimologia & Significado & Fonte \\
\hline Skajpo & $<$ Skype & Skype, software & revistas \\
que permite comu- & \\
['skajpo] & ['skajp] & $\begin{array}{l}\text { nicação on-line por } \\
\text { voz e vídeo }\end{array}$ & \\
\hline
\end{tabular}

\begin{tabular}{|l|l|l|l|}
\hline 37. & Etimologia & Significado & Fonte \\
\hline $\begin{array}{l}\text { skrablo } \\
{[\text { 'skrablo] }}\end{array}$ & $\begin{array}{l}<\text { scrabble } \\
{[\text { 'skræbl] }}\end{array}$ & palavras cruzadas & revistas \\
\hline
\end{tabular}

\begin{tabular}{|c|c|c|c|c|}
\hline & Palavra & Etimologia & Significado & Fonte \\
\hline 38. & $\begin{array}{l}\text { skiflo } \\
\text { ['skiflo] }\end{array}$ & $\begin{array}{l}<\text { skiffle } \\
\left.\text { ['skif }{ }^{\ominus} l\right]\end{array}$ & ritmo musical & revistas \\
\hline
\end{tabular}

\begin{tabular}{|c|c|c|c|c|}
\hline & Palavra & Etimologia & Significado & Fonte \\
\hline 39. & $\begin{array}{l}\text { splajno } \\
\text { ['splajno] }\end{array}$ & $\begin{array}{l}<\text { spline } \\
\text { [splajn] }\end{array}$ & função matemática & Komputeko \\
\hline
\end{tabular}

\begin{tabular}{|l|l|l|l|}
\hline Palavra & Etimologia & Significado & Fonte \\
\hline $\begin{array}{l}\text { terabajto } \\
{[\text { tera'bajto }]}\end{array}$ & $\begin{array}{l}<\text { terabyte } \\
{[\text { terəbajt }]}\end{array}$ & 1 trilhão de bytes & Komputeko \\
\hline
\end{tabular}

\begin{tabular}{|c|c|c|c|c|}
\hline & Palavra & Etimologia & Significado & Fonte \\
\hline 41. & $\begin{array}{l}\text { tezaŭro } \\
\text { te'zawro] }\end{array}$ & $\begin{array}{l}<\text { thesaurus } \\
\text { [өr'so:rəs] }\end{array}$ & $\begin{array}{l}\text { tesauro, tipo de di- } \\
\text { cionário }\end{array}$ & Komputeko \\
\hline
\end{tabular}

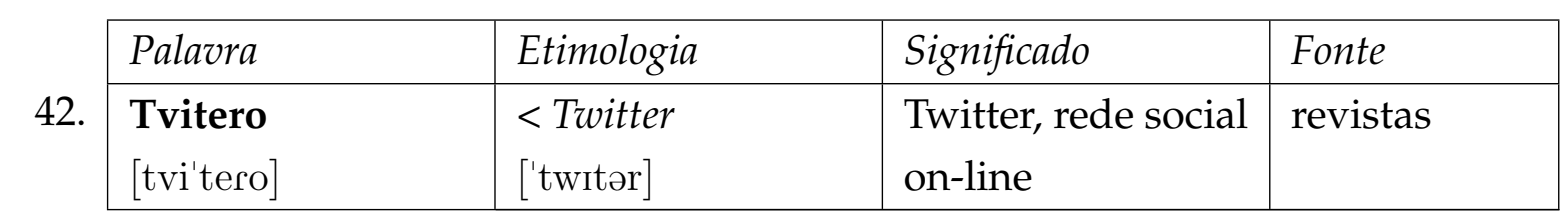

\begin{tabular}{|l|l|l|l|}
\hline Palavra & Etimologia & Significado & Fonte \\
\hline $\begin{array}{l}\text { Unikso } \\
\text { [u'nikso] }\end{array}$ & $\begin{array}{l}<\text { Unix } \\
\text { [ju:niks }]\end{array}$ & $\begin{array}{l}\text { Unix, sistema de } \\
\text { operação computa- } \\
\text { cional }\end{array}$ & Komputeko \\
\hline
\end{tabular}




\begin{tabular}{|c|c|c|c|c|}
\hline \multirow[b]{2}{*}{44.} & Palavra & Etimologia & Significado & Fonte \\
\hline & $\begin{array}{l}\text { Vacapo } \\
{[\text { va'tsapo] }}\end{array}$ & $\begin{array}{l}<\text { WhatsApp } \\
\text { ['wotsæp] }\end{array}$ & $\begin{array}{l}\text { WhatsApp, aplica- } \\
\text { tivo de mensagens } \\
\text { instantâneas }\end{array}$ & \\
\hline \multirow[b]{2}{*}{45} & Palavra & Etimologia & Significado & Fonte \\
\hline & $\begin{array}{l}\text { vifio } \\
\text { [vi'fio] }\end{array}$ & $\begin{array}{l}<w i-f i \\
\text { ['wajfaj] }\end{array}$ & $\begin{array}{l}\text { wi-fi, dispositivo } \\
\text { de rede de internet } \\
\text { local sem fio }\end{array}$ & \\
\hline \multirow[b]{2}{*}{46.} & Palavra & Etimologia & Significado & Fonte \\
\hline & $\begin{array}{l}\text { Vikipedio } \\
\text { [vikipe'dio] }\end{array}$ & $\begin{array}{l}<\text { Wikipedia } \\
\text { [wrki'pi:diə] }\end{array}$ & $\begin{array}{l}\text { Wikipedia, enciclo- } \\
\text { pédia on-line }\end{array}$ & revistas \\
\hline \multirow[b]{2}{*}{47.} & Palavra & Etimologia & Significado & Fonte \\
\hline & $\begin{array}{l}\text { Vindozo } \\
\text { [vin'dozo] }\end{array}$ & $\begin{array}{l}<\text { Windows } \\
\text { [windəwz] }\end{array}$ & $\begin{array}{l}\text { Windows, tipo de } \\
\text { sistema operacio- } \\
\text { nal }\end{array}$ & $\begin{array}{l}\text { Komputeko, } \\
\text { revistas }\end{array}$ \\
\hline
\end{tabular}

\section{Palavras provenientes do JAPONÊS}

\begin{tabular}{|l|l|l|l|}
\hline Palavra & Etimologia & Significado & Fonte \\
\hline anko & $<$ anko & pasta doce, feita de \\
fayko $]$ & $\begin{array}{l}\text { reijão, para recheio } \\
\text { de doces tradicio- } \\
\text { nais }\end{array}$ & \\
\hline
\end{tabular}

\begin{tabular}{|l|l|l|l|}
\hline Palavra & Etimologia & Significado & Fonte \\
\hline hibakuŝo & $<$ hibakusha & pessoa que sobre- & revistas \\
[hiba'kufo] & [çibakuca $]$ & $\begin{array}{l}\text { vivo ataques } \\
\text { de bomba atômica } \\
\text { que o Japão sofreu } \\
\text { em 1945 }\end{array}$ & \\
& & & \\
\hline
\end{tabular}




\begin{tabular}{|l|l|l|l|}
\hline Palavra & Etimologia & Significado & Fonte \\
\hline karaoko & $<$ karaoke & karaokê, ação ca- & revistas \\
[kara'oko $]$ & racterística por can- & \\
karaokeo & tar uma música en- & \\
{$[$ karao'keo $]$} & & $\begin{array}{l}\text { quanto se olha a le- } \\
\text { tra dela em uma } \\
\text { tela }\end{array}$ & \\
& & & \\
\hline
\end{tabular}

51.

\begin{tabular}{|l|l|l|l|}
\hline Palavra & Etimologia & Significado & Fonte \\
\hline $\begin{array}{l}\text { mangao } \\
\text { [man'gao }]\end{array}$ & $\begin{array}{l}<\text { manga } \\
\text { [manga }]\end{array}$ & $\begin{array}{l}\text { mangá, história em } \\
\text { quadrinhos com es- } \\
\text { tilo japonês }\end{array}$ & revistas \\
\hline
\end{tabular}

52.

\begin{tabular}{|l|l|l|l|}
\hline Palavra & Etimologia & Significado & Fonte \\
\hline $\begin{array}{l}\text { origamio } \\
\text { [origa'mio] }\end{array}$ & $\begin{array}{l}<\text { origami } \\
{[\text { origami }]}\end{array}$ & $\begin{array}{l}\text { origâmi, arte japo- } \\
\text { nesa de dobradura } \\
\text { de papel }\end{array}$ & revistas \\
\hline
\end{tabular}

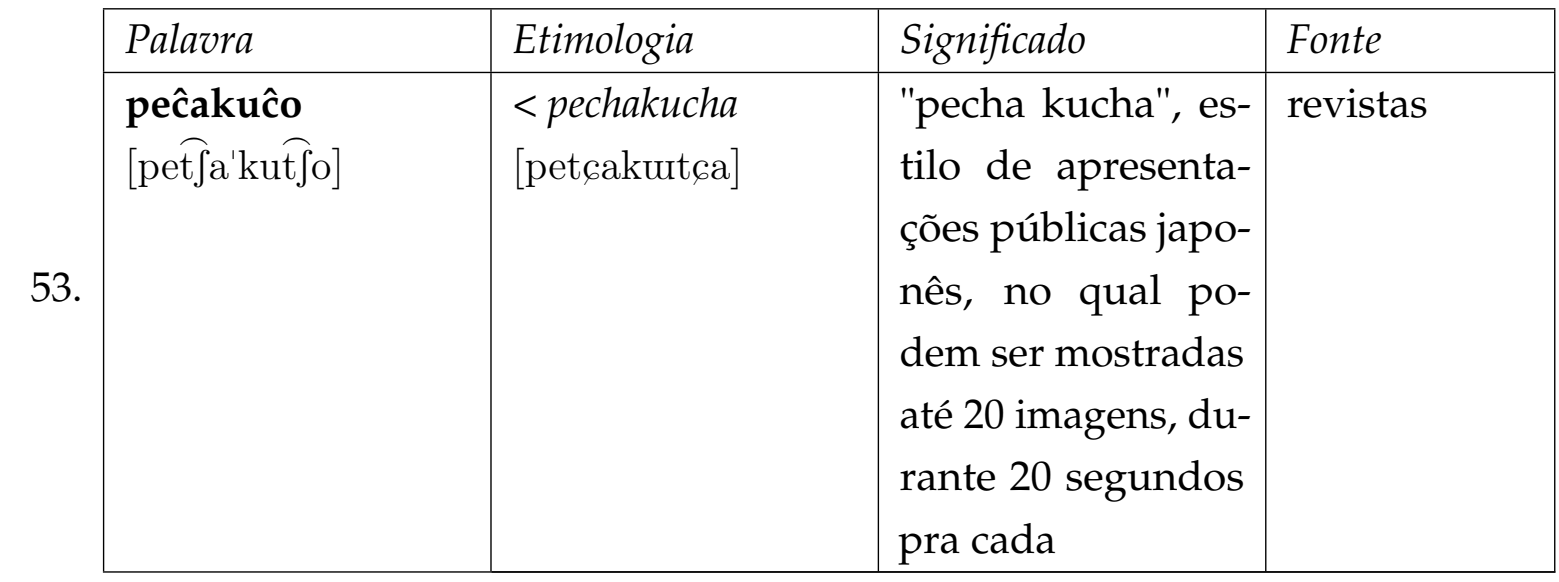

\begin{tabular}{|l|l|l|l|}
\hline Palavra & Etimologia & Significado & Fonte \\
\hline sudoko & $<$ suudoku & sudoku, quebra- & revistas \\
[su'doko $]$ & cabeça de origem & \\
& & japonesa, baseado & \\
& & em pensamento & \\
& & lógico numérico & \\
\hline
\end{tabular}

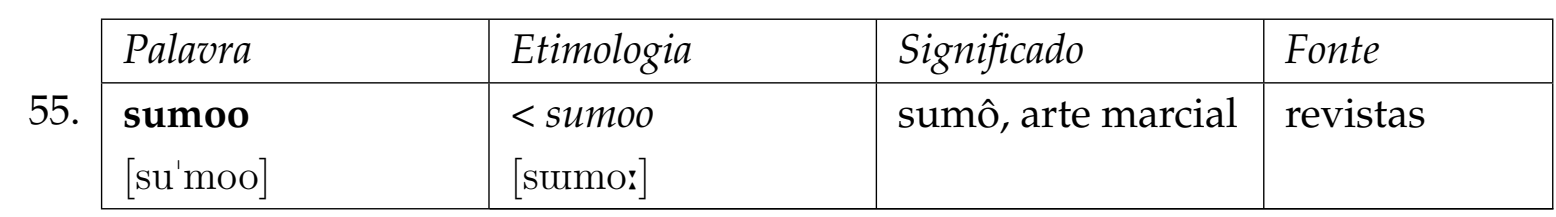




\begin{tabular}{|c|c|c|c|c|}
\hline \multirow[b]{2}{*}{56.} & Palavra & Etimologia & Significado & Fonte \\
\hline & $\begin{array}{l}\text { ŝogio } \\
{[\text { [o'gio] }}\end{array}$ & $\begin{array}{l}<\text { shoogi } \\
{[60: 9 i]}\end{array}$ & $\begin{array}{l}\text { shôgui, jogo de } \\
\text { tabuleiro, seme- } \\
\text { lhante ao xadrez }\end{array}$ & revistas \\
\hline \multirow[b]{2}{*}{57.} & Palavra & Etimologia & Significado & Fonte \\
\hline & $\begin{array}{l}\text { tofuo } \\
\text { [to'fuo] }\end{array}$ & $\begin{array}{l}<\text { tōfu } \\
{[\operatorname{to:} \phi u]}\end{array}$ & $\begin{array}{l}\text { tofu, alimento feito } \\
\text { de soja }\end{array}$ & revistas \\
\hline
\end{tabular}

\section{Palavra proveniente do KOMI}

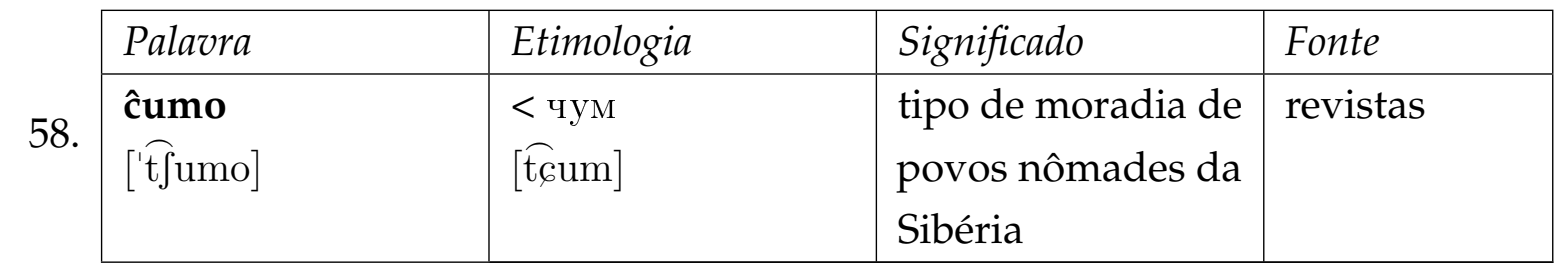

\section{Palavras provenientes do PORTUGUÊS}

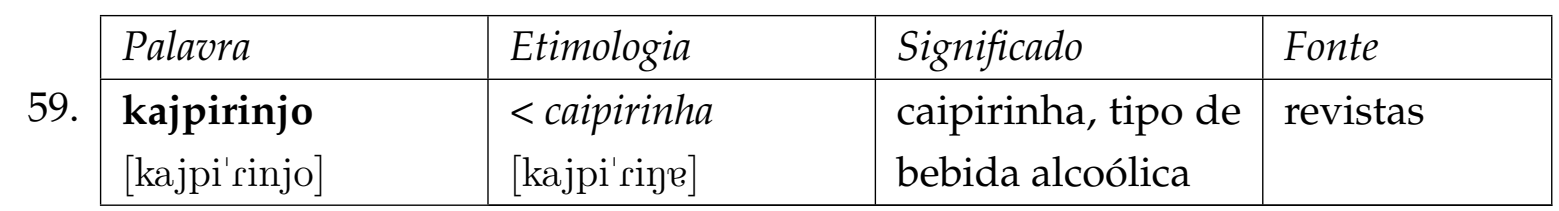

\begin{tabular}{|c|c|c|c|c|}
\hline & Palavra & Etimologia & Significado & Fonte \\
\hline 60. & $\begin{array}{l}\text { kaŝaso } \\
{\left[\mathrm{ka}^{\prime} \text { [aso }\right]}\end{array}$ & $\begin{array}{l}<\text { cachaça } \\
\text { [ka' 'ase] }\end{array}$ & $\begin{array}{l}\text { cachaça, tipo de be- } \\
\text { bida alcoólica }\end{array}$ & revistas \\
\hline
\end{tabular}

\begin{tabular}{|l|l|l|l|}
\hline Palavra & Etimologia & Significado & Fonte \\
\hline $\begin{array}{l}\text { pandero } \\
{[\text { pan'dero }]}\end{array}$ & $\begin{array}{l}<\text { pandeiro } \\
{[\text { pẽn'derv }]}\end{array}$ & $\begin{array}{l}\text { pandeiro, instru- } \\
\text { mento musical }\end{array}$ & revistas \\
\hline
\end{tabular}

\section{Palavra proveniente do RUSSO}




Palavras provenientes do TURCO

63.

\begin{tabular}{|l|l|l|l|}
\hline Palavra & Etimologia & Significado & Fonte \\
\hline $\begin{array}{l}\text { buzuko } \\
\text { [bu'zuko }]\end{array}$ & $\begin{array}{l}<\text { buzuk } \\
{[\text { bu'zuk }]}\end{array}$ & $\begin{array}{l}\text { bouzouki, instru- } \\
\text { mento musical } \\
\text { grego }\end{array}$ & \\
\hline
\end{tabular}

\begin{tabular}{|l|l|l|l|}
\hline Palavra & Etimologia & Significado & Fonte \\
\hline orkuto & $<$ orkut & orkut, rede social & revistas \\
[or'kuto] & on-line, que esteje & \\
& & ativa entre 2004 e & \\
& & 2014 (a palavra é & \\
& & uma adaptação do & \\
& & nome do criador \\
do site, de naciona- & \\
& & lidade turca, Orkut & \\
& & Büyükkökten) & \\
\hline
\end{tabular}

\section{Palavra proveniente do SÂNSCRITO}

65.

\begin{tabular}{|l|l|l|l|}
\hline Palavra & Etimologia & Significado & Fonte \\
\hline $\begin{array}{l}\text { varno } \\
\text { ['varno] }\end{array}$ & $\begin{array}{l}<\text { varna } \\
{[\text { 'varne] }}\end{array}$ & $\begin{array}{l}\text { sistema de castas } \\
\text { do hinduísmo }\end{array}$ & revistas \\
\hline
\end{tabular}

\section{Palavra proveniente do SUAÍLI}

66.

\begin{tabular}{|l|l|l|l|}
\hline Palavra & Etimologia & Significado & Fonte \\
\hline $\begin{array}{l}\text { tabasami } \\
\text { taba'sami }]\end{array}$ & $\begin{array}{l}<\text { tabasamu } \\
{[\text { taba'samu }]}\end{array}$ & sorrir & revistas \\
\hline
\end{tabular}

\section{Origem não identificada}

\begin{tabular}{|l|l|l|l|l|}
\hline 67. & Palavra & Etimologia & Significado & Fonte \\
\hline $\begin{array}{l}\text { bingo } \\
{[\text { 'bingo }]}\end{array}$ & $<?$ & bingo & revistas \\
\hline
\end{tabular}




\begin{tabular}{|l|l|l|l|l|}
\hline 68. & Palavra & Etimologia & Significado & Fonte \\
\hline $\begin{array}{l}\text { bonuso } \\
\text { [bo'nuso }]\end{array}$ & $<?$ & bônus & revistas \\
\hline
\end{tabular}

\begin{tabular}{|l|l|l|l|}
\hline Palavra & Etimologia & Significado & Fonte \\
\hline celiakio & $<?$ & $\begin{array}{l}\text { celíaco, pessoa } \\
\text { que tem intolerân- } \\
\text { cia alimentícia a } \\
\text { [tselia'kio] }\end{array}$ & revistas \\
& & glúten & \\
\hline
\end{tabular}

\begin{tabular}{|l|l|l|l|}
\hline 70. & Etimologia & Significado & Fonte \\
\cline { 2 - 5 } & $\begin{array}{l}\text { gaigo } \\
\text { ['dzigo }]\end{array}$ & tipo de dança & revistas \\
\hline
\end{tabular}

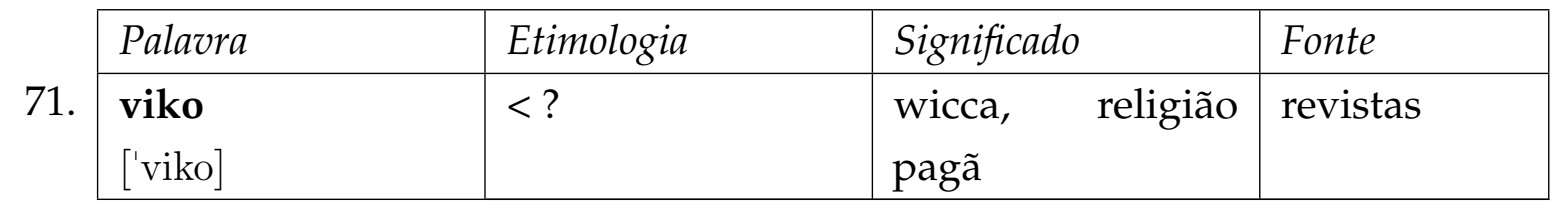

\begin{tabular}{|l|l|l|l|}
\hline Palavra & Etimologia & Significado & Fonte \\
\cline { 2 - 4 } & $\begin{array}{l}\text { voduo (varia com } \\
\text { vuduo) } \\
\text { [vo'duo }]\end{array}$ & religião africana & revistas \\
\hline
\end{tabular}




\section{Topônimos ${ }^{3}$, etnônimos ${ }^{4}$ e outros}

Nomes de lugares, línguas, povos e asteroide

73.

\begin{tabular}{|l|l|l|l|}
\hline Palavra & Etimologia & Significado & Fonte \\
\hline $\begin{array}{l}\text { Abhazio } \\
\text { [abha'zio] }\end{array}$ & $<$ Abkhaziya & $\begin{array}{l}\text { República da Abe- } \\
\text { cásia, território per- } \\
\text { tencente à Geórgia }\end{array}$ & revistas \\
\hline
\end{tabular}

74.

\begin{tabular}{|l|l|l|l|}
\hline Palavra & Etimologia & Significado & Fonte \\
\hline $\begin{array}{l}\text { Aluŝto } \\
\text { [a'lufto] }\end{array}$ & < Алу́шта & $\begin{array}{l}\text { Alushta, cidade na } \\
\text { região da Crimeia, } \\
\text { na Ucrânia }\end{array}$ & revistas \\
\hline
\end{tabular}

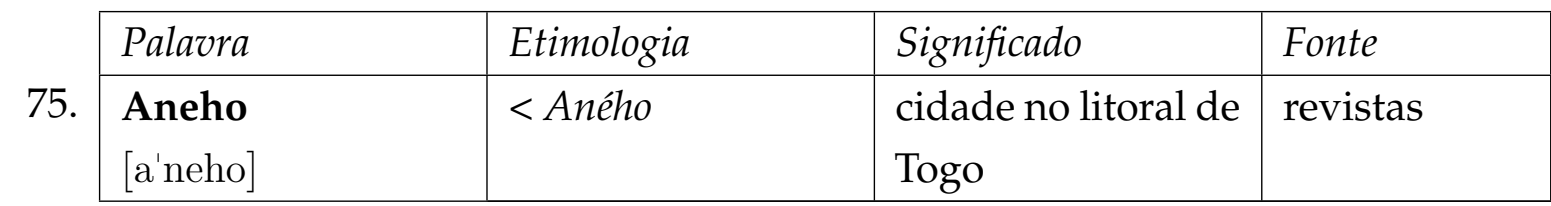

\begin{tabular}{|l|l|l|l|}
\hline Palavra & Etimologia & Significado & Fonte \\
\hline arieĝa & < ariejés & $\begin{array}{l}\text { subdialeto da lín- } \\
\text { gua gascão, varie- } \\
\text { [ari'edza }]\end{array}$ & $\begin{array}{l}\text { revistas } \\
\text { dade da língua oc- } \\
\text { citana, falada na } \\
\text { França }\end{array}$ \\
& & & \\
\hline
\end{tabular}

\begin{tabular}{|c|c|c|c|}
\hline Palavra & Etimologia & Significado & Fonte \\
\hline $\begin{array}{l}\text { Aruŝa } \\
{\left[a^{\prime} r u \int a\right]}\end{array}$ & $<$ Arusha & $\begin{array}{l}\text { cidade no norte da } \\
\text { Tanzânia }\end{array}$ & revistas \\
\hline
\end{tabular}

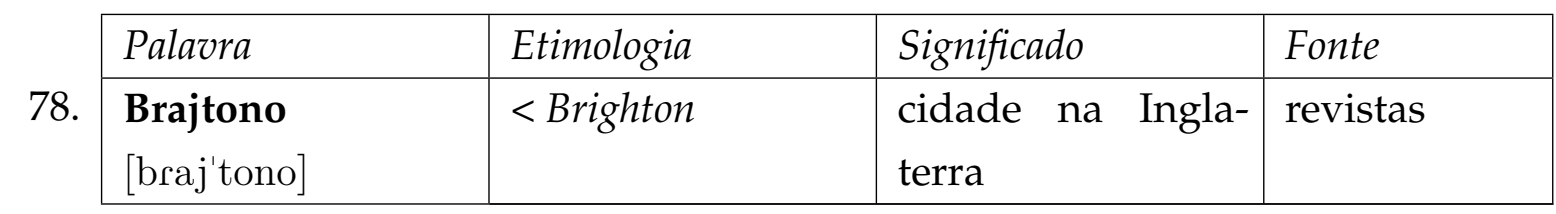

\footnotetext{
${ }^{3}$ (to.pô.ni.mo) sm. 1. Nome próprio de um lugar como rio, cidade, povoação, país etc.; GEÔNIMO 2. História, procedência de um nome geográfico. [F.: top(o)- + -ônimo.] (definição do dicionário Aulete digital, disponível em <http:/ / www.aulete.com.br/topônimo > .

${ }^{4}$ (et.nô.ni.mo) sm. 1. Antr. Palavra que designa o nome de tribo, casta, etnia, nação etc., e, p.ext., nomes de comunidades (políticas, religiosas etc.) que possam ser consideradas num sentido étnico [F.: etn (o)- + -ônimo.] (definição do dicionário Aulete digital, disponível em $<$ http://www.aulete.com.br/etnônimo>).
} 


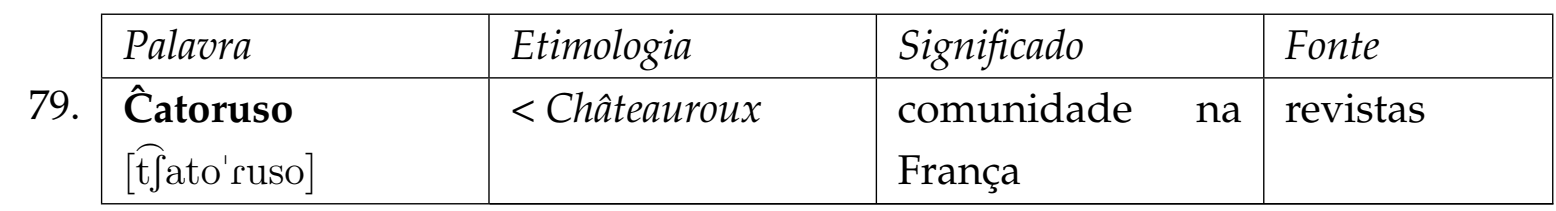

80. \begin{tabular}{|l|l|l|l|}
\hline Palavra & Etimologia & Significado & Fonte \\
$\begin{array}{l}\text { Censtohovo } \\
\text { [t]ensto'hovo] }\end{array}$ & $<$ Częstochowa & cidade na Polônia & revistas \\
\hline
\end{tabular}

81. \begin{tabular}{|l|l|l|l|}
\hline Palavra & Etimologia & Significado & Fonte \\
\hline $\begin{array}{l}\text { Cernobilo } \\
\text { [terno'bilo] }\end{array}$ & $<$ Chernobyl & cidade na Ucrânia & revistas \\
\hline
\end{tabular}

\begin{tabular}{|c|c|c|c|c|}
\hline \multirow[b]{2}{*}{82.} & Palavra & Etimologia & Significado & Fonte \\
\hline & $\begin{array}{l}\text { Ĉerokio } \\
{\left[\widehat{t} \int \text { ero'kio }\right]}\end{array}$ & $<$ Cherokee & $\begin{array}{l}\text { grupo indígena } \\
\text { nos Estados Uni- } \\
\text { dos }\end{array}$ & revistas \\
\hline \multirow[b]{2}{*}{83.} & Palavra & Etimologia & Significado & Fonte \\
\hline & $\begin{array}{l}\text { ĉivavo } \\
{\left[\widetilde{t} \int i^{\prime} \text { vavo }\right]}\end{array}$ & $<$ Chihuahua & estado no México & revistas \\
\hline
\end{tabular}

\begin{tabular}{|c|c|c|c|c|}
\hline & Palavra & Etimologia & Significado & Fonte \\
\hline 84. & $\begin{array}{l}\text { ĉukĉo } \\
{\left[\text { 't } \int \mathrm{ukt} \widetilde{\mathrm{t}} \mathrm{o}\right]}\end{array}$ & $<$ Chukchi & $\begin{array}{l}\text { grupo indígena da } \\
\text { Rússia }\end{array}$ & revistas \\
\hline
\end{tabular}

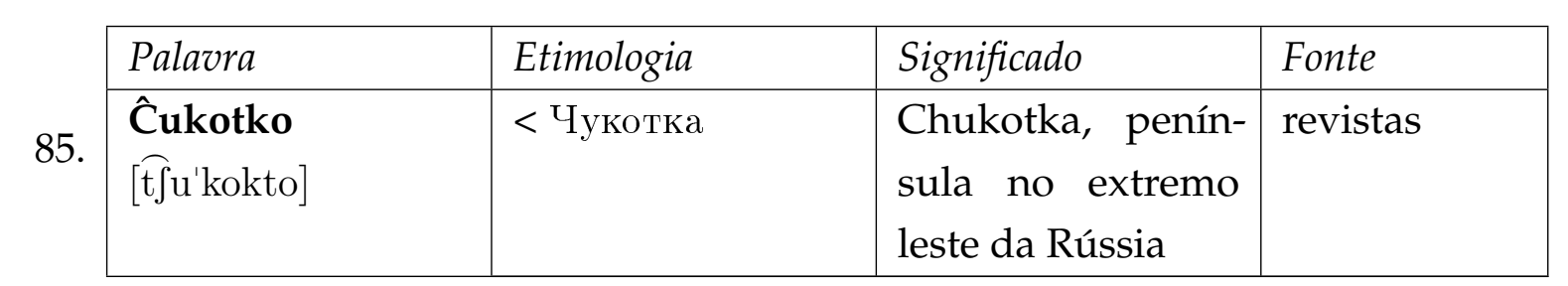

\begin{tabular}{|c|c|c|c|c|}
\hline & Palavra & Etimologia & Significado & Fonte \\
\hline 86. & $\begin{array}{l}\text { Dinano } \\
\text { [di'nano] }\end{array}$ & $<$ Dinan & $\begin{array}{l}\text { Dinan, cidade na } \\
\text { França }\end{array}$ & revistas \\
\hline
\end{tabular}

\begin{tabular}{|c|c|c|c|c|}
\hline & Palavra & Etimologia & Significado & Fonte \\
\hline 87. & $\begin{array}{l}\text { Dubajo } \\
{[\text { du'bajo }}\end{array}$ & $<$ Dubayy & $\begin{array}{l}\text { cidade nos Emira- } \\
\text { dos Árabes }\end{array}$ & revistas \\
\hline
\end{tabular}




\begin{tabular}{|c|c|c|c|c|}
\hline \multirow[b]{2}{*}{88.} & Palavra & Etimologia & Significado & Fonte \\
\hline & $\begin{array}{l}\text { Gojaso } \\
{[\text { go'jaso }]}\end{array}$ & $<$ Goiás & estado brasileiro & revistas \\
\hline
\end{tabular}

\begin{tabular}{|c|c|c|c|c|}
\hline & Palavra & Etimologia & Significado & Fonte \\
\hline 89. & $\begin{array}{l}\text { Gurzufo } \\
{[\text { gur'zufo] }}\end{array}$ & $<$ Gurzuf (Hurzuf) & $\begin{array}{l}\text { município na Cri- } \\
\text { meia }\end{array}$ & revistas \\
\hline
\end{tabular}



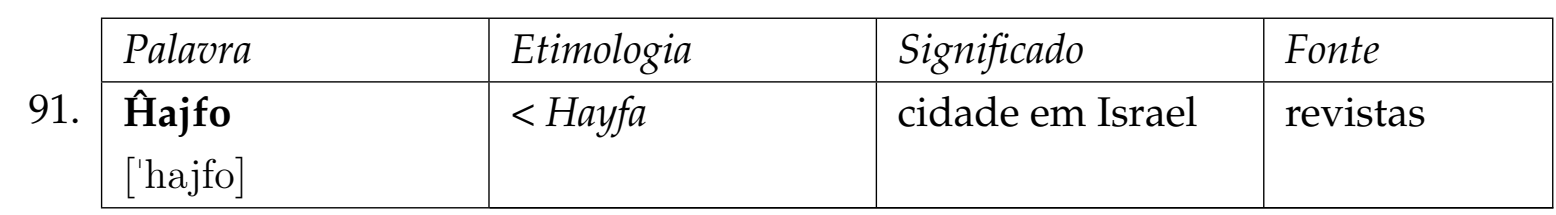

\begin{tabular}{|l|l|l|l|}
\hline 9alavra & Etimologia & Significado & Fonte \\
\hline Harlemo & $<$ Harlem & bairro da cidade de & revistas \\
[har'lemo $]$ & & $\begin{array}{l}\text { Nova Iorque, nos } \\
\text { Estados Unidos }\end{array}$ & \\
\hline
\end{tabular}

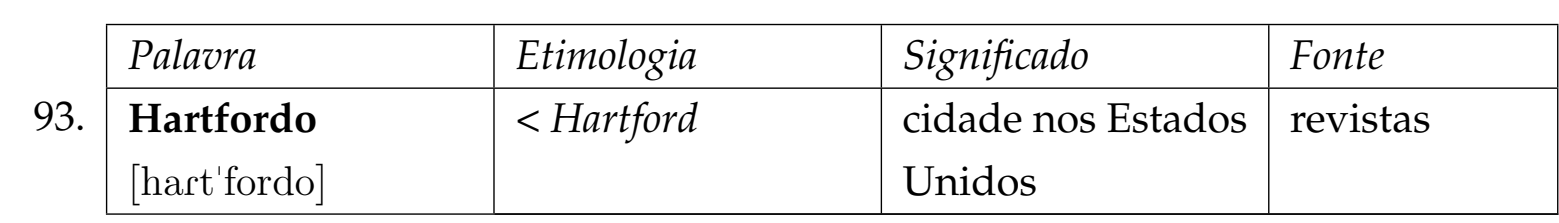

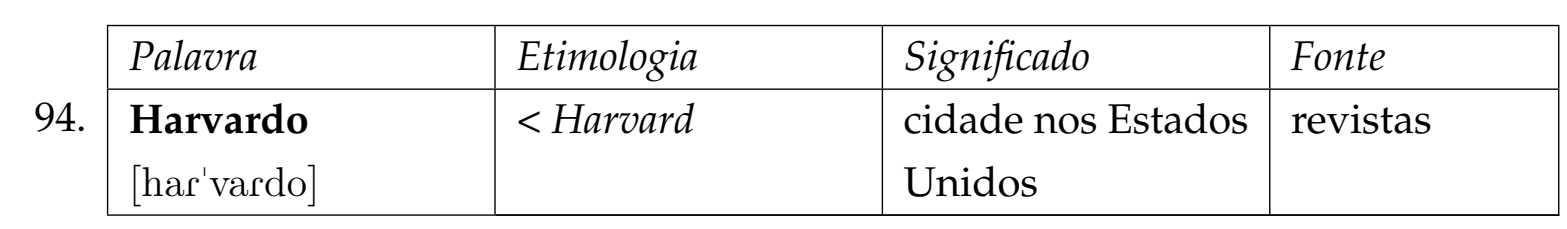

\begin{tabular}{|c|c|c|c|c|}
\hline & Palavra & Etimologia & Significado & Fonte \\
\hline 95. & $\begin{array}{l}\text { hutuoj } \\
{[\text { hu'tuoj] }}\end{array}$ & $<$ Bahutu & $\begin{array}{l}\text { povo que vive na } \\
\text { África Central }\end{array}$ & revistas \\
\hline
\end{tabular}

\begin{tabular}{|c|c|c|c|c|}
\hline & Palavra & Etimologia & Significado & Fonte \\
\hline 96. & $\begin{array}{l}\text { inguŝoj } \\
{[\text { in'gufoj] }}\end{array}$ & $<$ ingush & $\begin{array}{l}\text { povo que vive no } \\
\text { norte do Cáucaso }\end{array}$ & revistas \\
\hline
\end{tabular}




\begin{tabular}{|c|c|c|c|c|}
\hline & Palavra & Etimologia & Significado & Fonte \\
\hline 97. & $\begin{array}{l}\text { Iseo } \\
{[i \text { 'seo }]}\end{array}$ & $<$ Iseo & $\begin{array}{l}\text { comunidade da Itá- } \\
\text { lia e/ou vila na } \\
\text { Suécia }\end{array}$ & revistas \\
\hline \multirow[b]{2}{*}{98.} & Palavra & Etimologia & Significado & Fonte \\
\hline & $\begin{array}{l}\text { Ivanovo } \\
\text { [iva'novo] }\end{array}$ & $<$ Иваново & cidade na Rússia & revistas \\
\hline \multirow[b]{2}{*}{99.} & Palavra & Etimologia & Significado & Fonte \\
\hline & $\begin{array}{l}\text { Jerŝovo } \\
{[\text { jer'fovo] }}\end{array}$ & $<$ Ершово & $\begin{array}{l}\text { vila de uma provín- } \\
\text { cia de Moscou, na } \\
\text { Rússia }\end{array}$ & revistas \\
\hline \multirow[b]{2}{*}{100.} & Palavra & Etimologia & Significado & Fonte \\
\hline & $\begin{array}{l}\text { Kaŭno } \\
\text { ['kawno] }\end{array}$ & $<$ Kaunas & cidade na Lituânia & revistas \\
\hline \multirow[b]{2}{*}{101.} & Palavra & Etimologia & Significado & Fonte \\
\hline & $\begin{array}{l}\text { Kagaŭa } \\
{[\text { ka'gawa] }}\end{array}$ & $<$ Kagawa & cidade no Japão & revistas \\
\hline \multirow[b]{2}{*}{102.} & Palavra & Etimologia & Significado & Fonte \\
\hline & $\begin{array}{l}\text { Kambriĝo } \\
{[\text { kam'bridzo }]}\end{array}$ & $<$ Cambridge & $\begin{array}{l}\text { cidade na Ingla- } \\
\text { terra }\end{array}$ & revistas \\
\hline \multirow[b]{2}{*}{103.} & Palavra & Etimologia & Significado & Fonte \\
\hline & $\begin{array}{l}\text { Karaĝo } \\
{\left[\mathrm{ka}^{\prime} \operatorname{rad}_{30}\right]}\end{array}$ & $<$ Karaj & cidade na Irã & revistas \\
\hline \multirow[b]{2}{*}{104.} & Palavra & Etimologia & Significado & Fonte \\
\hline & $\begin{array}{l}\text { Karabio } \\
\text { [kara'bio] }\end{array}$ & < Караби & $\begin{array}{l}\text { região geográfica } \\
\text { na Crimeia }\end{array}$ & revistas \\
\hline \multirow[b]{2}{*}{105.} & Palavra & Etimologia & Significado & Fonte \\
\hline & $\begin{array}{l}\text { Karlovo } \\
{[\text { kar'lovo] }}\end{array}$ & $<$ Карлово & cidade na Bulgária & revistas \\
\hline
\end{tabular}




106. \begin{tabular}{|l|l|l|l|}
\hline $\begin{array}{l}\text { Palavra } \\
\text { Kasongo } \\
\text { [ka'songo }]\end{array}$ & Etimologia & Significado & Fonte \\
\hline 107. & $\begin{array}{l}\text { cidade na Repú- } \\
\text { blica democrática } \\
\text { do Congo }\end{array}$ & revistas \\
\begin{tabular}{|l|l|l|l|} 
Katavra \\
Katmandimanduo $]$ \\
Katmando \\
[ka'tmando $]$
\end{tabular} & Etimologia & Significado & Fonte \\
\hline
\end{tabular}

108. \begin{tabular}{|l|l|l|l|}
\hline Palavra & Etimologia & Significado & Fonte \\
\hline $\begin{array}{l}\text { Kazaĥio } \\
{[\text { kaza'hio }]} \\
\text { Kazaĥstano } \\
{[\text { kazah'stano }]}\end{array}$ & < Казахстан & Cazaquistão & revistas \\
\hline
\end{tabular}

109.

\begin{tabular}{|l|l|l|l|}
\hline Palavra & Etimologia & Significado & Fonte \\
\hline $\begin{array}{l}\text { Keio } \\
{[\text { ke'io }]}\end{array}$ & $<$ Keiō & cidade no Japão & revistas \\
\hline
\end{tabular}

110.

\begin{tabular}{|l|l|l|l|}
\hline Palavra & Etimologia & Significado & Fonte \\
\hline $\begin{array}{l}\text { Kerĉo } \\
{\left[\text { ker't } \int \mathrm{o}\right]}\end{array}$ & $<$ Керчь & cidade na Crimeia & revistas \\
\hline
\end{tabular}

\begin{tabular}{|l|l|l|l|}
\hline Palavra & Etimologia & Significado & Fonte \\
\hline $\begin{array}{l}\text { Kievo } \\
{[\text { ki'evo }]} \\
\text { Kijivo } \\
{[\text { kij'ivo }]}\end{array}$ & < Киев & cidade na Ucrânia & revistas \\
\hline
\end{tabular}

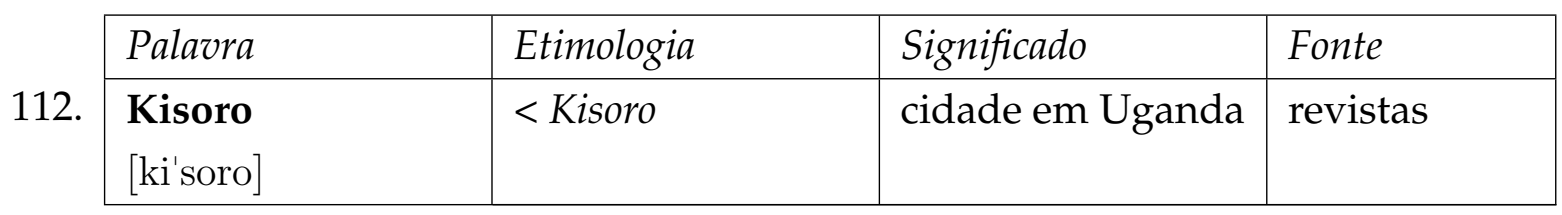

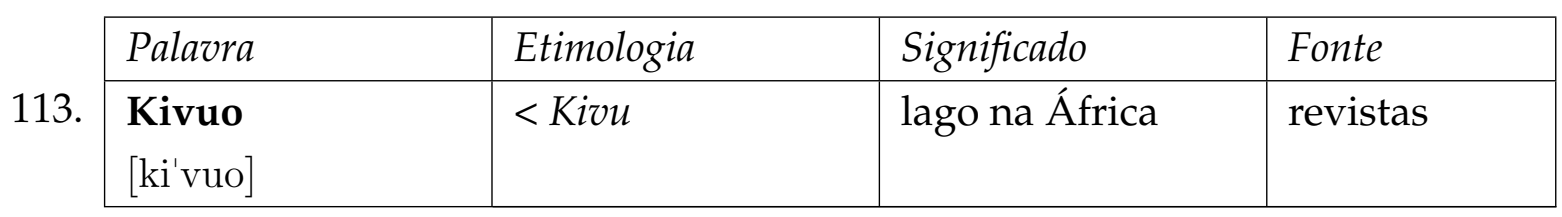




\begin{tabular}{|l|l|l|l|}
\hline Palavra & Etimologia & Significado & Fonte \\
\hline Kinglono & $<$ Klingon & $\begin{array}{l}\text { etnia fictícia pre- } \\
\text { sente nos filmes da } \\
\text { franquia cinemato- } \\
\text { gráfica Star Trek }\end{array}$ & \\
[kin'glono] & & revistas \\
\hline
\end{tabular}

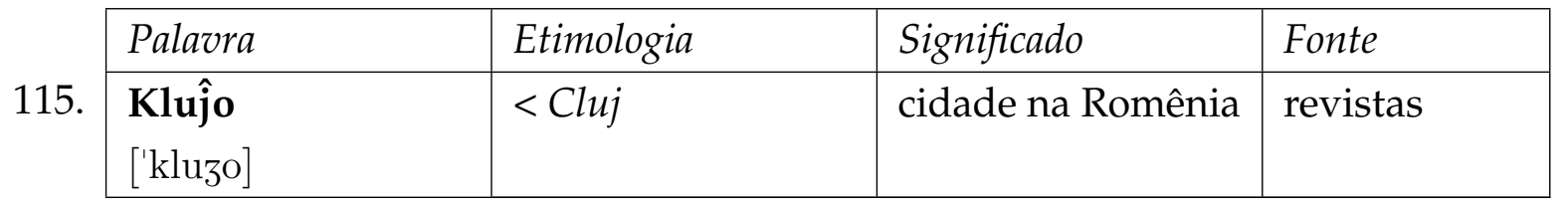

\begin{tabular}{|c|c|c|c|}
\hline Palavra & Etimologia & Significado & Fonte \\
\hline $\begin{array}{l}\text { Konso } \\
\text { ['konso] }\end{array}$ & $<$ Konso & cidade na Etiópia & revistas \\
\hline
\end{tabular}

\begin{tabular}{|l|l|l|l|}
\hline Palavra & Etimologia & Significado & Fonte \\
\hline $\begin{array}{l}\text { Kordobo } \\
\text { kor'dobo }]\end{array}$ & $<$ Córdoba & $\begin{array}{l}\text { cidade na Argen- } \\
\text { tina }\end{array}$ & revistas \\
\hline
\end{tabular}

\begin{tabular}{|c|c|c|c|c|}
\hline & Palavra & Etimologia & Significado & Fonte \\
\hline 118. & $\begin{array}{l}\text { korjaka } \\
\text { [ko'rjaka] }\end{array}$ & $<$ Коряки & $\begin{array}{l}\text { língua koryaque, } \\
\text { falada no leste da } \\
\text { Sibéria }\end{array}$ & revistas \\
\hline
\end{tabular}

\begin{tabular}{|c|c|c|c|c|}
\hline & Palavra & Etimologia & Significado & Fonte \\
\hline 119. & $\begin{array}{l}\text { Kotonuo } \\
\text { [koto'nuo] }\end{array}$ & $<$ Cotonou & cidade em Benim & revistas \\
\hline
\end{tabular}

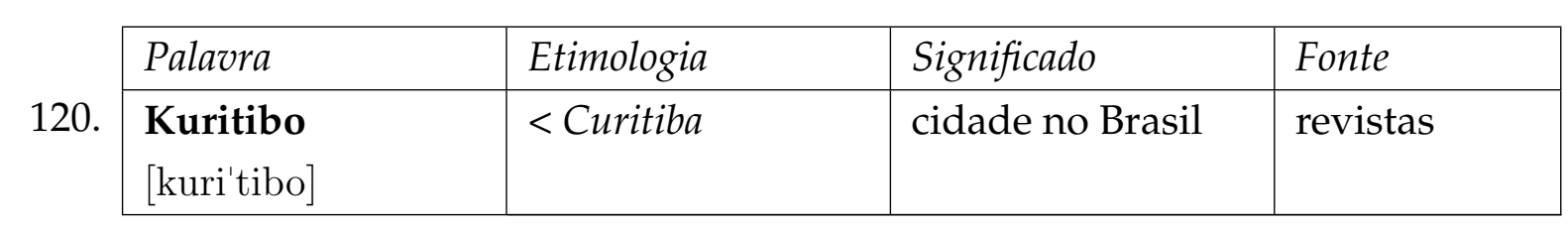

\begin{tabular}{|c|c|c|c|}
\hline Palavra & Etimologia & Significado & Fonte \\
\hline $\begin{array}{l}\text { Kusko } \\
\text { ['kusko] }\end{array}$ & $<$ Cusco & cidade no Peru & revistas \\
\hline
\end{tabular}

\begin{tabular}{|c|c|c|c|}
\hline Palavra & Etimologia & Significado & Fonte \\
\hline $\begin{array}{l}\text { Linco } \\
\text { ['lintso] }\end{array}$ & $<\operatorname{Lin} z$ & cidade na Áustria & revistas \\
\hline
\end{tabular}




\begin{tabular}{|c|c|c|c|}
\hline Palavra & Etimologia & Significado & Fonte \\
\hline $\begin{array}{l}\text { Linjano } \\
\text { [li'njano] }\end{array}$ & $<$ Lignano & cidade na Itália & revistas \\
\hline
\end{tabular}

\begin{tabular}{|c|c|c|c|}
\hline Palavra & Etimologia & Significado & Fonte \\
\hline $\begin{array}{l}\text { linto } \\
\text { ['linto] }\end{array}$ & $<$ linth & rio na Suíça & revistas \\
\hline
\end{tabular}

\begin{tabular}{|c|c|c|c|}
\hline Palavra & Etimologia & Significado & Fonte \\
\hline $\begin{array}{l}\text { Lodzo } \\
\text { ['lodzo] }\end{array}$ & $<€ o ́ d z ́$ & cidade na Polônia & revistas \\
\hline
\end{tabular}

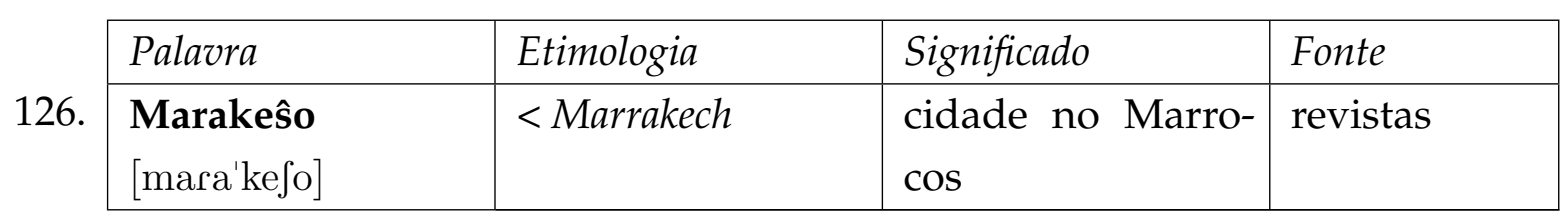

\begin{tabular}{|c|c|c|c|}
\hline Palavra & Etimologia & Significado & Fonte \\
\hline $\begin{array}{l}\text { Mariboro } \\
\text { [mara'boro] }\end{array}$ & $<$ Maribor & $\begin{array}{l}\text { cidade na Eslovê- } \\
\text { nia }\end{array}$ & revistas \\
\hline
\end{tabular}

\begin{tabular}{|l|l|l|l|}
\hline Palavra & Etimologia & Significado & Fonte \\
\hline 128. & Maĉupikĉuo \\
[mat̂upik'tfuo] & $\begin{array}{l}\text { <Machu Picchu (es- } \\
\text { panhol) / Machu } \\
\text { Pikchu (quéchua) }\end{array}$ & no Peru & \\
\hline
\end{tabular}

\begin{tabular}{|c|c|c|c|}
\hline Palavra & Etimologia & Significado & Fonte \\
\hline $\begin{array}{l}\text { Merano } \\
{[\text { me'rano] }}\end{array}$ & $<$ Meran & cidade na Itália & revistas \\
\hline
\end{tabular}

\begin{tabular}{|c|c|c|c|}
\hline Palavra & Etimologia & Significado & Fonte \\
\hline $\begin{array}{l}\text { Molizo } \\
\text { [mo'lizo] }\end{array}$ & $<$ Molise & região na Itália & revistas \\
\hline
\end{tabular}

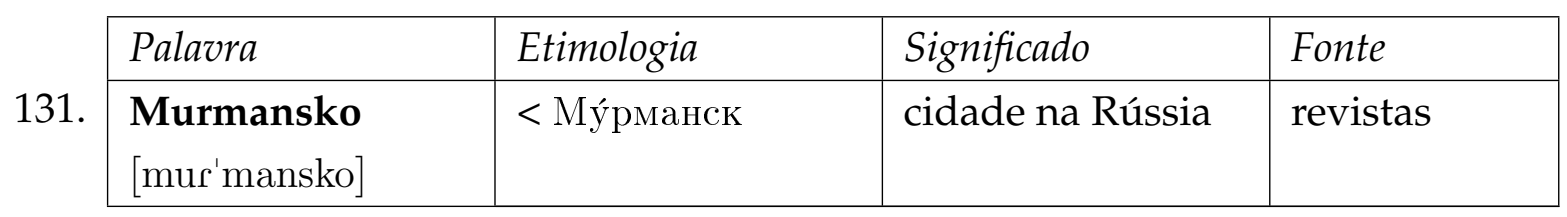




132. \begin{tabular}{|l|l|l|l|}
\hline $\begin{array}{l}\text { Nalavra } \\
\text { Nancio } \\
\text { [nan'tsio }]\end{array}$ & Etimologia & Significado & Fonte \\
\hline
\end{tabular}

\begin{tabular}{|c|c|c|c|c|}
\hline & Palavra & Etimologia & Significado & Fonte \\
\hline 133. & $\begin{array}{l}\text { Nanto } \\
\text { ['nanto] }\end{array}$ & $<$ Nantes & cidade na França & revistas \\
\hline
\end{tabular}

134. \begin{tabular}{|l|l|l|l|}
\hline $\begin{array}{l}\text { Palavra } \\
\begin{array}{l}\text { Negevo } \\
\text { [ne'gevo] }\end{array}\end{array}$ & Etimologia & Significado & Fonte \\
\hline
\end{tabular}
\begin{tabular}{|l|l|l|l|}
\hline Palavra & $\begin{array}{l}\text { região de deserto } \\
\text { em Israel }\end{array}$ & revistas \\
\hline $\begin{array}{l}\text { Ojo } \\
{[\text { 'ojo] }}\end{array}$ & Etimologia & Significado & Fonte \\
\hline
\end{tabular}

136. \begin{tabular}{|l|l|l|l|}
\hline Palavra & Etimologia & Significado & Fonte \\
\hline $\begin{array}{l}\text { Paderborno } \\
\text { [pader'borno }]\end{array}$ & $<$ Paderborn & $\begin{array}{l}\text { cidade na Alema- } \\
\text { nha }\end{array}$ & revistas \\
\hline
\end{tabular}

\begin{tabular}{|c|c|c|c|c|}
\hline & Palavra & Etimologia & Significado & Fonte \\
\hline 137. & $\begin{array}{l}\text { Paraibo } \\
\text { [para'ibo] }\end{array}$ & < Paraíba & estado no Brasil & revistas \\
\hline
\end{tabular}

138. \begin{tabular}{|l|l|l|l|}
\hline Palavra & Etimologia & Significado & Fonte \\
\hline $\begin{array}{l}\text { Paranao } \\
\text { [para'nao }]\end{array}$ & $<$ Paraná & estado no Brasil & revistas \\
\hline
\end{tabular}

139. \begin{tabular}{|l|l|l|l|}
\hline Palavra & Etimologia & Significado & Fonte \\
\hline Paranapiakabo & $<$ Paranapiacaba & cidade no Brasil & revistas \\
\hline
\end{tabular}

\begin{tabular}{|l|l|l|l|}
\hline Palavra & Etimologia & Significado & Fonte \\
\hline $\begin{array}{l}\text { Pirahana } \\
\text { [pira'hana] }\end{array}$ & $<?$ & $\begin{array}{l}\text { pirarrã, língua in- } \\
\text { dígena da região } \\
\text { do Amazonas }\end{array}$ & revistas \\
\hline
\end{tabular}

\begin{tabular}{|c|c|c|c|}
\hline Palavra & Etimologia & Significado & Fonte \\
\hline $\begin{array}{l}\text { Pirasikabo } \\
\text { [pirasi'kabo] }\end{array}$ & $<$ Piracicaba & cidade no Brasil & revistas \\
\hline
\end{tabular}




\begin{tabular}{|l|l|l|l|}
\hline 142. & Etimologia & Significado & Fonte \\
\hline $\begin{array}{l}\text { 308 Polikso } \\
\text { [po'likso }]\end{array}$ & $<308$ Polyxo & $\begin{array}{l}\text { asteroide desco- } \\
\text { berto no fim do } \\
\text { século XIX }\end{array}$ & revistas \\
\hline
\end{tabular}

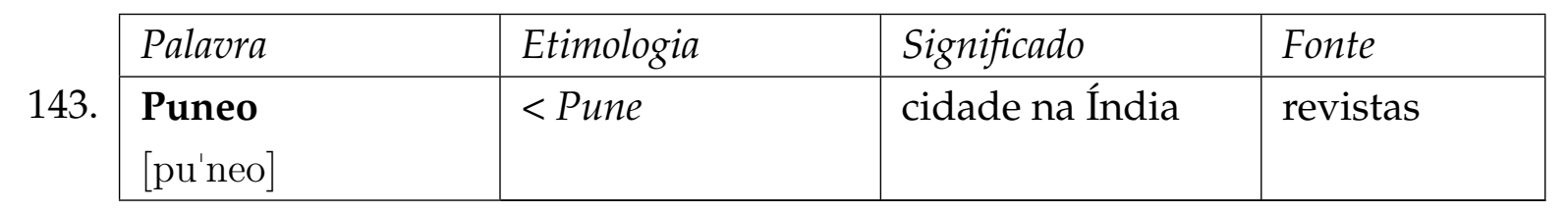

\begin{tabular}{|c|c|c|c|c|}
\hline & Palavra & Etimologia & Significado & Fonte \\
\hline 144. & $\begin{array}{l}\text { Ramlo } \\
\text { ['ramlo] }\end{array}$ & $<$ Ramla & cidade em Israel & revistas \\
\hline
\end{tabular}

\begin{tabular}{|c|c|c|c|c|}
\hline & Palavra & Etimologia & Significado & Fonte \\
\hline 145. & $\begin{array}{l}\text { ripuara } \\
{[\text { ripu'ara }]}\end{array}$ & < ripuarische & $\begin{array}{l}\text { dialeto falado na } \\
\text { Alemanha }\end{array}$ & revistas \\
\hline
\end{tabular}

\begin{tabular}{|l|l|l|l|}
\hline Palavra & Etimologia & Significado & Fonte \\
\hline $\begin{array}{l}\text { Rodoso } \\
\text { [ro'doso }]\end{array}$ & $<$ Ródos & $\begin{array}{l}\text { ilha integrante do } \\
\text { território adminis- } \\
\text { trativo da Grécia }\end{array}$ & revistas \\
\hline
\end{tabular}

\begin{tabular}{|l|l|l|l|}
\hline Palavra & Etimologia & Significado & Fonte \\
\cline { 2 - 4 } & $\begin{array}{l}\text { Rostovo } \\
{[\text { ros'tovo }]}\end{array}$ & $\begin{array}{l}\text { província na Rús- } \\
\text { sia }\end{array}$ & revistas \\
\hline
\end{tabular}

\begin{tabular}{|c|c|c|c|c|}
\hline & Palavra & Etimologia & Significado & Fonte \\
\hline 148. & $\begin{array}{l}\text { Rufisko } \\
{\left[r u^{\prime} f i s k o\right]}\end{array}$ & $<$ Rufisque & cidade em Senegal & revistas \\
\hline
\end{tabular}

\begin{tabular}{|c|c|c|c|c|}
\hline & Palavra & Etimologia & Significado & Fonte \\
\hline 149. & $\begin{array}{l}\text { Sahelo } \\
\text { [sa'helo] }\end{array}$ & $<$ sahel & região da África & revistas \\
\hline
\end{tabular}

\begin{tabular}{|c|c|c|c|}
\hline Palavra & Etimologia & Significado & Fonte \\
\hline $\begin{array}{l}\text { Samso } \\
\text { ['samso] }\end{array}$ & $<$ Samsø & $\begin{array}{l}\text { ilha pertencente ao } \\
\text { território da Dina- } \\
\text { marca }\end{array}$ & revistas \\
\hline
\end{tabular}




\begin{tabular}{|c|c|c|c|}
\hline Palavra & Etimologia & Significado & Fonte \\
\hline $\begin{array}{l}\text { Saratovo } \\
{[\text { sara'tovo] }}\end{array}$ & $<$ Саратов & $\begin{array}{l}\text { província na Rús- } \\
\text { sia }\end{array}$ & revistas \\
\hline
\end{tabular}

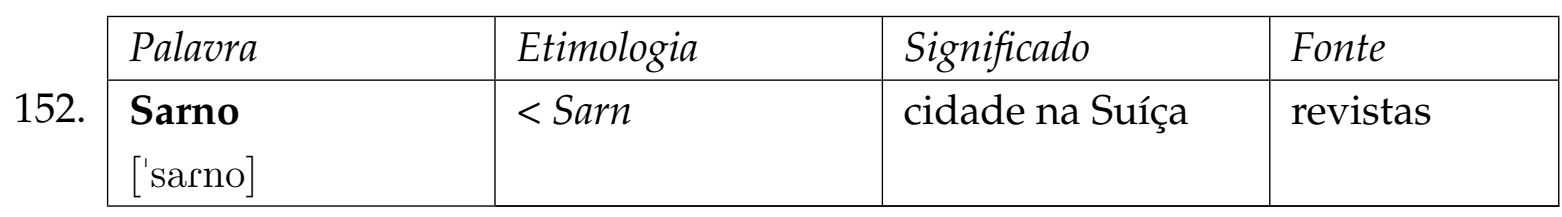

\begin{tabular}{|c|c|c|c|c|}
\hline \multirow[b]{2}{*}{153.} & Palavra & Etimologia & Significado & Fonte \\
\hline & $\begin{array}{l}\text { Seatlo } \\
\text { [se'atlo] }\end{array}$ & $<$ Seattle & $\begin{array}{l}\text { cidade nos Estados } \\
\text { Unidos }\end{array}$ & revistas \\
\hline \multirow[b]{2}{*}{154.} & Palavra & Etimologia & Significado & Fonte \\
\hline & $\begin{array}{l}\text { Seborgo } \\
{[\text { se'borgo] }}\end{array}$ & $<$ Seborga & $\begin{array}{l}\text { comunidade na Itá- } \\
\text { lia }\end{array}$ & revistas \\
\hline
\end{tabular}

\begin{tabular}{|c|c|c|c|}
\hline Palavra & Etimologia & Significado & Fonte \\
\hline $\begin{array}{l}\text { Segedo } \\
\text { [se'gedo] }\end{array}$ & $<$ Szeged & cidade na Hungria & revistas \\
\hline
\end{tabular}

\begin{tabular}{|c|c|c|c|}
\hline Palavra & Etimologia & Significado & Fonte \\
\hline $\begin{array}{l}\text { Seulo } \\
{\left[\mathrm{se}^{\prime} \mathrm{ulo}\right]}\end{array}$ & $<$ Seoul & $\begin{array}{l}\text { cidade na Coreia } \\
\text { do Sul }\end{array}$ & revistas \\
\hline
\end{tabular}

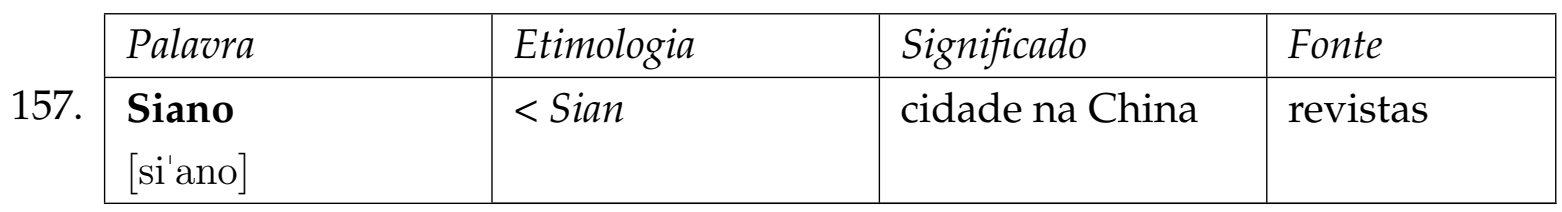



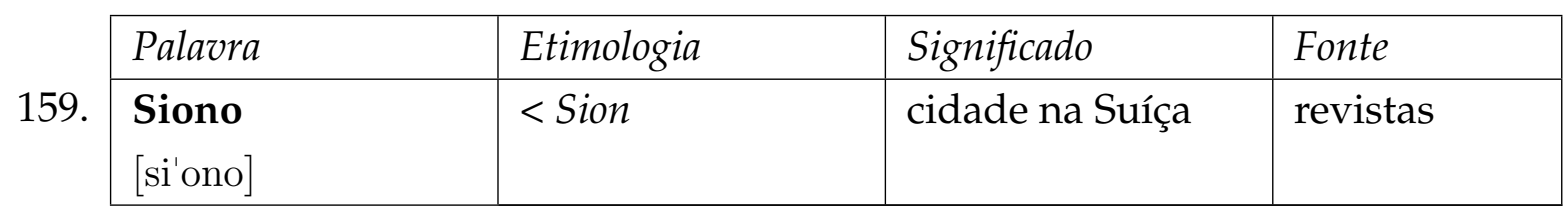

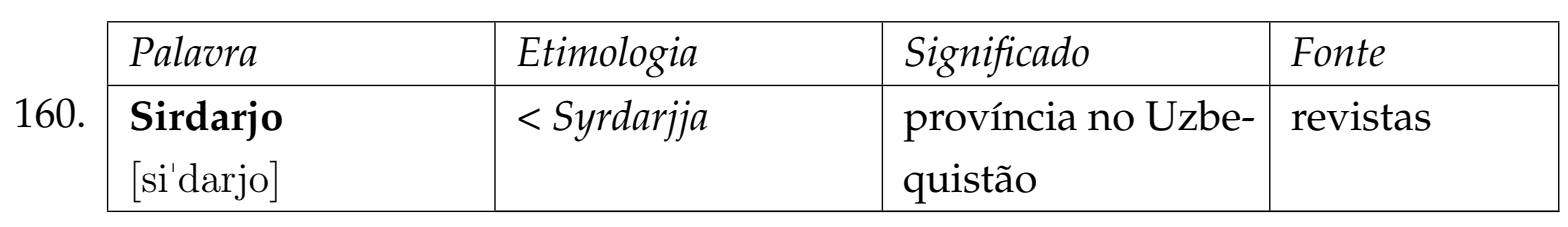




\begin{tabular}{|c|c|c|c|}
\hline Palavra & Etimologia & Significado & Fonte \\
\hline $\begin{array}{l}\text { Soĉìo } \\
\text { [so't ţio] }\end{array}$ & $<$ Со́чи & cidade na Rússia & revistas \\
\hline
\end{tabular}

\begin{tabular}{|c|c|c|c|c|}
\hline & Palavra & Etimologia & Significado & Fonte \\
\hline 162. & $\begin{array}{l}\text { Stiro } \\
\text { ['stiro] }\end{array}$ & $<$ Стырь & rio na Ucrânia & revistas \\
\hline
\end{tabular}

163. \begin{tabular}{|l|l|l|l|}
\hline Palavra & Etimologia & Significado & Fonte \\
\hline $\begin{array}{l}\text { Sanghajo } \\
\text { [jang'hajo] }\end{array}$ & <Shànghăi & cidade na China & revistas \\
\hline
\end{tabular}

\begin{tabular}{|c|c|c|c|c|}
\hline & Palavra & Etimologia & Significado & Fonte \\
\hline 164. & $\begin{array}{l}\text { serpa } \\
\text { ['Serpa] }\end{array}$ & $<$ Sherpa & $\begin{array}{l}\text { língua falada no } \\
\text { Nepal }\end{array}$ & revistas \\
\hline
\end{tabular}

\begin{tabular}{|l|l|l|l|}
\hline Palavra & Etimologia & Significado & Fonte \\
\hline $\begin{array}{l}\text { tagaloga } \\
\text { [taga'loga }]\end{array}$ & $<$ tagalog & $\begin{array}{l}\text { idioma falado na } \\
\text { República das Fili- } \\
\text { pinas }\end{array}$ & revistas \\
\hline
\end{tabular}

166. \begin{tabular}{|l|l|l|l|}
\hline Palavra & Etimologia & Significado & Fonte \\
\hline $\begin{array}{l}\text { Taragono } \\
\text { tara'gono] }\end{array}$ & $<$ Tarragona & $\begin{array}{l}\text { província na Espa- } \\
\text { nha }\end{array}$ & revistas \\
\hline
\end{tabular}

167. \begin{tabular}{|l|l|l|l|}
\hline Palaura & Etimologia & Significado & Fonte \\
\hline $\begin{array}{l}\text { Tajo } \\
{[\text { 'tazo] }}\end{array}$ & $<$ Tajo, Tejo & $\begin{array}{l}\text { rio que corta a Es- } \\
\text { panha e Portugal }\end{array}$ & revistas \\
\hline
\end{tabular}

\begin{tabular}{|c|c|c|c|c|}
\hline & Palavra & Etimologia & Significado & Fonte \\
\hline 168. & $\begin{array}{l}\text { tetuna } \\
\text { [te'tuna] }\end{array}$ & $<$ tetun & $\begin{array}{l}\text { língua falada no Ti- } \\
\text { mor Leste }\end{array}$ & revistas \\
\hline
\end{tabular}

\begin{tabular}{|l|l|l|l|l|}
\hline 169. & Palavra & Etimologia & Significado & Fonte \\
\hline & $\begin{array}{l}\text { Tomsko } \\
{[\text { 'tomsko] }}\end{array}$ & < Toмcк & cidade na Rússia & revistas \\
\hline
\end{tabular}

\begin{tabular}{|c|c|c|c|}
\hline Palavra & Etimologia & Significado & Fonte \\
\hline $\begin{array}{l}\text { Toruno } \\
\text { [to'runo] }\end{array}$ & $<$ Toruń & cidade na Polônia & revistas \\
\hline
\end{tabular}




\begin{tabular}{|c|c|c|c|}
\hline Palavra & Etimologia & Significado & Fonte \\
\hline $\begin{array}{l}\text { tucio } \\
{[\text { to'tsio] }}\end{array}$ & $<$ Tutsi & $\begin{array}{l}\text { tribo que vive no } \\
\text { continente africano }\end{array}$ & revistas \\
\hline
\end{tabular}

\begin{tabular}{|c|c|c|c|}
\hline Palavra & Etimologia & Significado & Fonte \\
\hline $\begin{array}{l}\text { Tuvio } \\
\text { [tu'vio] }\end{array}$ & < Тыва́ & $\begin{array}{l}\text { república na Rús- } \\
\text { sia }\end{array}$ & revistas \\
\hline
\end{tabular}



\begin{tabular}{|c|c|c|c|}
\hline Palavra & Etimologia & Significado & Fonte \\
\hline $\begin{array}{l}\text { volgio } \\
\text { [vol'gio] } \\
\text { volgo } \\
\text { ['volgo] }\end{array}$ & < Волга & rio na Rússia & revistas \\
\hline
\end{tabular}

